\title{
A CROSS-SHORE BEACH PROFILE EVOLUTION MODEL
}

\author{
MANTRIPATHI PRABATH RAVINDRA JAYARATNE \\ School of Architecture, Computing and Engineering \\ University of East London, Docklands Campus \\ 4-6 University Way, London E16 2RD, UK \\ Tel: +44-208-223-2536; Fax: +44-208-223-2963 \\ r.jayaratne@uel.ac.uk
}

MD REZAUR RAHMAN

Department of Civil and Environmental Engineering

University of South Florida

4202 E. Fowler Avenue

Tampa, FL 33620-5350, USA

rahman3@mail.usf.edu

TOMOYA SHIBAYAMA

Department of Civil and Environmental Engineering,

Faculty of Science and Engineering,

Waseda University,

3-4-1 Okubo, Shinjuku-ku, Tokyo 169-8555, Japan

Tel/Fax: +81-3-5286-8296

shibayama@waseda.jp 


\begin{abstract}
Developing an accurate and reliable time-averaged beach profile evolution model under normal and storm conditions is a challenging task. Over the last few decades, a number of beach deformation models have been developed under limited experimental conditions and uncertainties, and sometimes they required a long computation time. It is quite evident that a large amount of wave, current, sediment and beach profile data is available today. The present study leads to the development of a simple two-dimensional beach profile evolution model with on-offshore sand bar formation under non-storm and storm conditions based on the time-averaged suspended sediment concentration models of Jayaratne \& Shibayama [2007] and Jayaratne et al. [2011]. These models were formulated for computing sediment concentration in and outside the surf zone under three different mechanisms: 1) suspension due to turbulent motion over sand ripples, 2) suspension from sheet flow layer and, 3) suspension due to turbulent motion under breaking waves. The suspended load is calculated by the product of time-averaged sediment concentration and undertow velocity from edge of the wave boundary layer to wave trough, and mass transport velocity from wave trough to crest (bore-like wave region). Sediment transport in wave boundary layer is computed from the modified Watanabe [1982] model. Rattanapitikon and Shibayama [1998] wave model is used to calculate the average rate of energy dissipation due to wave breaking. The beach deformation is calculated from the conservation of sediment mass while the avalanching concept of Larson and Kraus [1989] is used to re-distribute the sediment mass in neighbouring grids for a steady solution. Published field-scale experimental and natural beach profiles from 5 high-quality data sources from 1983-2009 [Kajima et al., 1983; Kraus and Larson, 1988; Port and Airport Research Institute, Japan, 2005, 2009; Hasan \& Takewaka, 2007, 2009; Ruessink et al., 2007] are used to verify the performance of the proposed numerical model. The key feature in this process-based model is that it takes about a couple of minutes to simulate beach profiles of a 2-3 days storm qualitatively at a fairly satisfactory level using a standard personal computer. It is found that the present numerical predictions are not better than the null hypothesis as the model is in a stage of ongoing development. Therefore, it is believed that the final model is often more value to a practical coastal engineer than a very detailed study of hydrodynamics and sediment transport study, however an incorporation of swash dynamics, more precise evaluation of offshore sand bar formation and continuation to a longer time scale with precise beach deformation is recommended as the next stage of the model.
\end{abstract}

Key words: Two-dimensional beach profile evolution model; time-averaged suspended sediment concentration; on-offshore sand bar formation; average rate of energy dissipation; conservation of sediment mass; avalanching concept; field-scale experimental and natural beach profile data; processbased model; standard personal computer; practical coastal engineer. 


\section{Introduction}

\subsection{General}

In recent years, the utilisation of coastal areas has steadily been increasing for human activities such as habitation, transportation and tourism. Protection of the coastal environment from wind-induced high waves and extreme events exacerbated by global warming has become a task of paramount importance. Coastal zone management requires a quantitative predictive capability that represents beach profile changes due to such events. To tackle this problem, numerical tools have gradually evolved as a powerful methodology to predict crossshore sediment transport rates and beach profile evolution. But due to the complexity of the sediment transport problem, a full description of these mechanisms has not reached a satisfactory level. Even at the current stage of research, the research is still far from complete and there is no thorough understanding of all phenomena induced by the ocean waves and tides on the coastlines or on the coastal structures. The following section covers a summary of sediment transport formulae, measurements of field-scale beach profile changes and the development of key process-based beach profile models over the last three decades.

\subsection{Summary of previous process-based profile models and field-scale measurements}

Watanabe et al. [1980] studied net on-offshore sediment transport from the measured beach profile changes. Further, it was proposed that the dimensionless net transport rate was proportional to Shields parameter. The importance of the critical shear stress and of asymmetrical to-and-fro water particle motion near the bottom was also pointed out. Watanabe [1982] developed a two-dimensional depth-averaged model for simulating wave, current and beach profile changes. Wave transformation was computed from conservation of energy flux. Nearshore currents were computed from depth-averaged momentum and continuity equations. The empirical formula of Komar [1977] was modified to compute local longshore sediment transport. Based on the laboratory results of Watanabe et al. [1980], the 
formula for computing cross-shore sediment transport was developed. Reasonably good nearshore current field and beach deformation were expounded by the proposed model.

Kajima et al. [1983] performed prototype scale experiments at the Central Research Institute of Electrical Power Industry (CRIEPI) in Japan to investigate the mechanism of cross-shore sediment transport and beach profile changes. The experimental programme consisted of 24 cases with various wave and sediment conditions and initial beach profiles. All cases were run under regular waves with fixed water depth. Wave height, suspended sediment concentration, fluid velocity and beach profiles were measured during this study.

Dally and Dean [1984] developed a two-layer sediment transport model based on the time-averaged sediment flux concept. The layers were separated by the falling distance of sediment particles within a wave period. The sediment velocity in the lower layer was assumed to be composed of orbital velocity and time-averaged velocity. Only time-averaged velocity contributed to the upper part. The concentration profile was assumed to be an exponential shape both in offshore zone and surf zone. The concentration and velocity profiles were not compared with any experimental data. A sudden change of direction and magnitude of transport rate around the breaking point was given by the transport model. A special treatment was employed to smooth the computed transport rate around the breaking point.

Stive and Battjes [1984] developed a numerical model for cross-shore sediment transport and beach deformation under irregular waves. They assumed that the suspended load was the dominant factor of sediment transport. The sediment transport rate was described as the product of time-averaged velocity and suspended sediment concentration. The model was limited to compute only offshore-directed sediment transport. To compute time-averaged velocity under irregular wave action, the model of Stive and Wind [1982] was modified. A suspended sediment concentration model was derived based on the works of Nielsen et al. [1978] for non-breaking waves and Bosman [1982] for breaking waves. The 
wave model of Battjes and Janssen [1978] was used to compute wave height transformation. Three cases of laboratory experiments were used to verify the model results. Realistic, first order predictions of beach profile changes were obtained.

Shibayama and Horikawa [1985] developed a numerical model for computing crossshore beach transformation. Calculated wave height transformation was based on energy flux conservation by using non-linear wave theory $\left(1^{\text {st }}\right.$ order Cnoidal or Stokes waves) in the offshore zone and by using the energy dissipation model of Mizuguchi [1980] inside the surf zone. The model of Shibayama and Horikawa [1982], which included suspended load caused by ripple vortex, computed sediment transport rates. Experiments of beach profile change in a small-scale wave flume were performed to verify the model results and found that the model presented a reasonable estimation.

Kraus and Larson [1988] described and collected beach profile change data in a large wave tank in which experiments were performed by the US Army Corps of Engineers during 1956-1957 and 1962 (Saville, 1957; Caldwell, 1959) at Dalecarlia Reservation, Washington, DC. The experiment program consisted of 18 cases with various wave and sediment conditions performed under regular waves. Larson et al. [1988] developed an empirical based numerical model to simulate beach profile change in the surf zone produced by wave-induced cross-shore sand transport. This model simulated the dynamics of macro-scale growth and movement of berms and bars at wave breaking point. Two field-scale data sets (18 cases from the US Army Corps of Engineers Water Experiment Station and 24 cases from the Central Research Institute of Electrical Power Industry, Japan) were used for the development and verification of the model.

The SBEACH (Storm-induced BEAch CHange) model was developed based on physical principles to calculate beach and dune erosion under storm water levels and wave action by Larson and Kraus [1988] at the US Army Corps of Engineers Waterways Experiment Station. SBEACH is applicable primarily to the dune, beach face and surf zone 
and could not predict sediment movement in offshore under the non-breaking waves. Calculations can be performed for an arbitrary initial beach profile shape with given sand grain diameter, hydraulic, and monochromatic and random wave conditions.

Hedegaard et al. [1991] developed a beach deformation model. The sediment transport was computed from time-varied sediment flux added with time-averaged Lagrangian sediment flux. Wave height transformation was computed from an empirical formula of Andersen and Fredsøe [1983]. A velocity profile model was developed based on the works of Longuet-Higgins [1953], Fredsøe [1984], Svendsen [1984b], Deigaard et al. [1986], Deigaard and Fredsøe [1989]. The model of Deigaard et al. [1986] was used to compute concentration profiles. The computed sediment transport rate could not be used to compute beach profile change directly. The smoothing technique was employed to obtain the computed transport rates.

Southgate and Nairn [1993] developed a quasi-3DH morphodynamic model to compute beach deformation (COSMOS Model). Wave height was computed from energy flux conservation using the energy dissipation formula of Battjes and Janssen [1978]. Breaking position was computed from the formula of Southgate [1989]. The model of De Vriend and Stive [1987] was applied to compute the cross-shore velocity profile. A sediment transport formula was developed based on the energetic approach of Bagnold [1963]. The beach profile evolution phase of the model is capable of considering a fixed boundary such as a seawall or an erodible as in the case of a sandy beach overlying a cohesive till substratum. It was reported that for the situations with materials coarser than sand the model required some modifications to ensure accurate predictions. Also, this numerical model was not always a dependable tool in predicting onshore sand transport, particularly for accretion conditions, and undulating profile shape due to the absence of the standing long wave structure. Further, it is reported that their model may only be applied under conditions where bed form features (e.g. sheet flow and ripples) do not exist. 
Rattanapitikon and Shibayama [1996] developed a numerical model for computing beach profiles under regular wave condition. The proposed model was composed of suspended load and bed load separately. The suspended load was given as the product of the time-averaged suspended sediment concentration and the time-averaged velocity from bottom to wave trough while the bed load used in the model was similar to the model of Watanabe [1983]. The model of Dally et al. [1985] was modified and used to calculate wave height transformation. The beach profile change was computed from the conservation of sediment mass. It was stated that reasonably good agreement was obtained between measured and computed beach profiles.

Larson and Wise [1998] presented simple theoretical models based on descriptions of wave and sediment transport processes to calculate equilibrium beach profile shape under non-breaking and breaking wave conditions. For the case of computing equilibrium beach profile shape under breaking waves, a power relationship was obtained between water depth and sediment flux. For the case of computing equilibrium beach profile shape under nonbreaking waves, three different sub models were derived: one for wave energy dissipation; another for the integration of small-scale sediment transport over a wave period and a third for the mechanisms of onshore and offshore sediment transport.

Grasmeijer [2002] developed a cross-shore process-based model to simulate the sediment transport rates near Egmond aan Zee in the Netherlands. The wave related transport rates were on average of factor 4 smaller than the current related components. The model was used to simulate calm weather waves with onshore bar mitigation and storm waves with offshore bar mitigation near DUCK in North Carolina, USA. The morphological changes in the nearshore were mainly driven by the cross-shore gradients in the current related transport rate.

Kobayashi et al. [2000] analysed cross-shore sediment transport on beaches using timedependant, depth-integrated sediment continuity equation including sediment suspension, 
deposition, advection and settling. The time-averaged model together with the simplified assumptions of Dean [1977] yielded a uniform suspension rate for the standard equilibrium profile. The simplified time-averaged model with boundary conditions at the shoreline and breaker point was shown to predict both erosion and accretion type beach profile evolutions under regular waves in a large wave tank.

Jayaratne [2004] developed a practical numerical model for cross-shore beach profile evolution with on-offshore sand bar formation, considering his time-averaged suspended sediment concentration models. His model was also based on the energetic approach and the efficiency factors in theoretical models were calibrated using large amount of small-scale and field-scale published data from regular wave experiments. Jayaratne and Shibayama [2011] further extended beach deformation model of Jayaratne [2004] with the suspended sediment concentration models of Jayaratne and Shibayama [2007] and Jayaratne et al. [2011] with limited field-scale beach profile data. The predicted results were shown to be in good agreement with measured data.

Ruessink et al. [2007] presented a coupled, wave-averaged, cross-shore wavescurrents-bathymetric evolution model using data gathered at the barred beaches of DUCK (USA), Hasaki (Kashima Coast, Japan) and Egmond (Netherlands). Good match between observed onshore and offshore bar migration and associated changes in the cross-shore bar shape and simulated results were obtained by fine-tuning four free parameters in undertow and sediment transport models.

Kobayashi et al. [2008] developed simple formulae to predict time-averaged crossshore suspended load and bed load transport rates. The suspended sand transport was expressed in terms of the depth averaged-current and the suspended sediment volume per unit bottom area while the net bed load transport rate was expressed as the standard deviation of the horizontal velocity. These formulae were incorporated into a time-averaged wave model and the continuity equation of bottom sediment to predict profile changes for an arbitrary 
initial beach profile (CSHORE model). It was reported that the beach profile evolution model was verified with small-scale and large-scale test data and confirmed that it did not always predict the fairly subtle profile changes including bar migration accurately. Johnson et al. [2009] applied CSHORE model for two storm response data sets of east and west coasts of United States and confirmed that it performed reasonably well without site-specific calibration, but some improvement was required by increasing the effect for the dissipation due to breaking waves on the west coast of USA.

Suzuki and Kuriyama [2008] developed a simple cross-shore sediment transport model for berm formation and erosion with two and half years of beach profile data at the Hazaki Oceanographic Research Station (HORS), Hazaki, Japan. The special distribution of the cross-shore sediment transport rate for berm formation was modelled with the offshore wave energy flux and the distribution for berm erosion was modelled with the berm height. It was reported that numerical results and observed data match well in a qualitative sense. Kuriyama [2009] developed a one-dimensional beach profile change model to predict longshore bar migration. In his model, cross-shore sediment transport rate was determined by the suspended load due to wave breaking and bed load due to velocity skewness and beach slope. The model results were compared with measured beach profiles at Hazaki from 1989 to 1990 and reported that the model reasonably predicted the repeated seaward bar migration for about 2 years.

Sasaoka et al. [2009] developed a numerical model, capable of reproducing fairly complicated beach profile changes under three sediment transport processes: asymmetrical on-offshore sheet flow, mean flow, and bore-induced vortex and turbulence in the surf zone. The sediment suspension due to bore-induced vortex and turbulence in the surf zone was modelled using Jayaratne and Shibayama [2004] models. The predicted results were compared with the large-scale wave flume experiments conducted by Shimizu et al. [1985] 
and confirmed that whether a beach is accreted or eroded would be determined by the balance of the above three transport mechanisms and the gravitational effect.

Roelvink et al. [2010] reported a nearshore processes model (XBeach) as a numerical tool to compute the natural coastal response during time-varying storm and hurricane conditions, including dune erosion, overwash and breaching. The motivation to develop this model came after the devastating effects of hurricanes on low-lying sandy coasts during the 2004 and 2005 and urgent need of assessing the vulnerability of coastal areas and redesigning of coastal protection for future events. The model consists of formulations for short wave envelope propagation, non-stationary shallow water equations, sediment transport and bed update. The model has been validated with a series of analytical, laboratory and field test cases. It is further reported that this model performed well in different coastal situations including dune erosion, overwash and breaching with a standard set of parameter settings.

Baldock et al. [2011] conducted large-scale beach profile experiments at CIEM wave flume at UPC, Barcelona as a part of the SUSCO experiment in the European Hydralab III Program. These experiments were designed to compare variation in beach profile evolution between monochromatic and unsteady waves with the same mean energy flux and used both erosive and accretive conditions.

The above process-based simulation models based on either empirical or semiempirical formulae derived with the help of experimental investigations. The performances of these models depend on the comparison between measured and computed results of sediment transport rates. The applicability of such models for various hydraulic, sediment and bed conditions are rather difficult to establish and hence this opens the doors to develop a timeaveraged beach profile evolution model, which can be utilised for practical purposes by the decision and policy makers, and coastal engineers. The model described in this paper is originally established with the conventional application of an energetic sediment transport approach by Jayaratne [2004] at Yokohama National University, Japan and further extended 
with field-scale and natural beach profile data collected in USA, Europe and Asia in the period of 1983-2009.

\section{Model Description}

\subsection{Wave model}

\subsubsection{Characteristics of wave model}

Wave height at each location is essential in order to compute sediment transport rate and change of beach profile. Numerous wave models have been proposed by previous researchers to account for wave height transformation including wave propagation, decay and wave breaking. By comparing existing wave models, a more suitable model is chosen for this study. The selection of the wave model depends on the components and the computation time it takes. If the model can be kept as simple as possible, it can be used for more practical purposes. To avoid such situations, wave height transformation in the cross-shore direction is computed from energy flux conservation [Eq. (1)].

$$
\frac{\partial E c_{g}}{\partial x}=-D_{B}
$$

where $E$ is the wave energy density $\left(=\rho g H^{2} / 8\right), c_{g}$ is the group velocity, $x$ is the distance in cross-shore direction, $D_{B}$ is the energy dissipation rate, $\rho$ is the fluid density, $g$ is the gravitational acceleration and $H$ is the wave height.

Shuto [1974] and Isobe [1985] showed that at locations of high Ursell number, linear wave theory gave an under-estimation of predicted wave height while Shibayama [1984] and Larson and Kraus [1989] showed that non-linear wave theory gave an over-estimation. In the offshore zone, energy flux can be computed using the analytical solution based on linear wave theory while the other is based on non-linear wave theory (finite amplitude wave theory). Moreover, Shibayama [1984] and Watanabe et al. [1986] showed that estimating bottom orbital velocity and radiation stresses from linear wave theory gave better results than 
from non-linear wave theory. The present study is limited to cross-shore direction under monochromatic waves however the representative wave parameters of irregular waves (significant wave height and peak period) are used to simulate random wave cases.

Computing $D_{B}$ inside the surf zone is very important, if the energy flux conservation approach is employed. Since the wave breaking phenomena is complicated, computing $D_{B}$ depends on empirical relationships. The next section discusses the different analytical solutions of energy dissipation due to wave breaking.

\subsubsection{Energy dissipation models}

Le Mehaute [1962], Svendsen et al. [1978], Thornton and Guza [1983], Dally et al. [1985], Okayasu et al. [1988] and Rattanapitikon and Shibayama [1998] are to name a few researchers, who proposed different explicit formulas for computing the energy dissipation rate inside the surf zone. Equations (2)-(7) show most widely used dissipation models.

Le Mehaute [1962] suggested using a bore model, based on the similarities between a broken wave and a hydraulic jump.

$$
D_{B}=\frac{\rho g}{4} \frac{(B H)^{3}}{h^{2}} Q
$$

where $B$ is the breaker coefficient accounting for any differences in various breaker types, $h$ is the water depth and $Q$ is the volumetric discharge per unit area of water across the bore.

Following Thornton and Guza [1983], the bore model can be expressed in the form given below.

$$
D_{B}=\frac{\rho g}{4 T} \frac{(B H)^{3}}{h}
$$

where $T$ is the wave period.

Assuming energy dissipation rate is proportional to the difference between the local energy flux and the stable energy flux, Dally et al. [1985] developed the following relationship. 


$$
D_{B}=\frac{K_{d}}{h}\left[E c_{g}-\left(E c_{g}\right)_{s}\right]
$$

where $K_{d}$ is a constant $(=0.15)$, subscript $s$ refers to variables at stable wave (e.g. $\left.E_{s}=\rho g H_{s}^{2} / 8\right), H_{s}$ is the stable wave height $(=\Gamma h)$ and $\Gamma=0.4$.

After calculating variables from the linear wave theory, Eq. (4) can be re-written as follows.

$$
D_{B}=\frac{0.15 c_{g} \rho g}{8 h}\left[H^{2}-(\Gamma h)^{2}\right]
$$

The main advantage of this model is that it is capable of reproducing the pause in the wave breaking process at a finite wave height on a horizontal bed or in the recovery zone.

Following the work of Goda and Kweon [1994], Rattanapitikon and Shibayama [1998] proposed an empirical formula for parameter, $\Gamma$.

$$
\Gamma=\exp \left[-0.36-1.25 \frac{h}{\sqrt{L H}}\right]
$$

where $L$ is the wavelength.

Following the modified formula of Dally et al. [1985] and Eq. (6), Rattanapitikon and Shibayama [1998] proposed an explicit form of an equation for computing energy dissipation rate in terms of hydraulic parameters under regular waves.

$$
\frac{D_{B}}{\rho}=\frac{0.15 c g}{8 h}\left\{H^{2}-\left[h \exp \left(-0.36-1.25 \frac{h}{\sqrt{L H}}\right)\right]^{2}\right\}
$$

where $c$ is the wave celerity.

It is seen in the model of Rattanapitikon and Shibayama [1998], the average root mean square (rms) relative error for 490 test cases of 11 data sources of small-scale, large-scale laboratory and field experiments is $2 \%$ less than that produced by the modified model of Dally et al. [1985]. Since the form of the equation is similar to the modified model of Dally et al. [1985], this model also reproduces the pause for breaking process in the simulation model. Therefore, for the present beach profile evolution model, the model of Rattanapitikon 
and Shibayama [1998] is employed to compute the average rate of energy dissipation due to wave breaking [Eq. (7)].

\subsubsection{Breaking location}

When water waves approach the shoreline, waves become steeper and start to break inducing a strong turbulence. The knowledge of breaking waves and its process is very limited and due to the complexity of the problem empirical methods are generally applied to predict the location of wave breaking and compute wave height transformation after breaking.

Goda [1970] proposed an empirical breaking index diagram of breaking wave height to depth ratio as a function of relative water depth for various bottom slopes. If this diagram is used together with linear wave theory, the location of wave breaking is shifted shoreward from the measured values, producing under-estimation of wave heights. In order to eliminate such a problem, Watanabe et al. [1984] proposed a relationship to convert the breaker depth index of Goda [1970] to a diagram of particle velocity to celerity ratio. For the usage of numerical models, Isobe [1987] approximated the diagram of Watanabe et al. [1984] as follows.

$$
\left(\frac{\hat{u}}{c}\right)_{b}=0.53-0.3 \exp \left[-3 \sqrt{\frac{h_{b}}{L_{0}}}\right]+5 m_{b}^{3 / 2} \exp \left[-45\left(\sqrt{\frac{h_{b}}{L_{0}}}-0.1\right)^{2}\right]
$$

where $\hat{u}$ is the amplitude of a horizontal water particle at the mean water level, $L_{0}$ is the deepwater wavelength, $m_{b}$ is the bottom slope and subscript $b$ corresponds to the values at the wave breaking location.

After simplifying Eq. (8), a more general form for a numerical study can be written in terms of wave height at the breaking point.

$$
H_{b}=\frac{L_{0}}{\pi \operatorname{coth}^{2}\left(k_{b} h_{b}\right)}\left\{0.53-0.3 \exp \left[-3 \sqrt{\frac{h_{b}}{L_{0}}}\right]+5 m_{b}^{3 / 2} \exp \left[-45\left(\sqrt{\frac{h_{b}}{L_{0}}}-0.1\right)^{2}\right]\right\}
$$

where $k_{b}$ is wave number at breaking point. 
Since Eq. (9) is derived using the breaking depth diagram of Goda [1970] it is referred as the Goda breaking index.

Rattanapitikon et al. [2003] made a proposal of an empirical relationship for computing breaking wave height by relating breaking wave steepness to deepwater wave steepness. The bottom slope effect was included explicitly into the proposed formula as a parabolic function.

$$
H_{b}=\left(-1.40 m^{2}+0.57 m+0.23\right) L_{b}\left(\frac{H_{0}}{L_{0}}\right)^{0.35}
$$

where $m$ is the bottom slope of the beach and subscripts $b$ and 0 denote breaking and deepwater wave characteristics respectively.

Selection of a suitable analytical model depends on the individual researcher. The performance of Eq. (9) in numerical models was widely recognised by many coastal researchers, hence for the present numerical simulation model, Eq. (9) is used to compute breaking wave height, $H_{\mathrm{b}}$.

\subsection{Sediment concentration models}

\subsubsection{Background}

A significant portion of the sediment transport in the coastal environment is due to the suspension mechanism. Sediment suspension usually occurs in and outside the surf zone due to turbulent motion generated by sand ripples, moving of the bottom layer with high bed shear stresses and turbulence motion generated by wave breaking.

Sand ripples are generated at the sea bottom when the coastal waves propagate into the shallow water region. Vortex ripples increase the flow separation and turbulence, which induce a considerable amount of energy dissipation and sand agitation (Sato, 1987). Therefore, sediment suspension over vortex ripples plays a dominant role in various coastal processes such as sediment transport, wave attenuation and mass transport due to wavecurrent coexistent field. The characteristics of movement of sediment particles in the sheet 
flow regime are completely different over the ripple-formed bed. The rippled seabed gives way to the sheet flow region in the breaker zone under extreme wave conditions (e.g. storms and typhoons). Under these conditions, large wave heights cause large near-bed velocities thus the sand is suspended over the thin layer close to the bed. The concentration profile itself is not exactly similar in the case of rippled bed. Sand movement in the surf zone is influenced by the turbulence and the organised motion of vortices and eddies generated by the breaking waves and the asymmetric oscillatory motion under shallow-water waves. Sato et al. [1990] pointed out that the sediment suspension mechanism at the breaking point is particularly important, where the turbulence and large-scale vortices agitate a large amount of sediment to form a sand cloud with extremely high concentrations.

Developing a complete set of time-averaged suspended sediment concentration model is a challenging task due to the complexity of the suspension mechanism and uncertainties involved in the modelling procedure. Concentration models of Sleath [1982], Nielsen [1986, 1988] and Rattanapitikon and Shibayama [1994] are widely used however these models did not cover all three suspension mechanisms.

Jayaratne and Shibayama [2007] derived a set of explicit empirical formulae to predict sediment concentration under a) suspension on the bottom boundary layer due to turbulent motion over sand ripples, b) suspension from sheet flow layer, and c) suspension due to turbulent motion under breaking waves. Reference concentrations and diffusion coefficients were derived separately for small-scale and large-scale studies using dimensional analysis and a best-fit technique. Time-averaged concentration profiles were developed based on the steady diffusion equation. A good correlation was found between measured and computed concentrations. Published small-scale and large-scale experimental data from 19 sources from 1977 to 1996 were used in the calibration of numerical constants in the theoretical models and comparison of model results. It is common in nearshore region that one or two suspension mechanisms such as ripples and breaking agitation or sheet flow and breaking 
agitation to occur simultaneously. Therefore, predominance of each suspension mechanism is verified with a newly developed explicit formula. Finally, the applicability of concentration models for irregular waves is also confirmed by the measured data sets.

Jayaratne et al. [2011] discuss an overview of their previous concentration models on large-scale rippled beds and sheet flow regimes with respect to the SANTOSS (Sand Transport in Oscillatory flows in the Sheet-flow regime) database (Van der Werf et al. [2009]). Similar to the previous models, dimensional analysis and best-fit technique were the main driving techniques for the formulation of bed reference concentrations and vertical distribution of diffusion coefficients. Model parameters were calibrated with the help of large-scale measured data. Time-averaged concentration profiles were derived from the steady diffusion equation. Two distinct suspension layers (i.e. lower and upper) were identified within the suspension over rippled bed therefore predictive models were given separately for each layer. In the case of sheet-flow regime, predictive models were given for suspension and upper-sheet flow layers. Seventy-five rippled bed and eighty sheet flow experiments from 1994 to 2007 [Van der Werf et al., 2009] are better explained by the proposed formulae with an appropriate selection of energy coefficients in each data set. The reason for this was identified primarily due to the presence of different flow types and nature of the experimental facility.

By considering the previous concentration models of Jayaratne and Shibayama [2007] and Jayaratne et al. [2011] the following sets of explicit empirical formulae were used to compute suspended sediment transport rate in the present study. The appropriate free parameters $\left(k_{1}-k_{8}\right)$ in rippled bed and sheet flow formulae were determined using trial and error method with compliance to the ranges specified in Jayaratne et al. [2011]. On the other hand, free parameters in breaking agitation formulae $\left(k_{9}-k_{12}\right)$ remained unchanged as in Jayaratne and Shibayama [2007]. 


\subsubsection{Sediment suspension over rippled bed}

One of the key features identified in the full-scale rippled bed model of Jayaratne et al. [2011] from Jayaratne and Shibayama [2007] is that the distribution profile consists of two layers. Figure 1 shows the distinct suspension layers (lower and upper layers) classified over rippled bed. Equations (11), (12), (14) and (15) present the corresponding bed reference concentration and diffusion coefficients.

(a) Lower suspension layer $(z \leq 2 \eta)$

$$
c_{r}=\frac{k_{1} \Theta v}{\sqrt{(s-1) g d}(\eta / 2)}
$$

where $c_{r}$ is bed reference concentration, $k_{1}=80$ is a numerical constant which depends on the flow type and nature of experiments, $\Theta$ is the mobility number, $v$ is the kinematic viscosity, $s$ is the specific gravity of sand, $d$ is the average grain diameter, $\eta$ is the rippled height and $z$ is the water depth.

$$
\varepsilon_{r}=k_{2} u_{*_{w c}} A_{b}\left(\frac{w_{s}}{u_{*_{w c}}}\right)^{2}\left(\frac{\eta}{d}\right)^{0.1}\left(\frac{\lambda}{d}\right)^{0.25} d_{*}^{-1.5}
$$

where $\varepsilon_{r}$ is the diffusion coefficient, $k_{2}=0.3$ is a numerical constant which depends on the flow type and nature of experiments, $u_{* w c}$ is the maximum combined wave-current bed shear velocity, $A_{b}$ is the orbital amplitude of fluid just above the boundary layer, $w_{s}$ is the settling velocity of sand particle, $d$ is the average grain diameter, $\lambda$ is the ripple wavelength and $d_{*}=d\left(s g / v^{2}\right)^{1 / 3}[$ Van Rijn, 1984].

The concentration profile in lower layer $[c(z)$, Eq. (13)] is defined with the help of known $c_{r}$ [Eq. (11)] and $\varepsilon_{r}$ [Eq. (12)]. Bed reference concentration level $(r)$ is set at $\eta / 2$ where this level is measurable without disturbing the formation of ripples (Skafel \& Krishnappan, 1984).

$$
c(z)=c_{r} \exp \left\{\frac{-w_{s}(z-r)}{\varepsilon_{r}}\right\}
$$


(b) Upper suspension layer $(z>2 \eta)$ :

$$
c_{r}=\frac{k_{3} \Theta v}{\sqrt{(s-1) g d}(\eta / 2)}
$$

where $k_{3}=75$ is a numerical constant which depends on the flow type and nature of experiments.

$$
M_{r}=k_{4}\left(\frac{\eta}{d}\right)^{0.1}\left(\frac{\lambda}{d}\right)^{0.25} d_{*}^{-1.5}
$$

where $k_{4}=5.0$ is a numerical constant which depends on the flow type and nature of experiments.

Equation (16) gives the concentration distribution profile in upper layer in terms of known $c_{r}$ [Eq. (14)] and $M_{r}$ [Eq. (15)].

$$
c(z)=c_{r}\left(\frac{z_{0}}{z}\right)^{M_{r}}
$$

where $z_{0}=10 d$ is the reference level in the upper suspension layer.

Figure 2 illustrates some examples of measured and computed results from the combined lower (exponential) and upper (power) suspension models. The comparison plots shown in Jayaratne et al. [2011] are reproduced with the new numerical constants proposed in the present study.

\subsubsection{Sediment suspension over sheet flow}

The distribution pattern of sediment concentration described in Jayaratne and Shibayama [2007] consists of two different trends from the initial bed level to the top of water surface. The most recent study of Jayaratne et al. [2011] also shows the same patterns such as an exponential form for the upper-sheet flow layer and a power law for the suspension layer.

Figure 3 shows the distinct layers (upper sheet flow and suspension layer) identified over full-scale sheet flow regime. Equations (17) and (20) show the bed reference concentration models while Eqs. (18) and (21) show the diffusion coefficients over sheet flow. 
(a) Upper sheet flow layer:

$$
c_{s}=\frac{k_{5} \psi v}{\sqrt{(s-1) g d}(d)}
$$

where $c_{s}$ is the bed reference concentration, $k_{5}=2500$ is a numerical constant which depends on the magnitude of net-current, amplitude of wave, grain size and distribution, $\psi$ is the Shields parameter.

$$
\varepsilon_{s}=k_{6} u_{*_{w c}} A_{b}\left(\frac{w_{s}}{u_{*_{w c}}}\right)^{1.8} d_{*}^{-1.5}
$$

where $\varepsilon_{s}$ is the diffusion coefficient, $k_{6}=0.1$ is a numerical constant which depends on the experimental conditions such as flow type, grain size and distribution.

$$
c(z)=c_{s} \exp \left\{\frac{-w_{s}(z-d)}{\varepsilon_{r}}\right\}
$$

Concentration distribution profile [Eq. (19)] over upper sheet flow layer is derived using Eqs. (17) and (18). Bed reference level is taken at $z=d$.

(b) Suspension layer:

$$
c_{s}=\frac{k_{7} \psi v}{\sqrt{(s-1) g d}(d)}
$$

Bed reference concentration was taken at a depth of $k_{7} d$ where $k_{7}$ is equal to 14.0.

$$
M_{s}=\left(\frac{w_{s}}{u_{*_{w c}}}\right)^{k_{8}}
$$

where $k_{8}=0.6$ is a numerical constant which depends on the flow type.

Present model of suspended sediment concentration [Eq. (22)] within suspension layer follows a power-law as initially found by Ribberink and Al-Salem [1992]. Predicted concentrations show a good agreement with the measured data. Hence Eq. (22) becomes exactly the same as the previous model of Jayaratne and Shibayama [2007].

$$
c(z)=c_{s}\left(\frac{100 d}{z}\right)^{M_{s}}
$$


Non-dimensional parameter $M_{\mathrm{s}}$ in Eq. (22) is defined as the diffusion coefficient over suspension layer. Ribberink and Al-Salem [1994] defined it as the decay parameter and specified to be a constant which was approximately equal to 2.1 for a large number of waves with uniform sand diameter of $0.21 \mathrm{~mm}$.

Figure 4 illustrates some examples of measured and computed results from the combined upper sheet flow (exponential) and suspension (power) models. The comparison plots shown in Jayaratne et al. [2011] are reproduced with the new numerical constants proposed in the present study.

\subsubsection{Sediment suspension under breaking waves}

It is a clear fact that most present models do not elucidate the terms of sediment suspension by wave breaking phenomenon. Some models try to estimate the sediment pick-up rate as a function of Shields parameter or the relative strength of shear stress acting on the seabed. However, it is doubtful if the shear stress exercises any effect on the generation of large vortices by agitation of breaking waves (Goda, 2000).

The suspended sediment concentration outside the boundary layer is likely to be determined by the entrainment and mixing due to sources such as agitation of breaking waves. Waves that plunge heavily on shallow bars or on the step of steep beaches can form very strong jets that penetrate directly to the bed and hence introduce very strong external turbulence into the boundary layer itself. These jets are also able to inject large amounts of entrained air into the boundary layer, and when this air rises, it generates large localised, upward water velocities that act as very efficient elevators for suspended sediments (Jayaratne and Shibayama, 2007). Jayaratne and Shibayama [2007] introduced the local wave orbital velocity to the bed reference equation [Eq. 23] at the location to be considered in the surf zone. Bed reference level was taken at a level of $100 d$ from the bed $(z=100 d)$. 


$$
c_{b}=k_{9}\left(\frac{\hat{u}}{\hat{u}_{b}}\right)^{1.5}\left[10^{-9} g T \frac{\hat{u}_{b}^{2.3}}{w_{s}^{3.3}}\right]
$$

where $\hat{u}$ is the local wave orbital velocity at the location to be considered, $\hat{u}_{b}$ was selected as a parameter to represent the intensity of near-bottom flow at the wave breaking point (Sato et al., 1990) and $k_{9}$ is a numerical constant depends on $T$.

Using the trial and error method, the following constants are recommended for $k_{9}$ in such a way that when $6.0 s<T \leq 10.0 s$ the value of $k_{9}$ is $75 \%$ from the value when $T \leq 6.0 s$ and when $T>10.0 s$ the value of $k_{9}$ is $75 \%$ from the value when $6.0 s<T \leq 10.0 s$. As $T$ increases, wave breaking occurs at the surf zone boundary close to the offshore region and hence the magnitude of suspended sediment concentration becomes comparatively small. In other words, the value of $k_{9}$ has to be decreased as $X$ increases from the offshore boundary of the surf zone.

$$
k_{9}= \begin{cases}0.45 ; & ; T \leq 6.0 s \\ 0.34 ; & ; 6.0 s<T \leq 10.0 s \\ 0.25 ; & ; T>10.0 s\end{cases}
$$

Jayaratne and Shibayama [2007] proposed diffusion coefficient $\left(\varepsilon_{b}\right)$ by incorporating the effect of shearing force exerted on the sea bed to the eddy viscosity concept of Okayasu [1989].

$$
\varepsilon_{b}=\left[k_{10} u_{*_{w c}}^{\prime \prime}+k_{11}\left(\frac{D_{B}}{\rho}\right)^{1 / 3}\right] z
$$

where $k_{10}=0.08, k_{11}$ varies from 0.0675 at wave breaking point to 0.225 at transition point (Rattanapitikon and Shibayama, 1996) as the energy dissipation takes place throughout the width of the surf zone [Eq. 25], $u_{*_{w c}}^{\prime \prime}$ is the shear velocity under wave-current coexistent field and $D_{B}$ is calculated from Eq. (7).

$$
k_{11}=k_{12}\left[0.3+0.7 \frac{\left(x_{b}-x\right)}{\left(x_{b}-x_{t}\right)}\right]
$$


where $k_{12}=0.225$ is a constant which was assigned for spilling wave breaking condition of small-scale studies described in Jayaratne and Shibayama [2007], where $x$ is the position in cross-shore direction and subscripts $b$ and $t$ denote the distances from wave breaking and transition points respectively.

The solution of concentration profile with reference level $z=100 d$ is given in the following form by Jayaratne and Shibayama [2007].

$$
c(z)=c_{b}\left(\frac{100 d}{z}\right)^{M}
$$

where parameter $M$ is given by Eq. (27).

$$
M=\frac{w_{s} z}{\varepsilon_{b}}
$$

Figure 5 illustrates the measured and computed concentration distributions at different locations in cross-shore direction $(x)$ with a particular time $(t)$ from data sources of Kajima et al. [1983] and Dette and Uliczka [1986].

\subsection{Mass transport velocity model}

\subsubsection{Vertically averaged velocity}

Concentration and velocity profiles throughout the water column should be predicted precisely in order to compute the on-offshore sediment transport rates. From the laboratory and field observations, it is well known that a steady drift of fluid particles is induced by the water waves in addition to the oscillatory motion both for non-breaking and breaking waves. Due to additional mass flux caused by the surface roller, the mass transport velocity induced by breaking waves generally referred to as undertow, is larger than that induced by nonbreaking waves (Hansen and Svendsen, 1984).

The magnitudes of time-averaged components are usually smaller than those of oscillatory components and it has a significant effect on sediment transport. Quite a number of undertow models have been established by previous researchers, e.g. Hansen and 
Svendsen [1984], Okayasu et al. [1988], Rattanapitikon and Shibayama [1996, 2000] and those models produced satisfactory results.

The main advantage of selecting the undertow model of Rattanapitikon and Shibayama [1996] for the present study is that it is capable of accurately predicting timeaveraged velocity from the edge of the boundary layer to wave trough under a wide range of hydraulic parameters, as well as being applicable for various regimes in the surf zone. The vertically averaged velocity model of Rattanapitikon and Shibayama [1996] is given as follows.

$$
U_{m}=0.77\left[\frac{B_{0} \sigma H^{2} \operatorname{coth}(k h)}{h}\right]+b_{1} 0.1\left[\frac{c H}{h}\right]
$$

where $U_{m}$ is the vertically averaged velocity from the bed to wave trough caused by breaking waves, $\sigma$ is the angular frequency, $B_{0}$ is a parameter depends on hydraulic conditions and beach slope and expressed by Rattanapitikon and Shibayama [1996] as follows.

$$
B_{0}=0.125+0.60 m_{b}-0.089 \frac{H}{h}
$$

where $m_{b}$ is the bottom slope.

The constant, $b_{1}$ is expressed based on the different zones in the coastal environment.

$$
b_{1}= \begin{cases}0 & \text { Offshore Zone } \\ \left(1 / \sqrt{H}-1 / \sqrt{H_{b}}\right) /\left(1 / \sqrt{H_{t}}-1 / \sqrt{H_{b}}\right) & \text { Transition Zone } \\ 1 & \text { Inner Zone }\end{cases}
$$

where subscript $b$ indicates the value at the breaking point and subscript $t$ indicates the value at the transition point.

\subsubsection{Width of transition zone}

The inclusion of a transition zone in to the beach profile has an important effect on the predicted profiles particularly near bar features (Nairn et al., 1990). The distance from breaking point to the point where rather stable bore-like waves are formed is called the width 
of the transition zone (Svendsen et al., 1978). The behaviour of the variation of wave height and mean water level inside the transition zone is quite different from the inner surf zone. Wave height decays rapidly and if mean water level is relatively constant then there is an abrupt change in slope at the transition point (Svendsen, 1984a; Basco and Yamashita, 1986). Nairn et al. [1990] used the mean water level to define the transition point. According to experiments of Okayasu et al. [1986], the abrupt change in slope could not be found. Therefore, change of wave height was a parameter to define the transition point. Basco and Yamashita [1986] defined the transition point as the point just after the rapid decay of wave height while Okayasu [1989] defined it as the point where the fully developed bore-like wave was found. From the experimental results of Okayasu et al. [1988] and Nadaoka et al. [1982], it was found that the maximum in time-averaged velocity occurs at the transition point.

By considering the above facts, Rattanapitikon and Shibayama [1996] derived the following relationship in terms of hydraulic parameters.

$$
\left[\frac{h_{o t}}{h_{o b}}\right]=0.866-1.463 \xi_{b}
$$

where $h_{o t}$ is the still water depth at transition point, $h_{o b}$ is the still water depth at breaking point and $\xi_{b}=m_{b} / \sqrt{H_{b} / L_{b}}$ is the surf similarity parameter at the breaking point and $L_{b}$ is the wavelength at the breaking point.

\subsubsection{Vertical distribution of undertow up to wave trough}

In order to analyse vertical distribution of undertow induced by breaking waves, timeaveraged vertical distribution of shear stresses and eddy viscosity must be determined. Based on the dimensional analysis, Okayasu [1989] proposed a formula for computing the shear stress distribution $(\tau)$ and eddy viscosity coefficient $\left(v_{t}\right)$.

$$
\tau=\rho^{1 / 3} D_{B}^{2 / 3}\left[k_{13} \frac{z}{d_{t}}+k_{14}\right]
$$


where $k_{13}$ and $k_{14}$ are numerical constants.

The eddy viscosity coefficient can be calculated from the following formula.

$$
v_{t}=k_{15}\left(\frac{D_{B}}{\rho}\right)^{1 / 3} z
$$

where $k_{15}$ is also a numerical constant.

Since the measured values of $\tau$ and $v_{t}$ were not available, Eqs. (31) and (32) were represented in terms of undertow velocity. Using eddy viscosity model, the undertow can be written as,

$$
U(z)=\int \frac{\tau}{\rho v_{t}} d z
$$

By substituting Eqs. (31) and (32) in Eq. (33), and integrating and combining with $U_{m}$ [Eq. (28)], finally complete undertow distribution in transition and inner zones $[U(z)]$ is written as follows.

$$
U(z)=b_{2} \rho^{1 / 3} D_{B}^{1 / 3}\left[b_{3}\left(\frac{z}{d_{t}}-\frac{1}{2}\right)-0.22\left(\ln \frac{z}{d_{t}}+1\right)\right]+U_{m}
$$

where $b_{2}$ and $b_{3}$ are constants and expressed as,

$$
\begin{aligned}
& b_{2}= \begin{cases}0.3+0.7\left(x_{b}-x\right) /\left(x_{b}-x_{t}\right) & \text { Transition Zone } \\
1 & \text { Inner Zone }\end{cases} \\
& b_{3}= \begin{cases}\left(x_{b}-x\right) /\left(x_{b}-x_{t}\right) & \text { Transition Zone } \\
1 & \text { Inner Zone }\end{cases}
\end{aligned}
$$

In the transition zone, energy dissipation is assumed to be increased linearly from breaking point to the transition point.

\subsubsection{Vertical distribution of velocity from wave trough to crest}

Total sediment flux from the edge of wave boundary layer to wave trough per unit width $\left(q_{s l}\right)$ can be given as,

$$
q_{s l}=\int_{\delta}^{d_{t}} c(z) U(z) d z
$$


where $c(z)$ is the time-averaged concentration profile, $U(z)$ is the time-averaged velocity profile, $\delta$ is the edge of the wave boundary layer and $d_{t}$ is the depth at wave trough.

Using the concept of mass conservation, Eq. (36) is derived to calculate mass transport velocity, $U_{T C}$ from wave trough to crest. Assuming that the concentration is constant throughout the wave regime and is equal to the value at the trough level given by the predictive model of suspended sediment concentration under breaking agitation, Eq. (37) is proposed to compute total sediment flux from wave trough to crest per unit width, $q_{s u}$. Figure 6 illustrates definition sketch of different sediment flux layers.

$$
\begin{aligned}
& U_{T C}=\left(\frac{1}{H}\right) \int_{\delta}^{d_{t}} U(z) d z \\
& q_{s u}=U_{T C} c\left(d_{t}\right) H
\end{aligned}
$$

where $U(z)$ is given by Eq. (34).

Table 1 and 2 show the sediment flux at different layers such as wave crest $\left(q_{s u}\right)$, wave trough $\left(q_{s m}\right)$ and the edge of the boundary layer $\left(q_{s l}\right)$ from Case 4.3 of Kajima et al. [1983] Table 1 Table 2 and Case 500 of Kraus and Larson [1988] respectively. According to simulation results, it is found that a portion of sediment mass is directed in the offshore direction due to plunging vortexes, especially close to the breaker line, while another portion is directed in the onshore direction. The mass flux at the crest level is sometimes greater than that at the level of the edge of boundary layer (Table 2). It is identified that as $H$ (high waves) increases the mass flux also increases proportionately. From the results of Kajima et al. [1983] and Kraus and Larson [1988], it is revealed that mass flux from wave trough to wave crest has a secondary effect compared to the values at the edge of the boundary layer and wave trough. Generally, the sediment flux in this region gives a secondary effect compared to the values in the lower part of the water column. 


\subsection{Sediment transport rate formulae}

\subsubsection{Suspended and bed load formulae}

The formulas for predicting sediment concentration and mass transport velocity described in Sections 2.3 and 2.4 are used to compute the sediment transport rate. Figure 7 illustrates the definition sketch of three-layer sediment transport model. The temporal evolution of vertical distribution of sediment concentration, $c(z, t)$ and vertical distribution of flow velocity, $u_{s}(z, t)$ over a wave period requires a large computation time therefore it is worthwhile to adopt more simplified forms of $c(z)$ and $u_{s}(z)$.

Then, the total suspended sediment transport rate from bottom to wave crest can be written as,

$$
q_{t}=\int_{-\delta_{s}}^{d_{t}+H} c(z) u_{s}(z) d z
$$

where $-\delta_{s}$ is the elevation below the bottom surface where there is no effective movement of sand particles, $d_{t}$ is the depth at wave trough.

Due to the difficulty in measuring the concentration and velocity accurately at the region close to and inside the moveable bed, the experimental results in those regions are very limited. Therefore, reliable formulas for predicting sediment concentration and velocity distribution have not yet been developed. In the present study, the sediment transport above the edge of the boundary layer is treated according to the time-averaged approach of sediment transport and it is referred to as suspended load. The sand transport in the lower portion is generally referred to as bed load and for the present study it is incorporated in the modified bed load formula of Watanabe [1982].

The modified bed load transport formula of Watanabe [1982] can be written in the following form.

$$
q_{b}=K_{b}\left(\psi-\psi_{c}\right) \sqrt{\psi} w_{s} d
$$


where $q_{b}$ is the bed load transport, $K_{b}=2.0$ (Rattanapitikon and Shibayama, 1996) and $\psi_{c}=0.05$ is the critical Shields parameter.

Therefore, total net sediment transport rate from bottom to wave crest can be rewritten as,

$$
q_{t}=\int_{\delta_{s}}^{d_{t}+H} c(z) u_{s}(z) d z+q_{b}
$$

The thickness of the boundary layer $\left(\delta_{s}\right)$ is computed from the formula of Jonsson [1966] and the roughness is computed from the formula of Nielsen [1992]. The formula of Jonsson [1966] is given as,

$$
\frac{30 \delta_{s}}{k_{n}} \log \frac{30 \delta_{s}}{k_{n}}=1.2 \frac{A_{b}}{k_{n}}
$$

where $k_{n}$ is the equivalent Nikuradse roughness.

Nielsen [1992] used the measured data of Carstens et al. [1969] and Lofquist [1986] to calibrate the relationship and found the following equation for $k_{n}$.

$$
k_{n}=8 \frac{\eta^{2}}{\lambda}+170 \sqrt{\psi_{2.5}-0.05} d
$$

where $\psi_{2.5}$ is the grain Shields parameter using roughness equal to $2.5 \mathrm{~d}$.

Rattanapitikon and Shibayama [1996] proposed an explicit formula for boundary layer thickness, $\delta_{s}$, by considering Eqs. (41) and (42) using regression analysis.

$$
\frac{\delta_{s}}{k_{n}}=0.001\left[26.75\left(\frac{A_{b}}{k_{n}}\right)^{0.5}+33.04\left(\frac{A_{b}}{k_{n}}\right)^{0.8}+5.89\left(\frac{A_{b}}{k_{n}}\right)+26.89\right]
$$

\subsubsection{Modification to total transport rate formulae}

It is found that the selected wave model and the proposed sediment transport models can not exactly predict the same value as the measured results. This resulted in accumulating some error in every computation time step, since wave height transformation will produce beach 
profile change and beach profile change will feedback into the wave height transformation. Finally, the model becomes unstable and instability will be caused for long run predictions due to the high fluctuations of sediment transport rates between adjacent computation grids. Therefore, it is necessary to employ an artificial treatment or a modification to the sediment transport formula in order to control the stability of the beach deformation model.

A three-point weighted filter is applied to smooth the fluctuations of computed bed load from the modified formula of Watanabe [1982].

$$
q_{b s, i}=0.3 q_{b, i-1}+0.4 q_{b, i}+0.3 q_{b, i+1}
$$

where $q_{b s}$ is the smoothed bed load, $q_{b}$ is the bed load and subscript $i$ is the cell number.

The sediment in a steep slope is expected to move in the downward direction due to gravity. Therefore, the effect of local slope is treated with the work of Watanabe et al. [1986] and Larson and Kraus [1989] by introducing an additional term, $q_{a}$, to improve predictive transport rate.

$$
q_{a}=-C_{1}\left|q_{b s}\right| \frac{\partial z_{b}}{\partial x}
$$

where $C_{1}$ is the coefficient that depends on the sand diameter.

From the experience of previous researchers (e.g. Watanabe et al., 1986; Larson and Kraus, 1989; Rattanapitikon and Shibayama, 1996), $C_{1}$ is selected as 10.0 for the median sand diameter $\left(d_{50}\right)$ less than or equal to $0.47 \mathrm{~mm}$ to make the model more stable. Since most natural beaches are covered with the median sand diameter of $0.20 \mathrm{~mm}$, the most cases are limited to a maximum median sand diameter of $0.47 \mathrm{~mm}$, which is assumed to be a good representation of most natural sandy beaches around the world.

After smoothing bed load and adding the bottom slope term into Eq. (40), the total sediment transport rate from bottom to wave crest can be expressed as,

$$
q_{t}=\int_{\delta_{s}}^{d_{t}+H} c(z) u(z) d z+q_{b s}+q_{a}
$$




\subsection{Beach profile evolution model}

\subsubsection{Conservation of sediment mass}

The numerical simulation model described in this section is composed of a selected wave model and sets of predictive models described in Sections 2.1-2.4. The coefficients in wave and sediment transport models are kept constant for all test cases. The beach profile change is computed from the conservation of sediment mass.

$$
\frac{\partial z_{b}}{\partial t}=-\frac{1}{(1-n)} \frac{\partial q_{t}}{\partial x}
$$

where $n$ is the sediment porosity, assumed to be constant along the profile.

Equation (47) is solved numerically using the Finite Difference Method (FDM). The finite difference form of Eq. (47) can be expressed as,

$$
h_{i}^{k+1}=h_{i}^{k}-\frac{\Delta t}{(1-n) \Delta x}\left[\frac{q_{t i+1}^{k}+q_{t i}^{k}}{2}-\frac{q_{t i}^{k}+q_{t i-1}^{k}}{2}\right]
$$

By simplifying Eq. (48), we have,

$$
h_{i}^{k+1}=h_{i}^{k}-\frac{\Delta t}{2(1-n) \Delta x}\left[q_{t i+1}^{k}-q_{t i-1}^{k}\right]
$$

where $i$ is the grid number and $k$ is the time step number.

The bottom elevations at most seaward and shoreward boundaries should be specified in order to compute the bottom elevation from Eq. (49). The seaward boundary is taken as the line where there is no change in the bottom elevation and sediment can pass through the boundary. The shoreward boundary is defined at the wave run-up height and assumed to have zero change in bottom elevation. The characteristics of the swash zone are not included in the present study and the model is valid up to the end of surf zone, defined as a finite water depth close to the shoreline.

Run-up limit, $Z_{R}$, is computed from the formula of Larson and Kraus [1989], by analysing experimental data of Kajima et al. [1983] and Kraus and Larson [1988].

$$
Z_{R}=1.47 H_{0} \xi_{0}^{0.79}
$$


where $\xi_{0}=m_{b} / \sqrt{H_{0} / L_{0}}$ is the surf similarity parameter.

To verify computed cross-shore sediment transport rates obtained by the simulation model, the rate of change of measured beach profiles can be considered. In mathematical point of view, by integrating the mass conservation equation, Eq. (47), the spatial distribution of cross-shore transport, $q_{t}(x)$, can be expressed as follows.

$$
q_{t}\left(x, \frac{t_{i+1}+t_{i}}{2}\right)=\frac{1}{t_{i+1}-t_{i}} \int_{x_{0}}^{x}\left[h\left(x, t_{i+1}\right)-h\left(x, t_{i}\right)\right] d x
$$

where $x$ is the location in cross-shore direction, $x_{0}$ is the location of no profile change, $t_{i}$ and $t_{i+1}$ are the time to measure profiles and $h$ is the still water depth.

Figure 8 illustrates the definition sketch of numerical cell for computing wave height, water depth and sediment transport rate used in this study. Those three parameters are computed at the middle of the cell.

The suspended load is the dominant term describing both erosion and accretion types of beaches in the present study. The ability to predict sediment concentration formulas is limited for sand of diameter up to about $0.47 \mathrm{~mm}$ due to the lack of concentration measurements of coarse sand (see Table 3). Further, this resulted in using the sediment transport formula in the same range of sand diameter. For the present numerical model, cases with sand diameters up to $0.47 \mathrm{~mm}(0.18-0.47 \mathrm{~mm})$ are considered including $0.20 \mathrm{~mm}$ case as it is the common sand diameter found in many natural beaches. Watanabe et al. [1980] reported that ripple formation and sediment suspension occurred rarely in the case of $0.7 \mathrm{~mm}$ sand. Therefore, for the present study, sand diameter greater than $0.69 \mathrm{~mm}$ is taken as zero suspended load. Due to the availability of measurements of sediment concentration for sand with diameter greater than the above-specified value $(0.69 \mathrm{~mm})$, the existing conditions are replaced accordingly. 


\subsubsection{Avalanching concept of Larson and Kraus [1989]}

Larson and Kraus [1989] modified the avalanching concept of Allen [1970] by analysing the large wave flume data of Kajima et al. [1983] and Kraus and Larson [1988]. It was found that the repose angle $\left(\Phi_{r p}\right)$ and residual angle $\left(\Phi_{r s}\right)$ obtained by Larson and Kraus [1989] were significantly lower than that of those reported by Allen [1970]. Therefore, it was suggested to use $\Phi_{r p}$ as $28^{0}$ and $\Phi_{r s}$ as $18^{\circ}$. Further, it was also suggested to re-distribute the sediment mass in the neighbouring grids in downward direction in such a way that the local slope was less than or equal to the residual angle, provided that local beach slope exceeded the repose angle. Initially it is assumed in the present study that avalanching takes place between cell 1 and cell 2 as shown in Fig10. In order to obtain $\Phi_{r s}$, sand is moved between the cells. The new slope angle between cell 2 and cell 3 is checked to find out whether it exceeds $\Phi_{r p}$. If the local slope exceeds $\Phi_{r p}$, the computation is repeated from cell 1 to cell 3 to obtain $\Phi_{r s}$. This procedure is

continued until the local slope angle between cell $N$ and cell $N+1$ is less than or equal to $\Phi_{r s}$. Therefore, the iteration technique is employed to find out the avalanching number of cells $(N)$ in the computation domain (Fig. 9).

Quasi-steady condition for wave field computation is used. Wave height is assumed to be unchanged during a simulating time interval, $t_{i}\left(t_{i}<\Delta t\right)$. A simulation time interval of thirty minutes (e.g. $t_{i}=30,60,90,120 \mathrm{~min}$ intervals due to observed field and laboratory measurements) is used in the present study. The wave height is kept unchanged during specified time interval $\left(t_{i}\right)$ but the sediment transport rate at each grid point is changed due to the change of the bottom slope at every time step $(\Delta t)$. Since the present model requires a small computation time, i.e. 2 to 3 min to simulate 30 days beach deformation, setting up of a small time step, $\Delta t$ compared to simulating time interval, $t_{i}$ does not cause a significant effect on the computation time. In other words, $\Delta t$ remains 30 mins in most tested cases. However, if the model becomes unstable for a particular test case or dataset, the time-step, $\Delta t$ (e.g. Case 
$\mathrm{K} 42, \Delta t=10 \mathrm{~min}$ ) is further reduced in order to ensure the stability of the model and reduce the large bed deformations.

\subsubsection{Model structure}

The overall structure of the present beach profile evolution model is shown as a flow chart in

Fig. 10. The incident wave conditions $(H, T)$, initial bottom topography $(h)$ and initial bottom slope $\left(m_{b}\right)$ are the main input parameters of the model.

\section{Comparison of Simulated Results with Large-Scale and Natural Beach Data}

The robustness and applicability of the beach profile model is examined by comparing initial profile $(t=0 \mathrm{hr})$ and measured beach profiles at different time periods from 5 high-quality data sources of large-scale wave flume experiments and natural beaches in Japan and the Netherlands. The experimental beach profiles feature particularly offshore and onshore bars and berms, defined with respect to the initial beach profile. The beach profiles were measured at each wave run. It was reported that waves were run until beach profiles achieved to a state of equilibrium which means the particles move but there is no net sediment transport along the profile. All numerical coefficients (free parameters) in the sub models are kept constant for all test cases used in the computation. Table 4 shows the summary of data sources used in the study. Sections 3.1 and 3.2 discuss each data sources separately and model comparison results.

\subsection{Large-scale laboratory experiments}

\subsubsection{Kajima et al. [1983]}

Kajima et al. [1983] measured beach profiles in a large-scale wave flume $(205.0 \times 3.4 \times 6.0 \mathrm{~m})$ at the Central Research Institute of Electrical Power Industry (CRIEPI) of Japan in 1981. The total number of test cases performed by Kajima et al. [1983] is 19 and all cases started with a 
uniform initial beach slope, ranging from $1 / 50$ to $1 / 10$. The highest measured storm duration is $t=60 \mathrm{hr}$ (2.5 days). Most numerical results (e.g. Test Case 1.1, 1.2, 1.3, 1.4, 1.5, 1.6, 1.7, $3.1,3.2,3.3,3.4,4.1,4.2,4.3,4.4,5.1$ and 6.1$)$ show good agreement with the general trend of the measured beach profile from offshore to onshore, illustrating main morphological features such as sand bars and berm formation. This means that evolution of bars and berms were found to be regular under steady wave and gradually varying water depth. Some test cases such as Case 3.3, 3.4, 4.2, 4.3 and 6.1 illustrate shifting of the large sand bar towards onshore and this could result in shifting of the predicted breaker line. Predicted results of Case 4.4 and 5.2 show greater beach deformation as the storm duration increases (e.g. Case 4.4 at $t=10 \mathrm{hr}$ and Case 5.2 at $t=60 \mathrm{hr}$ ). One of the reasons for this discrepancy may be the non-conserved sediment mass in the cross-shore profile and perhaps it was not captured by the 2D model. Figures 11-20 represent the measured and computed beach profiles at equilibrium state. Table 5 shows the details of each test case used in the study.

\subsubsection{Kraus and Larson [1988]}

Kraus and Larson [1988] reported beach profile changes in a large wave flume $(193.5 \times 4.6 \times 6.1 \mathrm{~m})$ at the Coastal Engineering Research Centre (CERC) of the US Army Corps of Engineers Waterways Experiment Station, which were measured in 1956-1957 and 1962. The total number of test cases carried out by Kraus and Larson [1988] is 12 and two tests were performed with an irregular initial beach slope. The highest storm duration considered under these tests were $t=40.5 \mathrm{hr}$. Generally, the computed profiles show the same tendency as the measured profile at equilibrium state (e.g. KL101, KL200, KL400, KL510, KL600, KL610, KL700). Cases with extreme wave conditions such as Case KL100, KL300, KL500 and KL700 show some undulating nature at crest and trough of sand bar and erosion in the onshore and the reason might be the sudden deposition of sediment by gravity before suspension occurs. A sharp-crested offshore dune and an onshore sand bar are formed in Case 
KL510 and this can be due to the presence of irregular initial beach slope. The computed results of Case KL100, KL200, KL500 and KL700 illustrate shifting of the sand bar towards onshore region compared to the measured shape. The main cause is identified as the shifting of the predicted beaker line. Further, it is observed from Case KL100, KL101, KL300 and KL700 that they were performed under long period and high waves. Similar to Kajima et al. [1983], it is found from the computed results that the longer the simulation time the larger the instability of the model results due to the greater deformation of beach topography (e.g. KL300 $t=20 \mathrm{hr}$, KL700 $t=15 \mathrm{hr}$ ). In other words, smaller the wave climate (both smaller $H$ and $T$ and either smaller $H$ or smaller $T$ ) better the comparisons results are (e.g. KL510, KL600 and KL610). Figures 21-25 show the measured and computed beach profiles at equilibrium state. Table 6 shows the details of test cases used in the study.

\subsection{Field measurements}

\subsubsection{PARI data [2005, 2009]}

The Port and Airport Research Institute (PARI) of Japan owns the Hazaki Oceanographic Research Station (HORS). HORS operates a research pier of $427 \mathrm{~m}$ long on the sandy beach facing to the Pacific Ocean. This pier captures the waves in the surf zone, between wave breaking point and the limit of wave up-rush on the beach, where a large amount of sediment is transported by wave action and wave-induced nearshore currents. Beach profiles from the tip of the pier to the backshore are measured with intervals of $5.0 \mathrm{~m}$ daily. Table 7 shows the details of both non-storm and storm test cases used in the present study.

a) Non-storm conditions [2005]:

Under non-storm conditions, the predicted and measured beach profiles including inner and offshore bar migration and trough deepening $(x<450 \mathrm{~m})$ at Hazaki coast match very well at $t=24 \mathrm{hr}$ ( 1 day) to $t=240 \mathrm{hr}$ (10 days). Since the swash dynamics are not included in the 
present model, the predicted profiles in the upper part of the swash zone $(x \leq 75.0 \mathrm{~m})$ show an average beach slope. It was observed from the predicted results that the bar migration and trough deepening at $t=720 \mathrm{hr}$ (30 days) has shifted towards onshore due to the change of breaker line and weakening of wave attack in that area (less energetic conditions).

There are several possible factors affecting the estimation of topography (water depths). As the water depth becomes shallower towards the beach, the effect of non-linearity in wave behaviour become more significant, causing higher wave celerity than the linear theory predicts and hence causing an over estimate of water depths [Bell, 1999]. The influence of currents, both tidal and wave induced, are also a potential source of variability in topography estimation. Such currents make the derived water depths larger if the current is in the direction of wave motion or smaller if the current is in opposition to the waves [Bell et al., 2004]. In general, the present model shows very good agreement with the measured beach profiles up to $t=240 \mathrm{hr}$ (10 days) and some discrepancies when $t>240 \mathrm{hr}$ (e.g. $t=720 \mathrm{hr}$ ), but simulated results are reasonably acceptable which may be due to a coincidental cancelling of probable effects from different factors. Figure 26 shows the measured and computed beach profiles at $t=24-720 \mathrm{hr}$.

Figure 26

\section{b) Storm conditions [2009]:}

The measured beach profiles at Hazaki coastal under storm conditions in 2009 illustrate that a bar located fairly close to the shore may contain crescentic structures (see e.g. Case 1, 4 and 5) that are diminished during storms while a bar located further offshore is generally alongshore uniform (see e.g. Case 4, 5, 6). Cases 1, 2 and 4 were recorded with high wave action. In Case 1, the predicted profile at $t=24 \mathrm{hr}$ shows two nearshore peaks (around $x=250$, $300 \mathrm{~m}$ ) and large deformation in the offshore region after $x=375 \mathrm{~m}$. When $t=72 \mathrm{hr}$ and $t=96$ $\mathrm{hr}$, simulated profiles show more deposition than measured offshore bars $(x=275-350 \mathrm{~m})$ and in some point $(x=350-375 \mathrm{~m})$ both profiles match each other before deposition takes place 
again. In Case 2, when $t=24 \mathrm{hr}$ and $t=48 \mathrm{hr}$ some mis-match between observed and predicted profiles can be seen and when $t=72 \mathrm{hr}$ and $t=144 \mathrm{hr}$ close match between two profiles are noticed. The reason was identified as it was initially subjected to a large wave attack (significant wave height $=1.29 \mathrm{~m}$ ) and weakening of this action as time increases. In Case 4, moderate trough deepening is observed compared to measured trough at $x=275-375 \mathrm{~m}$ however, the offshore profiles are matched remarkably well up to $t=72 \mathrm{hr}$. In general, predicted results of low wave height cases (wave height $\leq 0.9 \mathrm{~m}$ ), Case 3,5 and 6 , show reasonably well agreement with measured profile evolution in nearshore and surf zone except in swash zone. Case 5 illustrates a deep, broad trench with steep side slopes in nearshore and offshore boundaries between about $x=300 \mathrm{~m}$ and $x=425 \mathrm{~m}$ and this feature is well simulated by the present numerical model. It is believed that this behaviour is primarily due to the presence of a long wave period (13.0 s) in the sea state. Figures 27-29 show the measured and computed beach profiles from six different wave conditions.

Figures 27-29

\subsubsection{Hasan \& Takewaka [2007, 2009]}

Hasan and Takewaka [2007, 2009] discussed an examination of wave field and wave run-up using an X-band nautical radar system during a storm event around HORS research pier in Hazaki, Japan. The typhoon BANYAN (Typhoon \#7, T7, 2005) travelled through the west of the Pacific Ocean in July 2005. The bathymetric survey data (water depths) used in their study based on the measurements around HORS on $26^{\text {th }}$ and $27^{\text {th }}$ of July 2005 . Water surface elevations were measured with several wave gauges mounted on the pier, and the bottom profile along the pier was surveyed. In the present numerical model, beach profile on $26^{\text {th }}$ July 2005 was taken as the initial condition to simulate the profile on $26^{\text {th }}$ July, which was subjected to storm condition. It was reported that foreshore beach profile along the pier

Figure 30 remained mostly unchanged during the storm. Significant erosion took place at about $x=150$ Table 8 $\mathrm{m}$ and this is reasonably well predicted by the present numerical model, apart from relatively 
small under-prediction. It is evident from the results that the gravitational effect is more dominant due to the steepness of the initial beach profile. The beach profile in the swash zone does not match with the measured profile as the model does not include the swash dynamics at this level. Figure 30 depicts the measured and computed beach profiles from swash zone to offshore at equilibrium state. Table 8 shows the details of test case used in the study.

\subsubsection{Ruessink et al. [2007]}

The data reported in this section measured at Egmond beach in the Netherlands in October to November in 1998. The hourly offshore water levels were computed by averaging two tidal gauges located about $15.0 \mathrm{~km}$ north and south of Egmond. The measurements show two clear offshore-directed sand bars. Both sand bars migrated about $30 \mathrm{~m}$ offshore during a 22-day period of high-wave events. In most cases, onshore bar migration resulted in a bar-trough relief reduction while the bar often became more pronounced when it moved offshore due to deepening of the trough. The inner Egmond bar was crescent shaped in plan throughout 22day span with an alongshore length scale of about $600 \mathrm{~m}$ and a cross-shore amplitude less than $20 \mathrm{~m}$, while the outer bar was alongshore uniform (Ruessink et al., 2000).

According to the predicted results, when $t=24 \mathrm{hr}$ to $t=168 \mathrm{hr}$ the model gives almost the same beach profile as measured while $t=216 \mathrm{hr}$ and $t=264 \mathrm{hr}$, some deposition of sand in offshore bar can be seen. When $t=284 \mathrm{hr}$ and $t=308 \mathrm{hr}$ wave breaker line moves towards the nearshore by about 30.0-40.0 $\mathrm{m}$ therefore some deviation in height of offshore bar is noticed, however both predicted and measured onshore and offshore bar shapes look very similar. In general, the present model shows a remarkable agreement with the Egmond beach data. Table 9 shows the details of wave conditions at Egmond beach used in the present study while Fig. Table 9

31 shows the measured and computed beach profiles at $t=24-308 \mathrm{hr}$. 


\subsection{Quantitative Assessment of Model Performance}

The Root Mean Square Error (RMSE) is a frequently used measure of the difference between values predicted by a model and the values actually observed from the environment that is being modelled rather than an error for the measured versus initial profile. The RMSE of a model prediction with respect to the estimated variable $Z_{\text {model }}$ is defined as the square root of the mean squared error [Eq. (52)].

$$
R M S E=\sqrt{\frac{\sum_{i=1}^{n}\left(Z_{o b s, i}-Z_{m o d e l, i}\right)^{2}}{n}}
$$

where $Z_{o b s}$ is the observed water depths, $Z_{\text {model }}$ is the modelled water depths at different crossshore distance $i$ and $n$ is the number of measurements.

Tables 10-16

Tables 10-16 show the difference between predictions and measurements against the initial bathymetry and its measurements in order to assess the model performance in a quantitative aspect. It is noted that some test cases, e.g. Kajima et al. [1983] and Kraus and Larson [1988] do not show smaller difference between predictions and measurements than the difference between initial bathymetry and measurements. This is primarily due to the predicted results of change in location of onshore-offshore sand bar and large deformation in the beach profile for longer time durations. Further, Figs. 32-34 illustrate the highest measured and predicted erosion depths and deposition heights in each test case for 3 data sources used in the study. For the cases 1.1, 1.2, 1.3, 1.5, 3.1, 3.4, 4.3 and 4.4 of Kajima et al. [1983] show large deposition heights (predicted) whereas the cases 1.2, 3.4, 4.3, 4.4, 5.2 and 5.3 show large erosion depths (predicted) compared to the measured values. In the case of Kraus and Larson [1988], the large deposition heights (predicted) are shown by the test cases of KL200 and KL901 while large erosion depths (predicted) are indicated by tests cases of KL100 and KL200. The deposition heights and erosion depths of most test cases of PARI [2009] are shown to be compliance with the measured values except the test case 1 . Therefore, the worst scenario test cases of PARI [2009] show a reasonable agreement for 
maximum values of erosion depths and deposition heights. It is believed that large deformation in beach profile is expected due to presence of large number of free parameters (model coefficients) in wave, hydrodynamic and sediment transport modules of the present numerical model. Due to the lack of data in test cases of Hasan and Takawaka [2007, 2009] and Ruessink et al. [2007] no scatter plots are generated to represent the highest deposition heights and erosion depths.

According to the sensitivity study, it is suggested further improving the model performance particularly in quantitative point of view to use as a practical model in future. Therefore, the present study is regarded as the initial attempt of developing a process-based numerical model in a qualitative manner. The model limitations and recommendations are discussed in Section 5.

\section{Concluding Remarks}

The first stage of two-dimensional beach profile evolution model is developed with the help of the time-averaged suspended sediment concentration models of Jayaratne and Shibayama [2007] and Jayaratne et al. [2011]. Suspension under sheet flow and wave breaking are the sole driving forces causing sand transport under storm conditions while suspension under ripples and wave breaking influences the sand transport under non-storm conditions. The model is designed to be used as an engineering tool for the prediction of short-term beach profile evolution (up to 30 days) and is capable of analysing a large amount of wave, hydrodynamic and sediment data. One of the distinguishing features of the numerical model is that it takes only a few minutes to simulate a 2 to 3 -day storm using a standard personal computer.

Simulations of observed onshore-offshore bar migration and undulating crescent shaped of beach profiles are obtained by fine-tuning 12 free parameters in the concentration models. The present model is applied to 5 high-quality data sets that are considered to be 
representative of natural sandy beaches subjected to storm and non-storm conditions. It can be seen that the present numerical model needs further development to predict both erosiveand accretive-type beaches with on-offshore sand bar and berm formation in a qualitative and quantitative manner, as the model results are generally no closer to the final measured values than are the initial conditions. If the latter is taken as the null hypothesis, then it has not yet been shown that the model produces better predictions than this null hypothesis, and the focus of the further development will be to improve this.

Using the concept of mass conservation in the water column below the wave trough and the bore-like wave region in the surf zone, a simple formula is derived to compute mass transport velocity above the wave trough. The numerical results confirm that values in the wave region are sometimes significant, especially for the combination of long period waves with moderate wave heights or large wave heights with short period waves, compared to the values at the edge of the boundary layer. But generally, the values of sediment flux in this region are small compared to the values at the edge of boundary layer to wave trough and therefore it can be regarded as a secondary factor for the precise sediment flux evaluation from the bottom of the sea to the crest of the wave.

\section{Model Limitation and Further Study}

The present stage of numerical model computes wave heights, hydrodynamics and associated sediment transport rates locally across the beach profile in a time-averaged manner and eventually the beach level change is given by the continuity of sediment mass. In such development of a deterministic model, there are number of potential problems and limitations associated with, for predicting extreme beach erosion and deposition under storm conditions. One of the major drawbacks of the present model is inadequately simulating extreme erosion events where there is considerable amount of wave energy dissipation occurred in the surf zone due to direct wave impact. Even though the erosion and deposition volumes due to wave 
impact on sheet flow, rippled beds and under breaking agitation are explicitly incorporated in the numerical model by the time-averaged sediment concentration models of Jayaratne and Shibayama [2007] and Jayarane et al. [2011], the very localised deposition and erosion which does occur at a position just offshore of the sand bar is not very well modelled. One of the other disadvantages of time-averaged approach primarily relate to the inability to simulate sediment flux coupling between velocity and concentration levels (Nairn and Southgate, 1993).

Further, the bedload transport rate of present numerical model is calculated using the Watanabe [1982] model and it is suggested incorporating a transport direction function (limiting parameter, $\Pi_{\mathrm{c}}$ ) proposed by Watanabe et al. [1986] in order to smooth an unrealistic discontinuities and abrupt undulations of beach profiles, as seen in some tested cases. Further, it is noted that the location of the offshore sand bar is shifted from the measured profile in some cases. The wave breaking phenomenon is quite complex and not yet fully understood by the current researches. The wave breaking index of Goda [1970], further modified by Isobe [1987] was used in the present model, therefore it is recommended to carry out a sensitivity study of wave breaking index models to choose the best predictive model.

It is noted that for medium and longer time durations, calibration is required to defeat the accumulation of small errors in the modelling procedure. It also provides a framework for future development of a model to overcome the existing deficiencies. Therefore, the present level of model could be considered providing a link between theoretical understanding and visual observations.

The present model is valid up to the end of surf zone, defined as a finite water depth close to the shoreline and calculated using Eq. [50]. Hence, in most test cases, the beach profile after shoreline is appeared as a flat bed, without transporting the beach material further onshore to build up a coastal dune. In other words, the present model did not include 
the swash zone physics therefore the following treatment is employed in to the model to cover this region as the next stage of model development. The swash zone sediment transport model of Larson et al. [2004] will be used to quantify the net transport rate over many swash cycles. Larson et al. [2004] integrated a shear stress based bed-load transport formula over a swash cycle to yield the net transport during the cycle. Sediment transport rate produced by this shear stress depends on the local swash velocity. The local swash velocity and duration needed to calculate the transport rate is obtained by employing a ballistic model, which have been shown to yield satisfactory results in many previous studies. The foreshore is kept plane sloping at all times from the finite water depth (run-up limit) to the still water level, which forms the seaward boundary of the swash zone. Transport through wet-dry bed boundary yields an instantaneous response in the foreshore, resulted in a uniform adjustment of the slope.

The current stage of the model is developed considering dominant coastal processes and for small grain diameter cases $\left(\mathrm{d}_{50} \leq 0.47 \mathrm{~mm}\right)$ therefore more detailed evaluation of long wave processes including swash zone dynamics is recommended in the next stage of study.

\section{Acknowledgements}

The research study reported in this paper is supported by the School of Architecture, Computing and Engineering (ACE), University of East London (UEL), the Grant-in-Aid for Scientific Research B from the Japan Society for the Promotion of Science (JSPS) [No. 22404011] and the Grant for Disaster Analysis and Proposal for Rehabilitation Process for the Tohoku Earthquake and Tsunami from Waseda University Research Initiative.

The authors also wish to thank Dr. Gerben Ruessink of Utrecht University, the Netherlands, Dr. Satoshi Nakamura of Port and Airport Research Institute, Japan and Dr. Satoshi Takewaka of Tsukuba University, Japan for providing the digital format of measured large-scale laboratory and natural beach profile data. 
The clarity and formatting of the paper was also improved by the helpful comments of two anonymous reviewers, whose contribution to the paper should also be mentioned.

\section{References}

Allen, J.R. [1970] "The avalanching of granular solids on dune and similar slopes," J. Geology, 78(3), 326-351.

Andersen, O.H. and Fredsøe, J. [1983] "Transport of suspended sediment along the coast," Inst. of Hydrodyn. \& Hydr. Eng., Techn. Univ. of Denmark, Progr. Rep. 59, 33-46.

Bagnold, R.A. [1963] "Beach and nearshore processes," In: M.N. Hill (Editor), The Sea, 3, Interscience, New York, USA.

Baldock, T.E., Alsina, J.A. and Power, H. [2011] "Large-scale experiments on beach profile evolution and surf and swash zone sediment transport induced by long waves, wave groups and random waves," Coastal Eng., Elsevier, 58, 214-227.

Basco, D.R. and Yamashita, T. [1986] "Towards a simple model of the wave breaking transition region in surf zones," Proc. $20^{\text {th }}$ Int. Conf. on Coastal Eng., ASCE, pp. 955-970.

Battjes, J.A. and Janssen, P.F.M. [1978] "Energy loss and set-up due to breaking of random waves," Proc. $16^{\text {th }}$ Int. Conf. on Coastal Eng., ASCE, pp. 569-587.

Bell, P.S. [1999] "Shallow water bathymetry derived from an analysis of X-band marine radar images of wave," Coastal Eng., Elsevier, 37, 513-527.

Bell, P.S., Williams, J.J., Clark, S., Morris, B.D. and Vila-Concejo, A. [2004] "Nested radar systems for remote coastal observations," J. Coastal Res., 39(SI).

Bosman, J.J. [1982] "Concentration measurements under oscillatory water motion," Rep. on model investigation, M1695-Part II, Delft Hydraulics Lab., The Netherlands.

Caldwell, J.M. [1959] "Shore erosion by storm waves," Miscellaneous Paper 1-59, Beach Erosion Board, Coastal Eng. Res. Centre (CERC), US Army Eng. Water. Exp. Station.

Carstens, M.R., Neilson, F.M. and Altinbilek, H.D. [1969] "Bed forms generated in the laboratory under an oscillatory flow," Technical Memo 28, Coastal Eng. Res. Centre (CERC), US Army Eng. Water. Exp. Station.

Clubb, G.S. [2001] "Experimental study of vortex ripples in full scale sinusoidal and asymmetric flows," PhD thesis, Uni. of Aberdeen, UK.

Dally, W.R. and Dean, R.G. [1984] "Suspended sediment transport and beach profile evolution," J. Waterways, P., C., and Ocean Eng., ASCE 110(1), 15-33.

Dally, W.R., Dean, R.G. and Dalrymple, R.A. [1985] "Wave height variation across beaches of arbitrary profile,” J. Geophy. Res., 90(C6), 11917-11927. 
Dean R.G. [1977] "Equilibrium beach profiles, US Atlantic and Gulf Coasts," Ocean Eng. Rep. 12, Dept. of Civil Eng., Uni. of Delaware, USA.

Deigaard, R. and Fredsøe, J. [1989] "Shear stress distribution in dissipative water waves," Coastal Eng., Elsevier, 13, 357-378.

Deigaard, R., Fredsøe, J. and Hedegaard, I.B. [1986] "Suspended sediment in the surf zone," J. Waterways, P., C., and Ocean Eng., ASCE 112(1), 115-128.

Dette, H.H. and Uliczka, K. [1986] "Velocity and sediment concentration field," Proc. 20"th Int. Conf. on Coastal Eng., ASCE, pp. 1062-1076.

De Vriend, H.J. and Stive, M.J.F. [1987] "Quasi-3D modelling of nearshore currents," Coastal Eng., Elsevier, 11, 565-601.

Dohmen-Janssen, C.M. [1999] "Grain size influence on sediment transport in oscillatory sheet flow, Phase lags and mobile-bed effects," PhD thesis, Delft Uni. of Tech., The Netherlands.

Fredsøe, J. [1984] "Turbulent boundary layer in wave and current motion," J. Hydraulic Eng., ASCE 110(8), 1103-1120.

Goda, Y. [1970] “A synthesis of breaking indices," Trans. Japan Soc. of Civil Eng., 2(2), pp. 227-230.

Goda, Y. [2000] "An overview of paradigm shifts in coastal engineering - Wave pressure, wave transformations and sediment transport," Proc. $27^{\text {th }}$ Int. Conf. on Coastal Eng., ASCE, pp. 1-18.

Goda, Y. and Kweon, H.M. [1994] "Stable wave height," Private Comm., Yokohama Nat. Uni., Japan.

Grasmeijer, B.T. [2002] "Process-based cross-shore modelling of barred beaches," $\mathrm{PhD}$ Thesis, Dept. of Phy. Geography, Uni. of Utrecht, The Netherlands.

Hamm, L., Katopodi, I., Dohmen-Janssen, M., Ribberink, J.S., Samothrakis, P., Cloin, B., Savioli, J.C., Chatelus, Y., Bosboom, J., Nicholson, J. and Hein, R. [1998] "Grain size, gradation and density effects on sediment transport processes in oscillatory flow conditions, Part I - The effect of grain size distribution (Series K)," WL|Deltares Hydraulics, The Netherlands.

Hansen, J.B. and Svendsen, I.A. [1984] "A theoretical and experimental study of undertow," Proc. $19^{\text {th }}$ Int. Conf. on Coastal Eng., ASCE, pp. 2246-2262.

Hasan, G.M.J. and Takewaka, S. [2007] "Observation of a stormy wave field with X-band radar and its linear aspects," Coastal Eng. J., JSCE 49(2), 149-171.

Hasan, G.M.J. and Takewaka, S. [2009] "Wave run-up analysis under dissipative condition using X-band radar,” Coastal Eng. J., JSCE 51(2), 177-204. 
Hedegaard, I.B., Deigaard, R., and Fredsøe, J. [1991] "Onshore/Offshore sediment transport and morphological modelling of coastal profiles," Proc. Int. Conf. on Coastal Sediments, ASCE, pp. 643-657.

Isobe, M. [1985] "Calculation and application of first-order cnoidal wave theory," Coastal Eng., Elsevier, 9, 309-325.

Isobe, M. [1987] "Parabolic equation model for transformation of irregular waves due to refraction, diffraction and breaking," Coastal Eng. in Japan, JSCE, 30(1), 33-47.

Jayaratne, M.P.R. [2004] "Modelling of suspended sediment concentration and cross-shore beach deformation model," PhD Thesis, Yokohama Nat. Uni., Japan.

Jayaratne, M.P.R. and Shibayama, T. [2004] "An evaluation method suspended sediment concentration in and outside the surf zone," Proc. $29^{\text {th }}$ Int. Conf. on Coastal Eng., ASCE, pp. $1715-1727$.

Jayaratne, M.P.R. and Shibayama, T. [2007] "Suspended sediment concentration on beaches under three different mechanisms," Coastal Eng. J., JSCE, 49(4), 357-392.

Jayaratne, R. and Shibayama, T. [2011] "A simple numerical simulation model for beach profile evolution", Proc. $7^{\text {th }}$ Int. Conf. on Coastal Sediments, ASCE, 2, pp.1687-1700.

Jayaratne, M.P.R., Sritharan, S. and Shibayama, T. [2011] "Examination of the suspended sediment concentration formulae using full-scale rippled bed and sheet flow data," Coastal Eng. J., JSCE, 53(4), 451-489.

Johnson, B., Graves, M., Wamsley, T. and Kobayashi, N. [2009] "A predictive model for beach profile evolution," Proc. $6^{\text {th }}$ Int. Conf. on Coastal Dynamics, Paper No. 64, pp. 1-9.

Jonsson, I.G. [1966] "Wave boundary layers and friction factors," Proc. 10 ${ }^{\text {th }}$ Int. Conf. on Coastal Eng., ASCE, pp. 127-148.

Kajima, R., Shimuzu, T., Maruyama, K. and Saito, S. [1983] "On-offshore sediment transport experiment by using large scale wave flume," Collected data No. 1-8, Central Res. Inst. of Electrical Power Industry (CRIEPI), Japan (in Japanese).

Katopodi, I., Ribberink, J.S., Ruol, P., Koelewijn, R., Lodahl, C., Longo, S., Crosato, A. and Wallace, H. [1994] "Intra-wave sediment transport in oscillatory flow superimposed on a mean current," Data report H 1684.33, Part III, WL|Deltares Hydraulics, The Netherlands.

Kraus, N.C. and Larson, M. [1988] "Beach profile change measured in the tank of large waves, 1956-1957 and 1962," Tech. Report CERC-88-6, US Army Eng. Water. Exp. Station.

Kobayashi, N., Johnson, B.D. and Karjadi, E.A. [2000] "Cross-shore sand transport on beaches," Proc. $27^{\text {th }}$ Int. Conf. on Coastal Eng., ASCE, pp. 3165-3178.

Kobayashi, N., Payo, A. and Schmied, L. [2008] "Cross-shore suspended sand and bed load transport on beaches," J. Geophy. Res., 113(C07001), 1-17.

Komar, P.D. [1977] "Beach sand transport - Distribution and total drift," Proc. ASCE, 103, WW2, 225-239. 
Kuriyama, Y. [2009] "Numerical model for bar migration at Hasaki, Japan," Proc. $6^{\text {th }}$ Int. Conf. on Coastal Dynamics, Paper No. 50, pp. 1-12.

Larson, M. and Kraus, N.C. [1989] "SBEACH: Numerical model for simulating storm induced beach change," Report 1, Tech. Report CERC-89-9, US Army Eng. Water. Exp. Station.

Larson, M. and Kraus, N.C. and Sunamura, T. [1988] "Beach profile change: Morphology, transport rate and numerical simulation," Proc. $21^{\text {st }}$ Int. Conf. on Coastal Eng., ASCE, pp. $1295-1309$.

Larson, M., Kubota, S. and Erikson, L. [2004] "Swash zone sediment transport and foreshore evolution," Marine Geo., Elsevier, 212, 61-79.

Larson, M. and Wise, R.A. [1998] "Simple models for equilibrium profiles under breaking and non-breaking waves," Proc. $26^{\text {th }}$ Int. Conf. on Coastal Eng., ASCE, pp. 2722-2735.

Le Mehaute, B. [1962] "On non-saturated breakers and the wave run-up," Proc. $8^{\text {th }}$ Int. Conf. Coastal Eng., ASCE, pp. 77-92.

Lofquist, K.E.B. [1986] "Drag on naturally rippled beds under oscillatory flows," Miscellaneous paper CERC-86-13, Coastal Eng. Res. Centre (CERC), US Army Eng. Water. Exp. Station.

Longuet-Higgins, M.S. [1953] "Mass transport in water waves," Phil. Trans. Roy. Soc. London, Series A, Vol. 245, 535-581.

Mizuguchi, M. [1980] A heuristic model of wave height distribution, Proc. $17^{\text {th }}$ Int. Conf. on Coastal Eng., ASCE, pp. 278-289.

Nadaoka, K., Kondoh, T. and Tanaka, N. [1982] "The structure of velocity field within the surf zone revealed by means of laser-doppler anemometry," Technical report, Port and Airport Res. Inst. (PARI), 21(2), 50-102 (in Japanese).

Nairn, R.B., Roelvink, J.A. and Southgate, H.N. [1990] "Transition zone width and implications for modelling surf zone hydrodynamics," Proc. $22^{\text {nd }}$ Int. Conf. on Coastal Eng., ASCE, pp. 68-81.

Nairn, R.B., and Southgate, H.N. [1993] "Deterministic profile modelling of nearshore processes. Part 2. Sediment transport and beach profile development," Coastal Eng., Elsevier, 19, 57-96.

Nielsen, P. [1986] "Suspended sediment concentrations under waves," Coastal Eng., Elsevier $10,23-31$.

Nielsen, P. [1988] "Three simple model of sediment transport," Coastal Eng., Elsevier, 12, 43-62.

Nielsen, P. [1992] "Coastal Bottom Boundary Layers and Sediment Transport," Adv. Series on Ocean Eng., $2^{\text {nd }}$ Ed., World Scientific, 131 pp. 
Nielsen, P., Svendsen, I.A. and Staub, C. [1978] "Onshore-offshore sediment movement on a beach," Proc. $16^{\text {th }}$ Int. Conf. on Coastal Eng., ASCE, pp. 1475-1492.

Okayasu, A. [1989] "Characteristics of turbulence structure and undertow in surf zone," $\mathrm{PhD}$ Thesis, Uni. of Tokyo, Japan.

Okayasu, A., Shibayama, T. and Horikawa, K. [1988] "Vertical variation of undertow in the surf zone," Proc. $21^{\text {st }}$ Int. Conf. on Coastal, Eng., ASCE, pp. 478-491.

Okayasu, A., Shibayama, T. and Mimura, N. [1986] "Velocity field under plunging waves," Proc. $20^{\text {th }}$ Int. Conf. on Coastal Eng., ASCE, pp. 660-674.

PARI: Port and Airport Research Institute [2005], Beach profiles under non-storm conditions, Yokosuka, Japan (www.pari.go.jp/en), Assessed on 15 $5^{\text {th }}$ February 2012.

PARI: Port and Airport Research Institute [2009], Beach profiles under storm conditions, Yokosuka, Japan (www.pari.go.jp/en), Assessed on 15 $5^{\text {th }}$ February 2012.

Rattanapitikon, W., and Shibayama, T. [1994] "Suspended sediment concentration profiles under non-breaking and breaking waves," Proc. $24^{\text {th }}$ Int. Conf. on Coastal Eng., ASCE, pp. 2813-2827.

Rattanapitikon, W. and Shibayama, T. [1996] "Cross-shore sediment transport and beach deformation model," Proc. 25th Int. Conf. on Coastal Eng., ASCE, pp. 3062-3075.

Rattanapitikon, W. and Shibayama, T. [1998] "Energy dissipation model for regular and irregular breaking waves," Coastal Eng. J., JSCE, 40(4), 327-346.

Rattanapitikon, W., and Shibayama, T. [2000] "Simple model for undertow profile," Coastal Eng. J., JSCE, 42(1), 1-30.

Rattanapitikon, W., Vivattanasirisak, T. and Shibayama, T. [2003] "A proposal of new breaker height formula," Coastal Eng. J., JSCE, 45(1), 29-48.

Ribberink, J.S. and Al-Salem, A.A. [1992] "Sediment transport, sediment concentrations and bed forms in simulated asymmetric wave conditions," Data report H840, Part V, WL|Deltares Hydraulics, The Netherlands.

Ribberink, J.S. and Al-Salem, A.A. [1994] "Sediment transport in the oscillatory boundary layers in cases of rippled beds and sheet flow," J. Geophy. Res., 99(C6), 12707-12727.

Roelvink, D., Reniers, A., Dougeren, A.V., De Vries J.V.T., Lescinski, J. and McCall, R. [2010] "XBeach model description and manual," Version 6, 1002266, Unesco-IHE Institute for Water Education, WL|Deltares Hydraulics and Delft Uni. Of Tech., The Netherlands.

Ruessink, B.G., Kuriyama, Y., Reniers, A.J.H.M., Roelvink, J.A. and Walstra D.J.R. [2007] "Modelling cross-shore sandbar behaviour on the timescale of weeks," J. Geophy. Res., 112, F03010.

Ruessink, B.G., Van Enckevort, I.M.J., Kingston, K.S. and Davidson, M.A. [2000] "Analysis of observed two- and three-dimensional nearshore bar behaviour," Marine Geo., 169, 161183. 
Sasaoka, S., Noguchi, K., Suwa, Y., Kobayashi, H., Watanabe, A. and Takagi, T. [2009] "A beach profile change model including three transport processes," Proc. $6^{\text {th }}$ Int. Conf. on Coastal Dynamics, Paper No. 62, pp. 1-13.

Sato, S. [1987] "Oscillatory boundary layer flow and sand movement over ripples," $\mathrm{PhD}$ Thesis, Uni. of Tokyo, Japan, Japan.

Sato, S., Homma, K., and Shibayama, T. [1990] "Laboratory study on sand suspension due breaking waves," Coastal Eng. in Japan, JSCE, 33(2), 219-231.

Saville, T. [1957] "Scale effects in two dimensional beach studies," Trans. $7^{\text {th }}$ General Meeting, Int. Ass. Hydraulic Res., Vol. 1, A3-1-A3-10.

Shibayama, T. [1984] "Sediment transport mechanism and two-dimensional beach transformation due to waves," PhD Thesis, Uni. of Tokyo, Japan.

Shibayama, T. and Horikawa, K. [1982] "Sediment transport and beach transformation," Proc. $18^{\text {th }}$ Int. Conf. on Coastal Eng., ASCE, pp. 1439-1458.

Shibayama, T. and Horikawa, K. [1985] "Numerical model for two-dimensional beach transformation,” Proc. JSCE, No. 357/II-3 (Hydraulic and Sanitary), pp. 167-176.

Shimizu, T., Saito, S., Maruyama, K., Hasegawa, H. and Kajima, R. [1985] "Modelling of offshore-onshore sand transport rate distribution based on the large-wave flume experiments," Collected data No. 384028, Central Res. Inst. of Electrical Power Industry (CRIEPI), Japan (in Japanese).

Shuto, N. [1974] "Non-linear long waves in channel of variable section," Coastal Eng. in Japan, JSCE, 17, 1-12.

Skafel, M.G. and Krishnappan, B.G. [1984] "Suspended sediment distribution in wave field," J. Waterways, P., C., and Ocean Eng., ASCE 110(2), 215-230.

Sleath, J.F.A. [1982] “The suspension of sand by waves,” J. Hydraulic Res., 20, 439-451.

Southgate, H.N. [1989] "A nearshore profile model of wave and tidal current interaction," Coastal Eng., Elsevier, 13, 219-245.

Southgate, H.N. and Nairn, R.B. [1993] "Deterministic profile modelling of nearshore processes", Part 1: Waves and currents, Coastal Eng., Elsevier 19, 27-56.

Stive, M.J.F. and Battjes, J.A. [1984] “A model for offshore sediment transport," Proc. $19^{\text {th }}$ Int. Conf. on Coastal Eng., ASCE, pp. 1420-1436.

Stive, M.J.F. and Wind, H.G. [1982] "A study of radiation stress and set-up in the nearshore region," Coastal Eng., Elsevier, 6, 1-25.

Suzuki, T. and Kurihama, Y. [2008] "Simple model of cross-shore sediment transport rate for berm formation and erosion," Proc. $31^{\text {st }}$ Int. Conf. on Coastal Eng., ASCE, pp. 1762-1773.

Svendsen, I.A. [1984a] "Wave heights and set-up in a surf zone," Coastal Eng., Elsevier, 8, 303-329. 
Svendsen, I.A. [1984b] "Mass flux and undertow in a surf zone," Coastal Eng., Elsevier, 8, 347-365.

Svendsen, I.A., Madsen, P.A. and Hansen, J.B. [1978] "Wave characteristics in the surf zone," Proc. $16^{\text {th }}$ Int. Conf. on Coastal Eng., ASCE, pp. 520-539.

Thorne, D.P., Davies, A.G. and Williams, J.J. [2003] "Measurements of near-bed intra-wave sediment entrainment above vortex ripples," Geophysical Res. Letters, 30(20), 2028.

Thornton, E.B. and Guza, R.T. [1983] "Transformation of wave height distribution," J. Geophy. Res., 88(C10), 5925-5938.

Thorne, D.P., Williams, J.J. and Davies, A.G. [2002] "Suspended sediments under waves in a large-scale flume facility," J. Geophy. Res. 107(C8), 3178.

Van der Werf, J.J., Doucette, J.S., O'Donoghue, T. and Ribberink, J.S. [2007] "Detailed measurements of velocities and suspended sand concentrations over full-scale ripples in regular oscillatory flow," J. Geophy. Res. 112, F02012.

Van der Werf, J.J., Ribberink, J.S., O’Donoghue, T. and Doucette, J.S. [2006] "Modelling and measurements of sand transport processes over full-scale ripples in oscillatory flow," Coastal Eng., Elsevier 53, 657-673.

Van der Werf, J.J., Schretlen, J.J.L.M., Ribberink, J.S. and O’Donoghue, T. [2009] "Database of full-scale laboratory experiments on wave-driven sand transport processes," Coastal Eng., Elsevier 56, 726-732.

Van Rijn, L.C. [1984] "Sediment transport, Part I: Bed load transport," J. Waterways, P., C., and Ocean Eng., ASCE 110(10), 1431-1456.

Watanabe, A. [1982] "Numerical model of nearshore currents and beach deformation model," Coastal Eng. in Japan, JSCE, 25, 147-161.

Watanabe, A. [1983] "Lecture I - Fundamentals of littoral transport," Seminar on sediment problems in beaches and estuaries, Manila and Jakarta.

Watanabe, A., Hara, T. and Horikawa, K. [1984] "Study on breaking condition for compound wave trains," Coastal Eng. in Japan, JSCE, 27, 71-82.

Watanabe, A., Maruyama, K., Shimizu, T. and Sakakiyama, T. [1986] "Numerical prediction model of three-dimensional beach deformation around a structure," Coastal Eng. in Japan, JSCE, 29, 179-194.

Watanabe, A., Riho, Y. and Horikawa, K. [1980] "Beach profiles and on-offshore sediment transport," Proc. $17^{\text {th }}$ Int. Conf. on Coastal Eng., ASCE, pp. 1106-1121. 


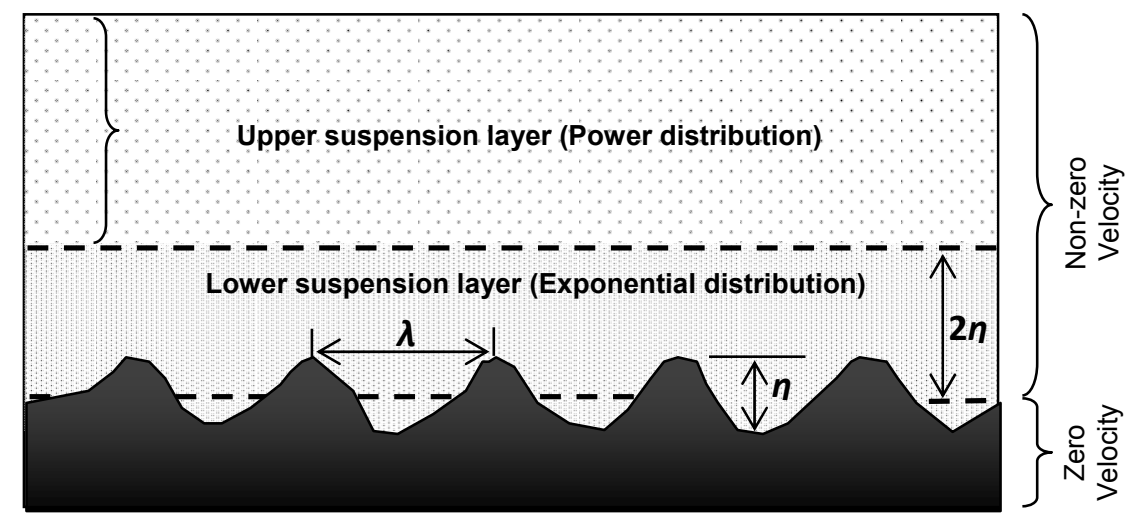

Fig. 1. Two-layer suspension model over full-scale rippled bed proposed by Jayaratne et al. [2011]. 

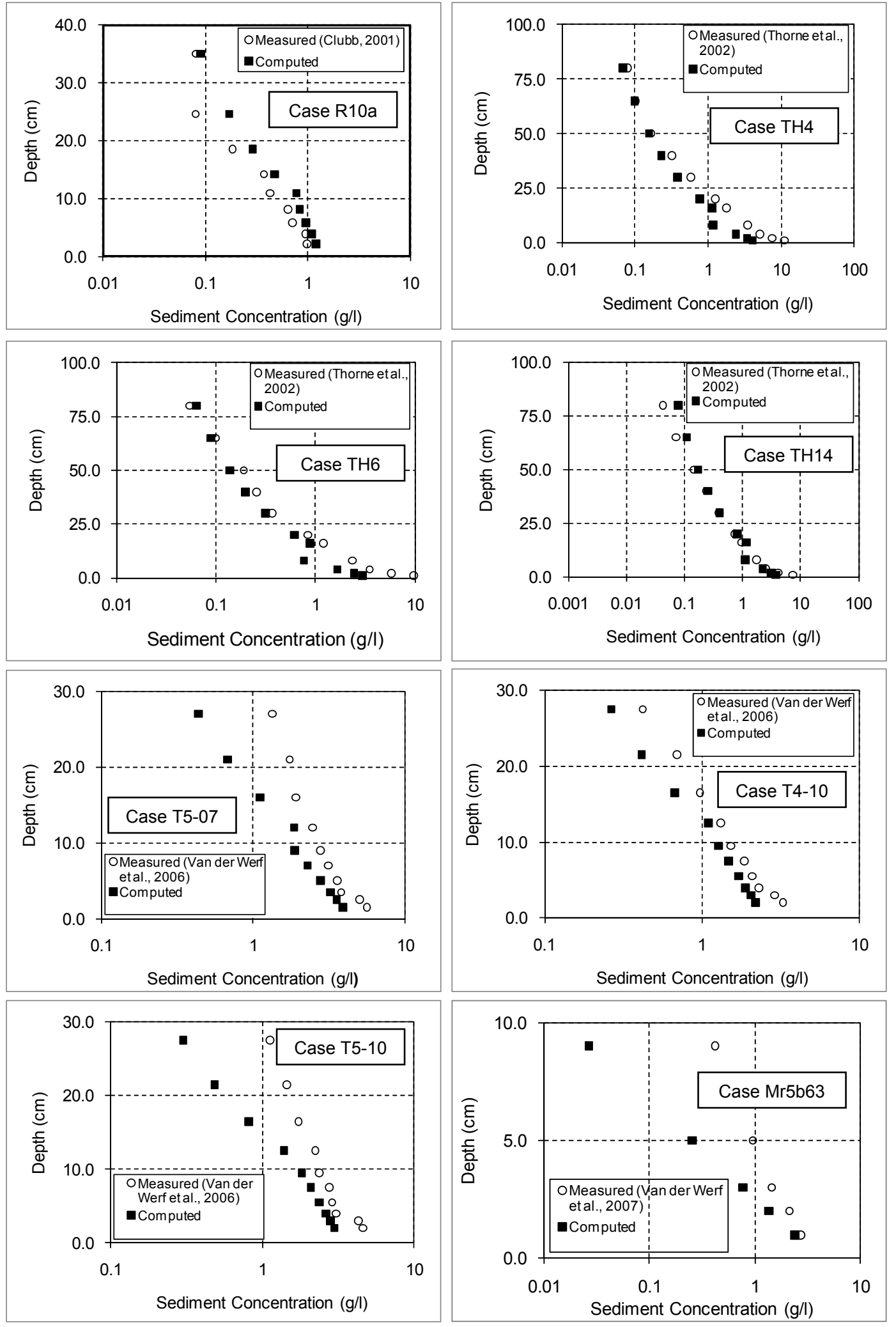

Fig. 2. Measured and computed suspended sediment concentration profiles over fieldscale rippled bed from Jayaratne et al. [2011] models, produced with new free parameters $\left(k_{1}, k_{2}, k_{3}\right.$ and $\left.k_{4}\right)$. 


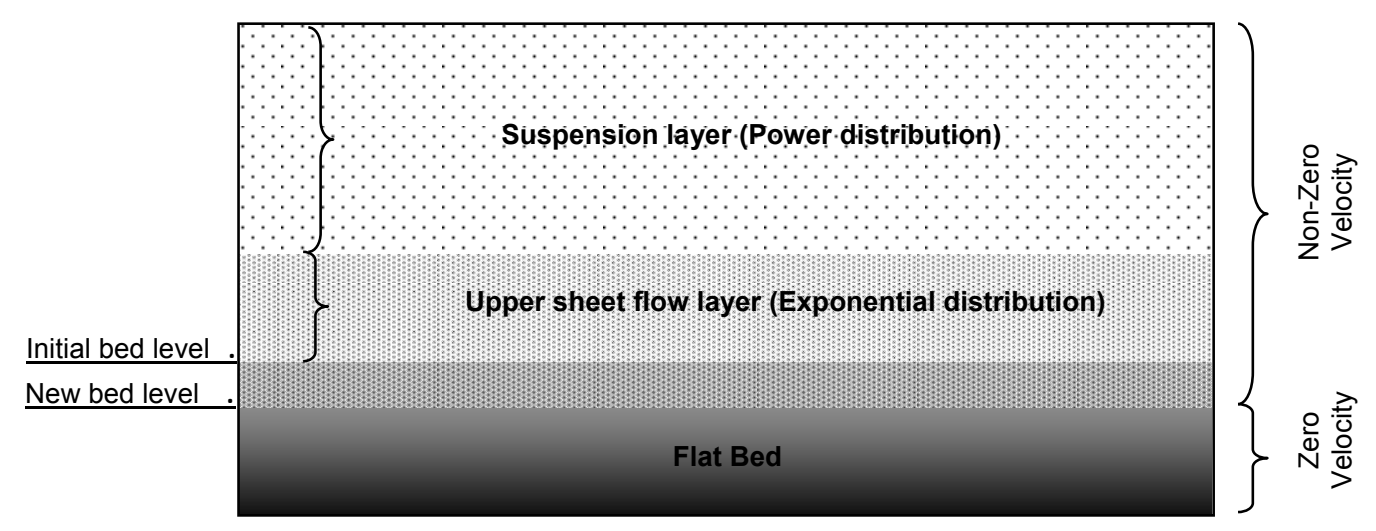

Fig. 3. Two-layer suspension model over full-scale sheet flow proposed by Jayaratne et al. [2011]. 

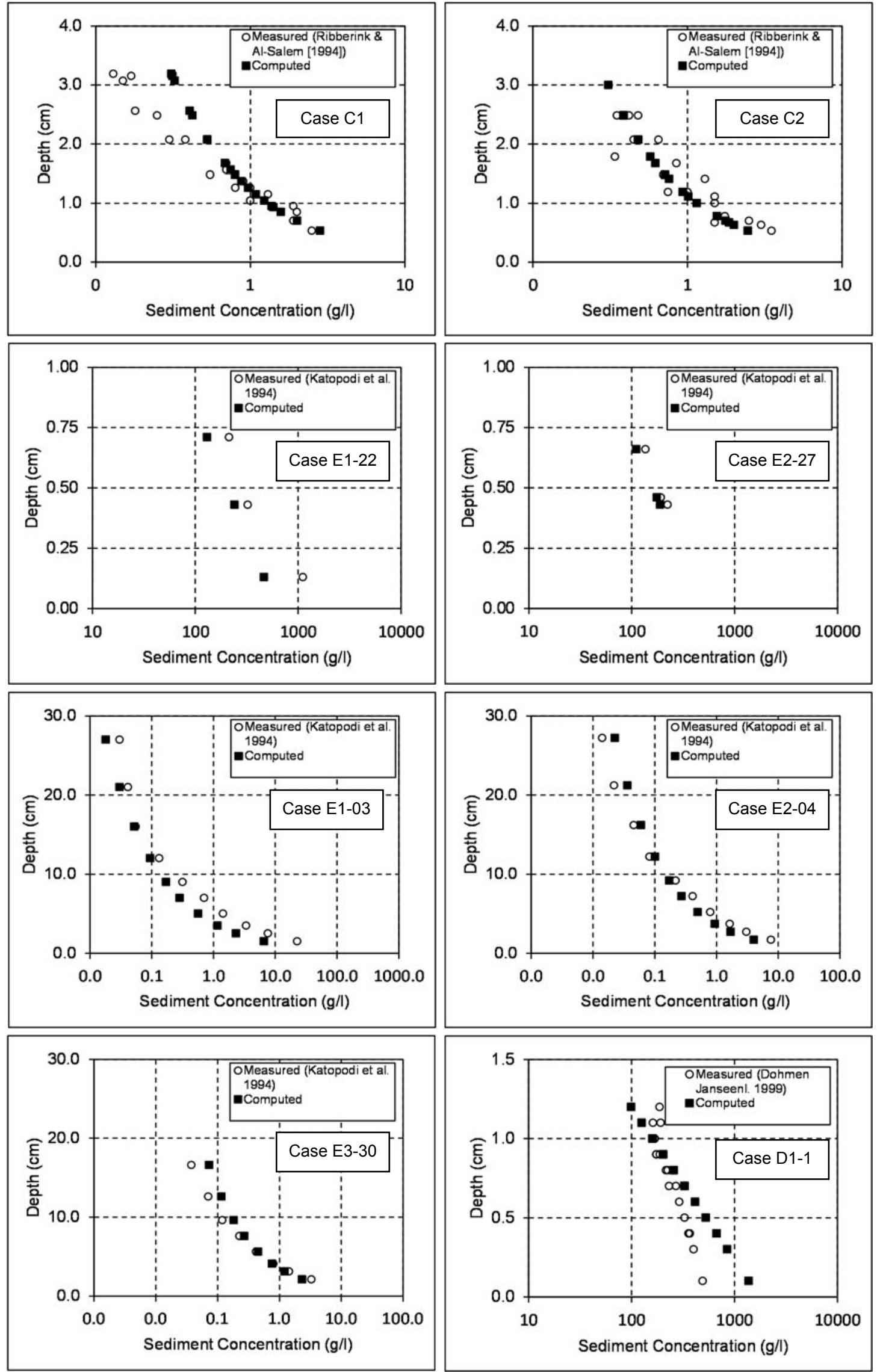

Fig. 4. Measured and computed suspended sediment concentration profiles over field-scale sheet flow from Jayaratne et al. [2011] models, produced with new free parameters $\left(k_{5}, k_{6}\right.$, $k_{7}$ and $k_{8}$ ). 

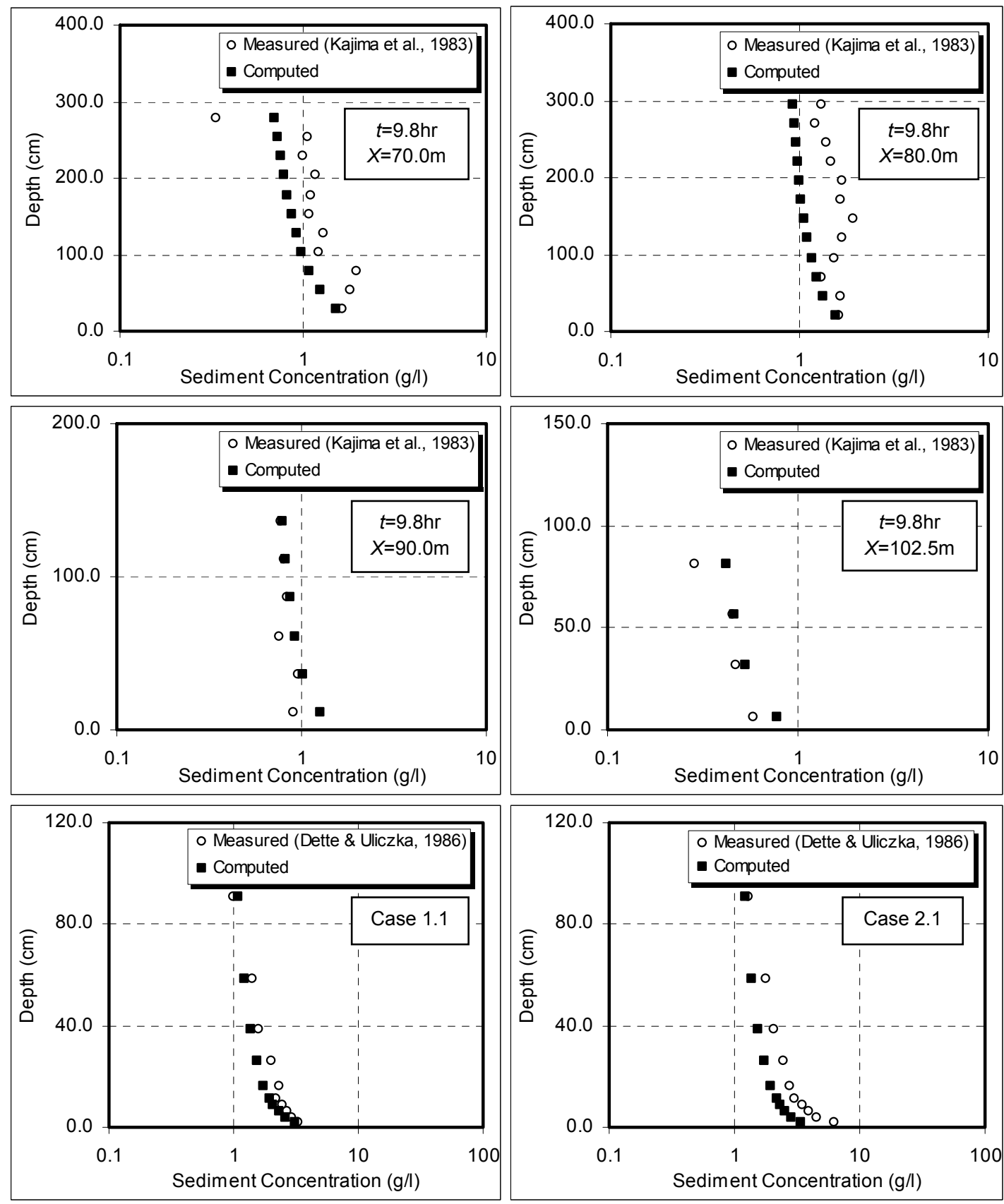

Fig. 5. Measured and computed suspended sediment concentration profiles under fieldscale breaking agitation from Jayaratne \& Shibayama [2007]. 


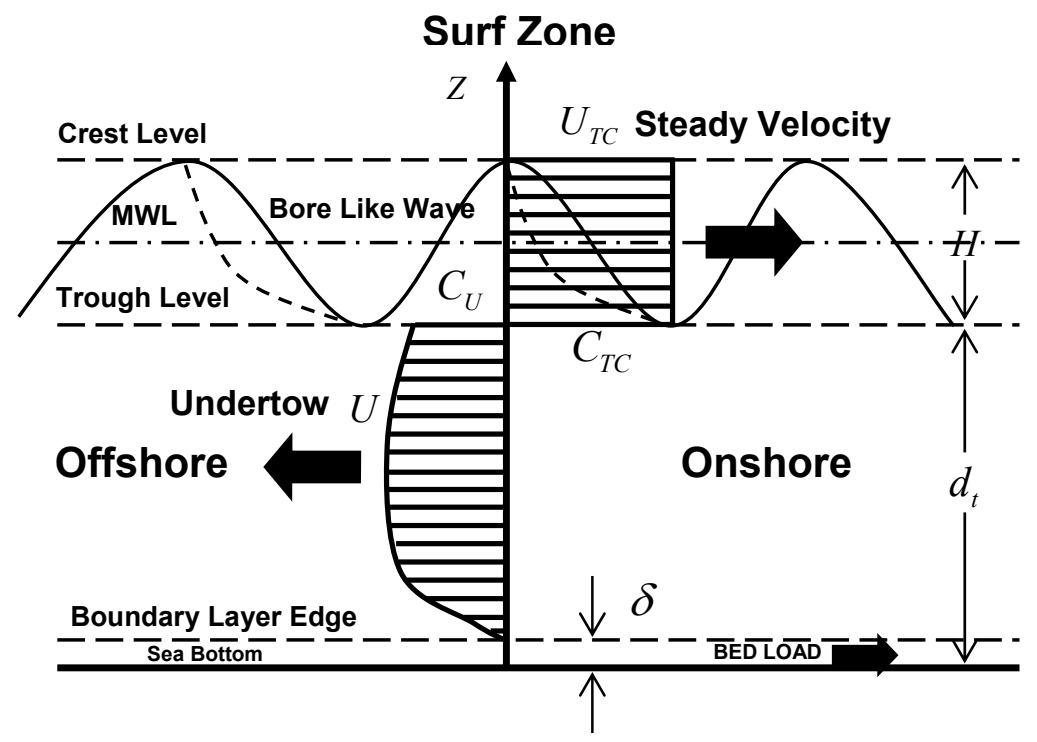

Fig. 6. Definition sketch of sediment flux layers (Bore-like wave region).

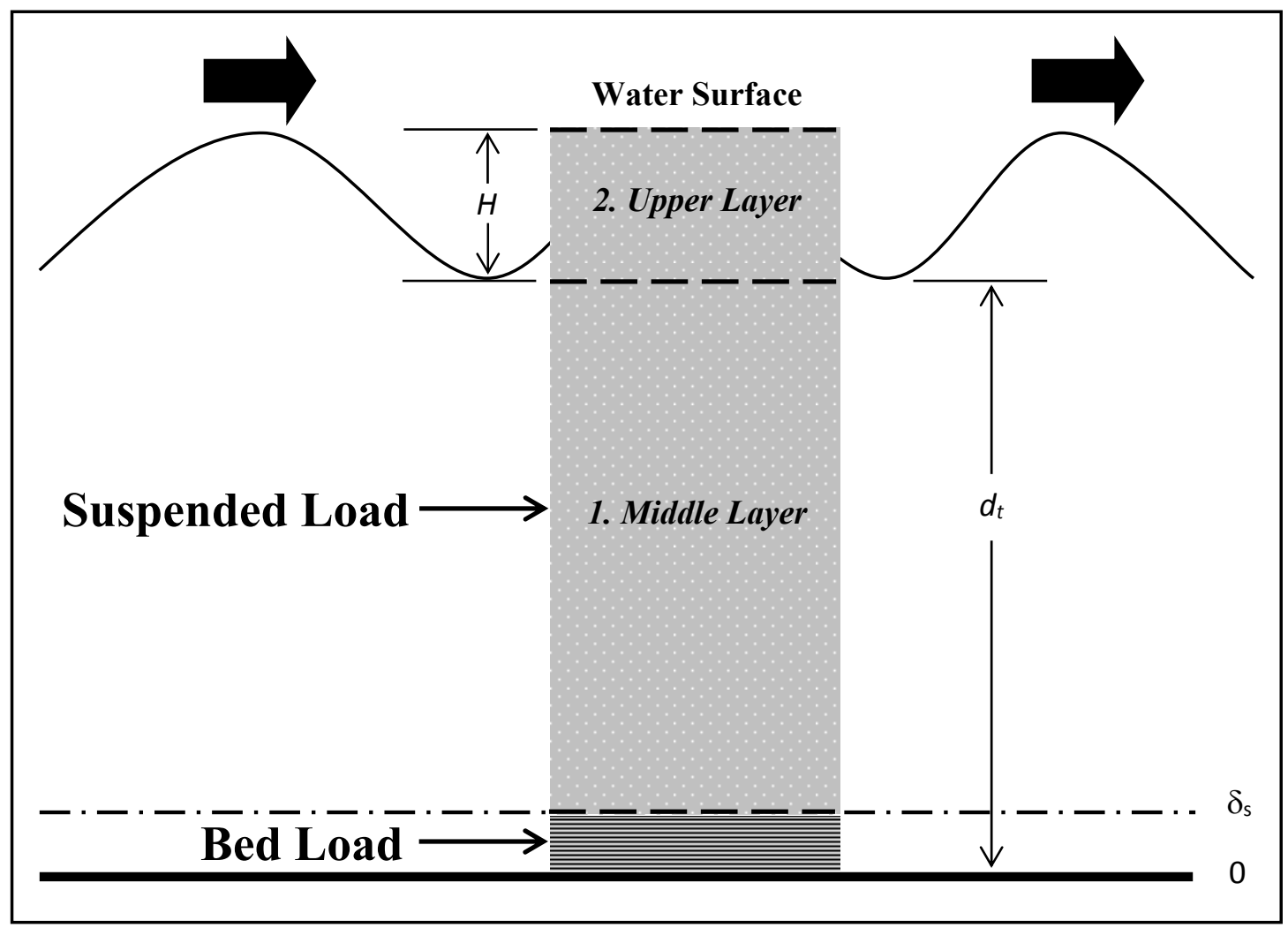

Fig. 7. Definition sketch of three-layer sediment transport model. 


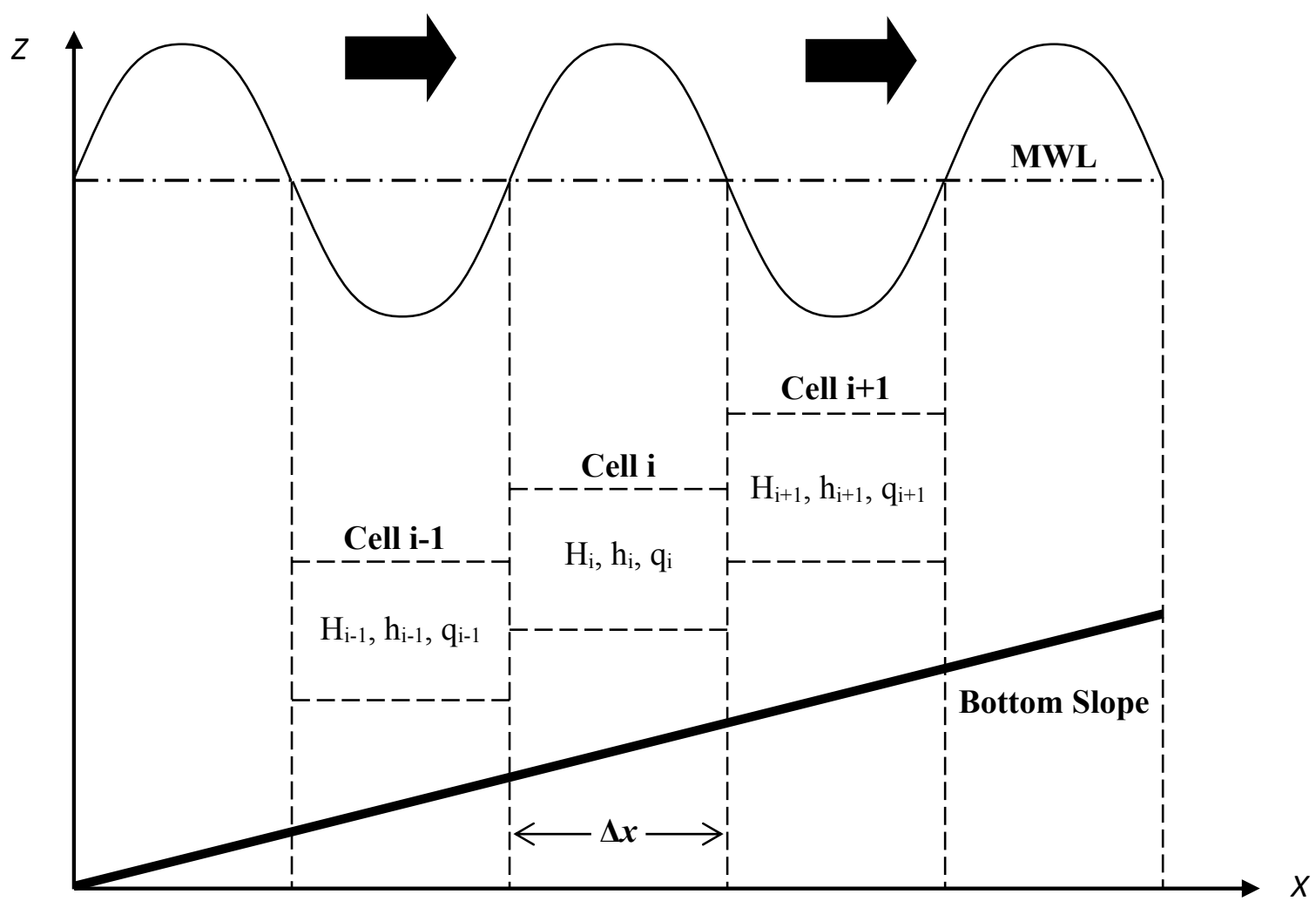

Fig. 8. Definition sketch of numerical cell.

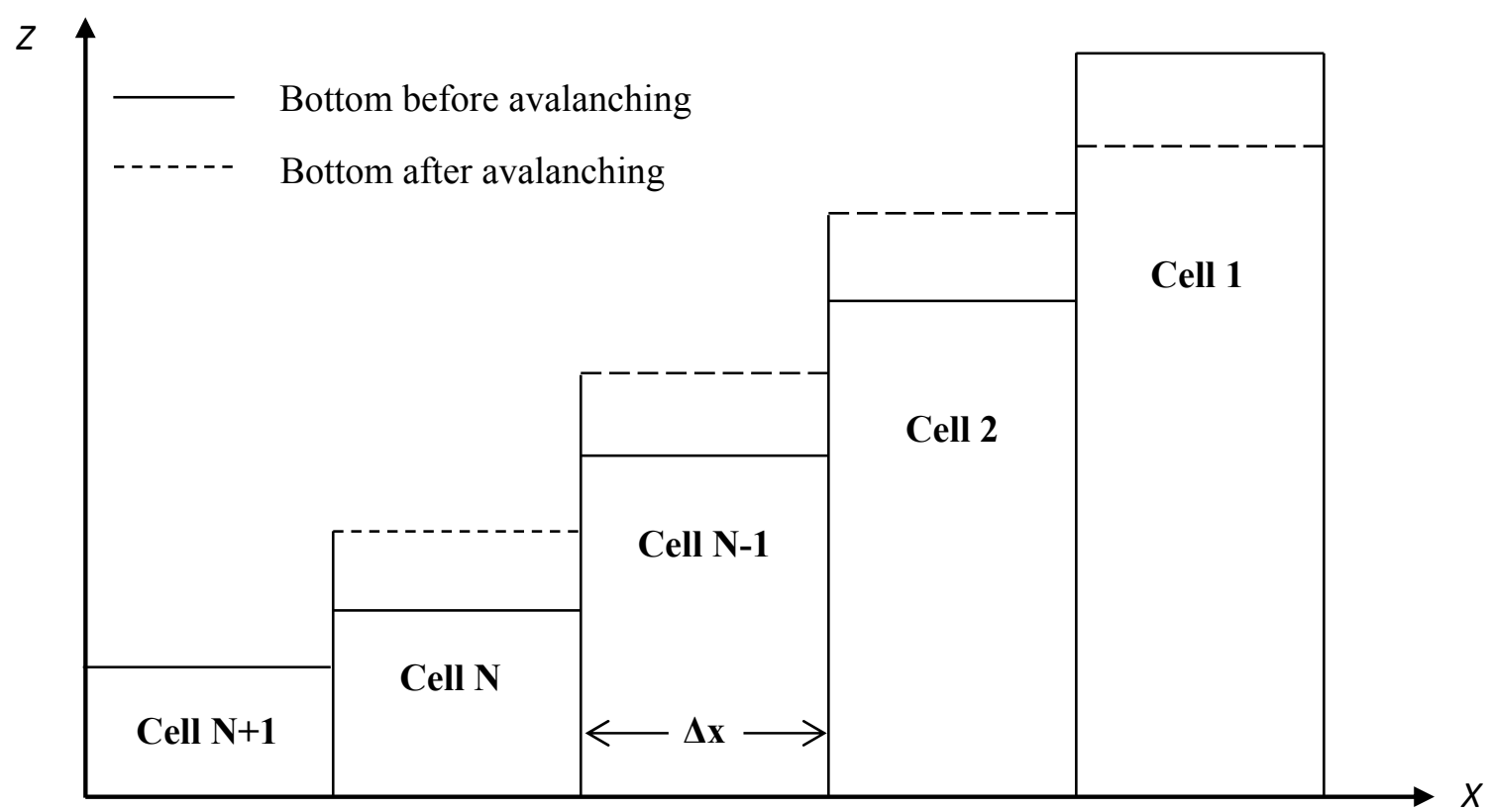

Fig. 9. Definition sketch of avalanching concept of Larson \& Kraus [1989]. 


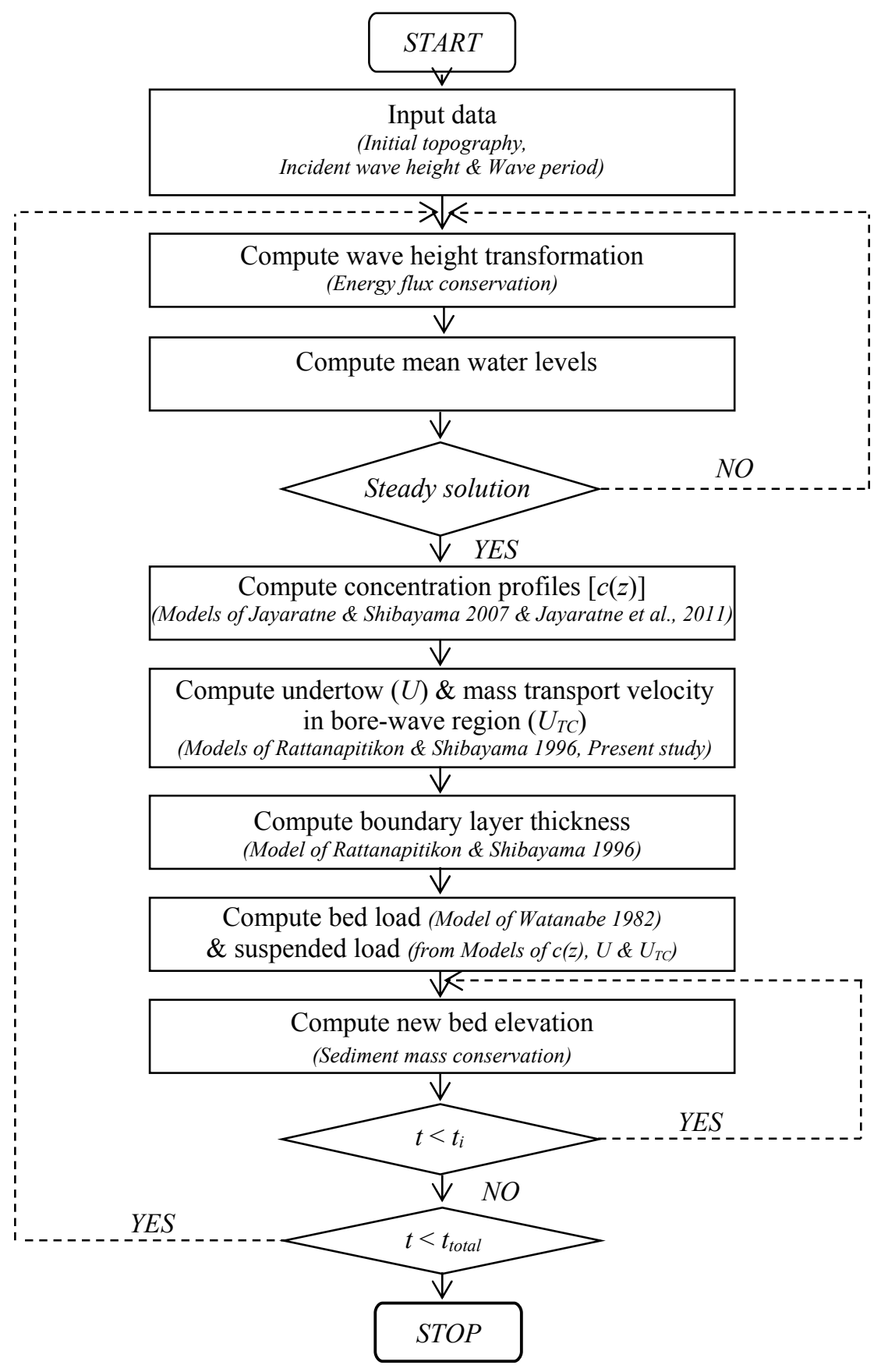

Fig. 10. Flow chart of proposed beach profile evolution model. 

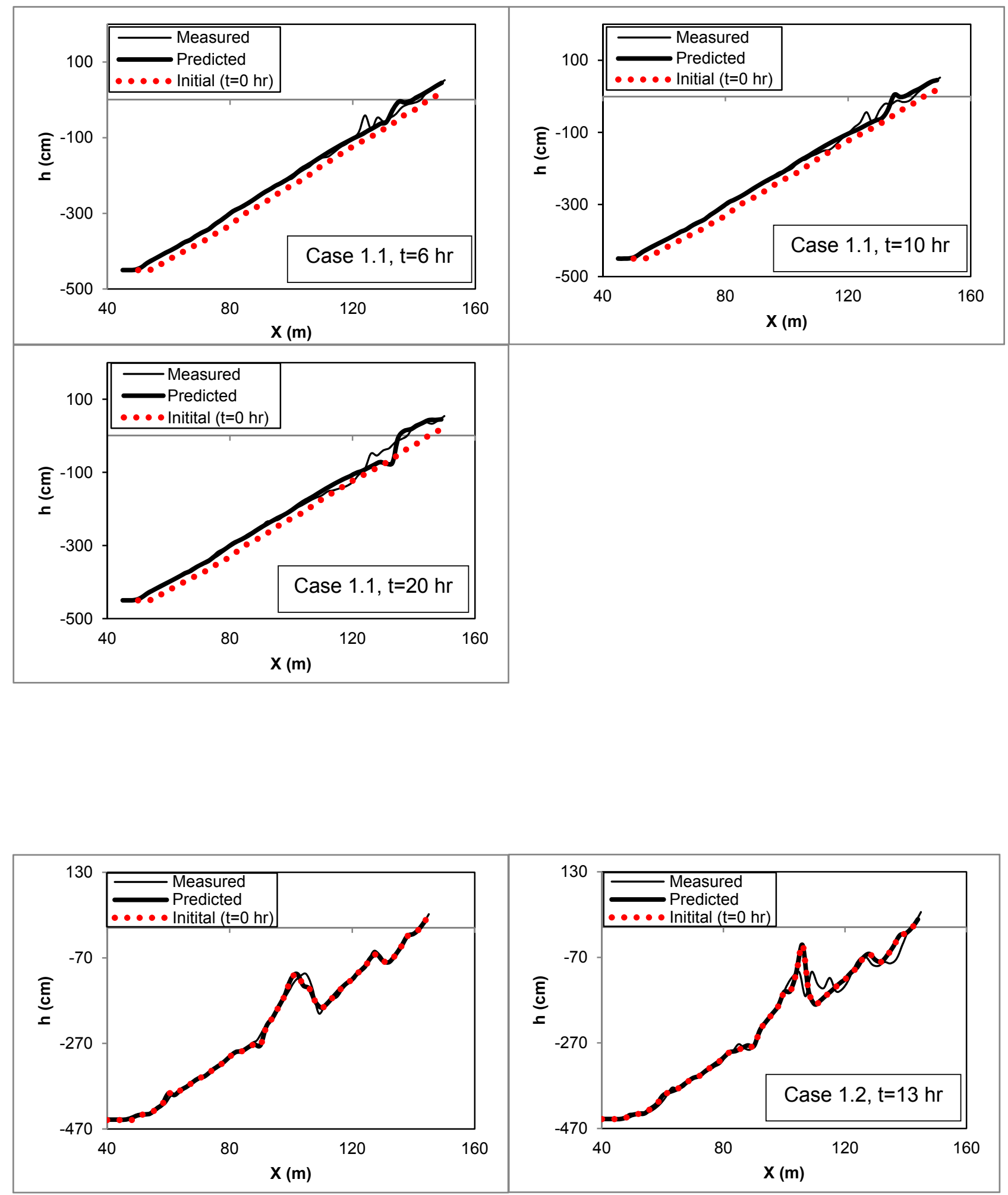

Fig. 11. Measured and computed beach profiles from Kajima et al. [1983], Case 1.1 \& 1.2. 

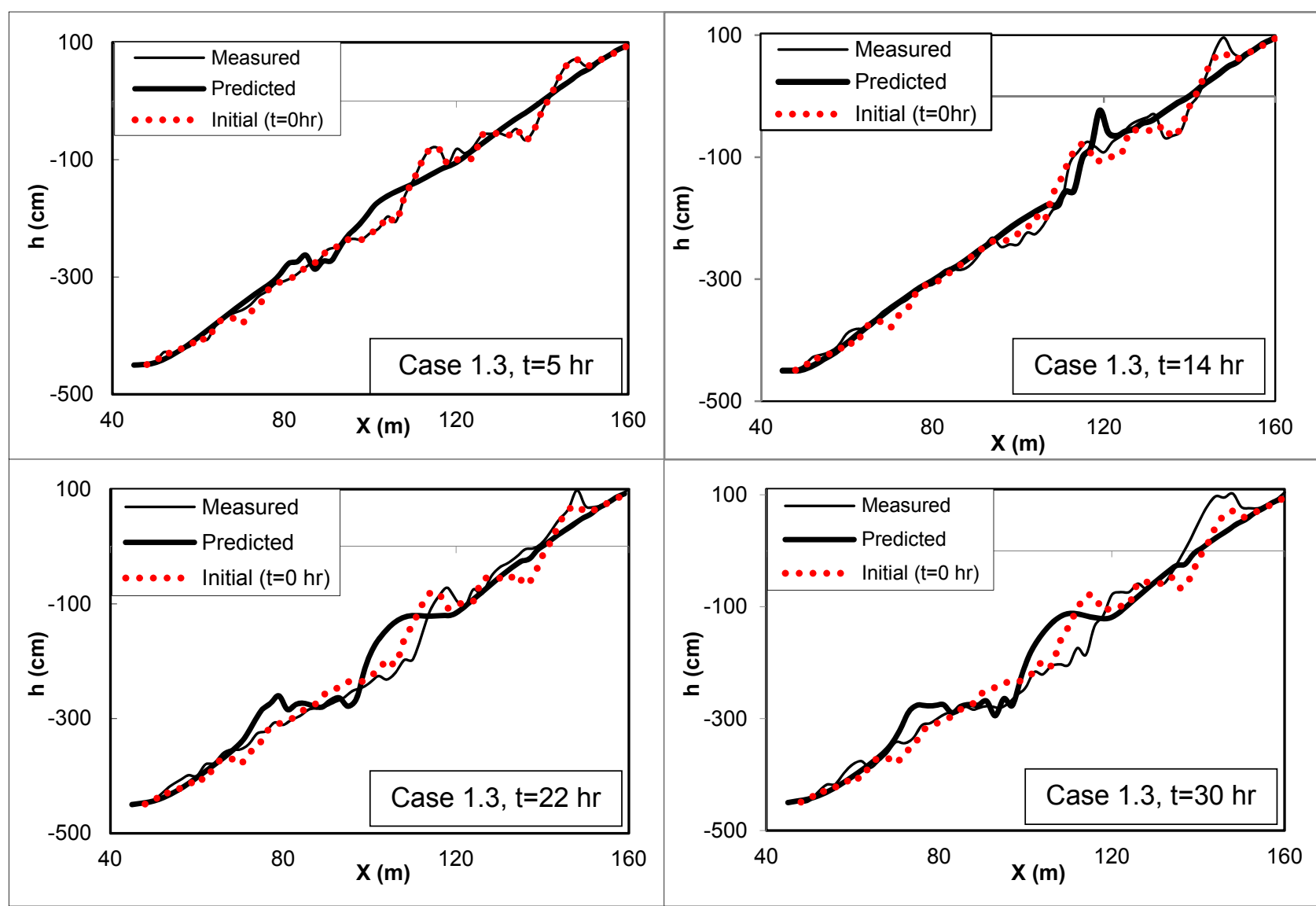

Fig. 12. Measured and computed beach profiles from Kajima et al. [1983], Case 1.3. 

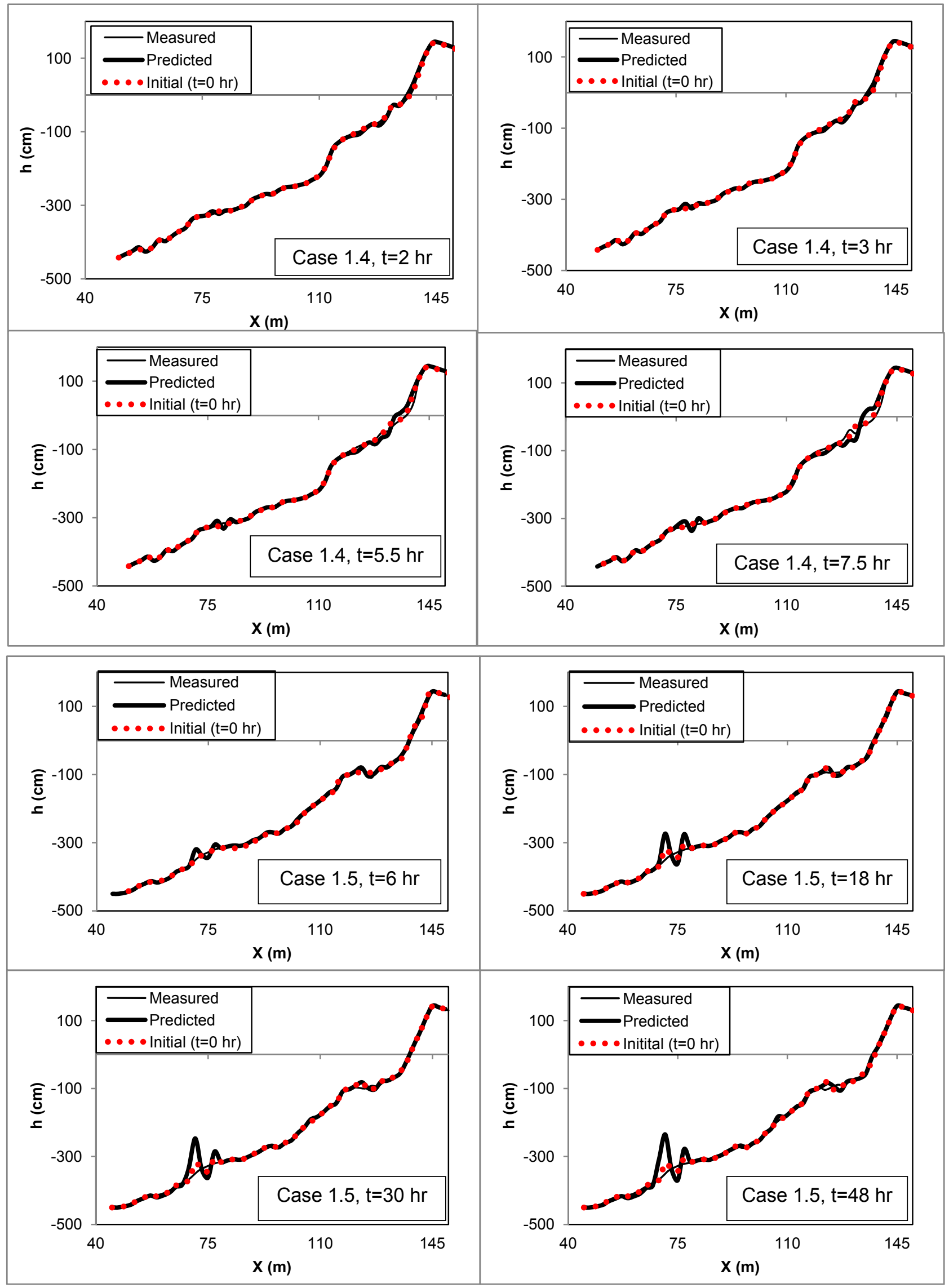

Fig. 13. Measured and computed beach profiles from Kajima et al. [1983], Case $1.4 \& 1.5$. 

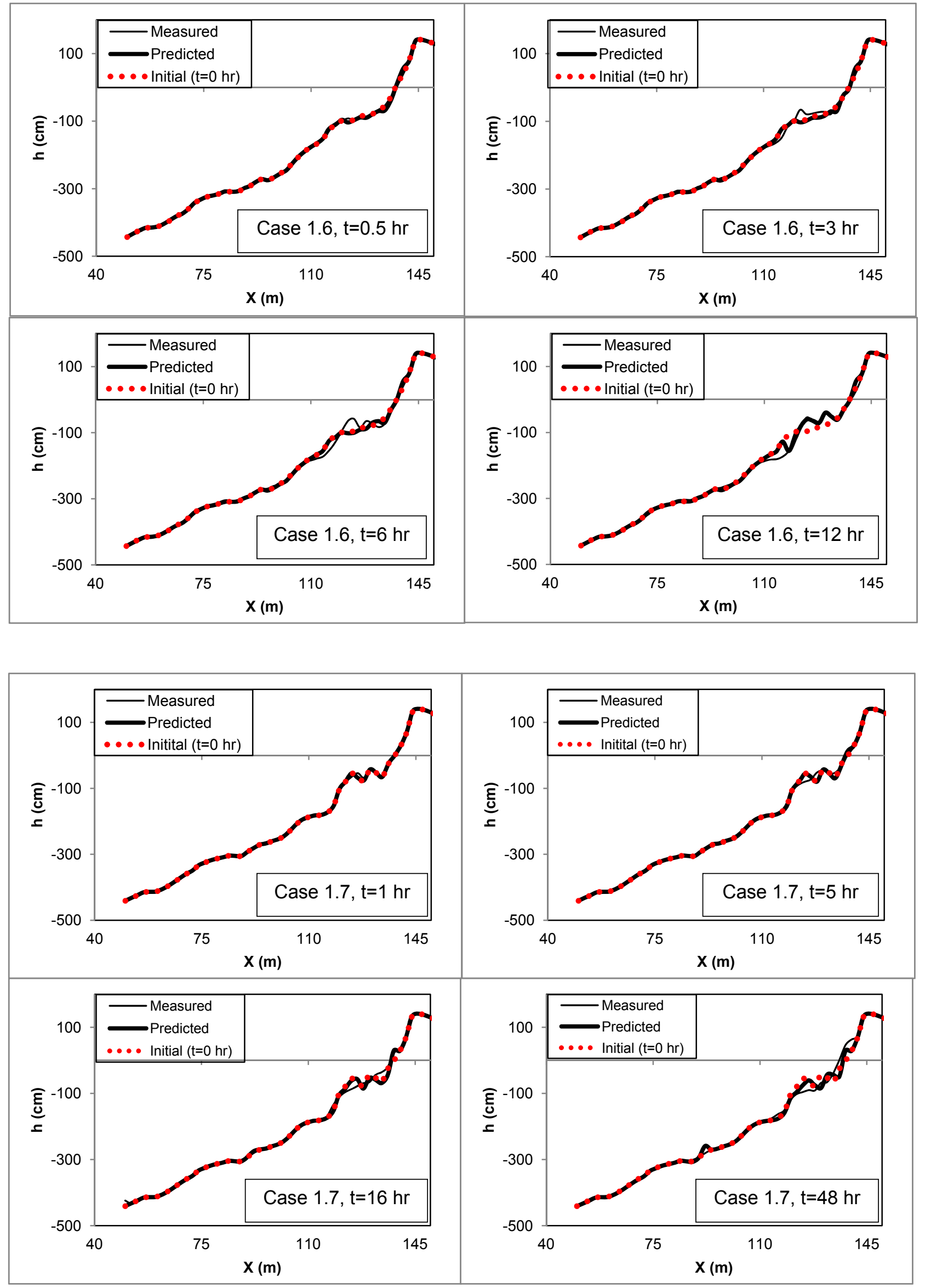

Fig. 14. Measured and computed beach profiles from Kajima et al. [1983], Case 1.6 \& 1.7. 

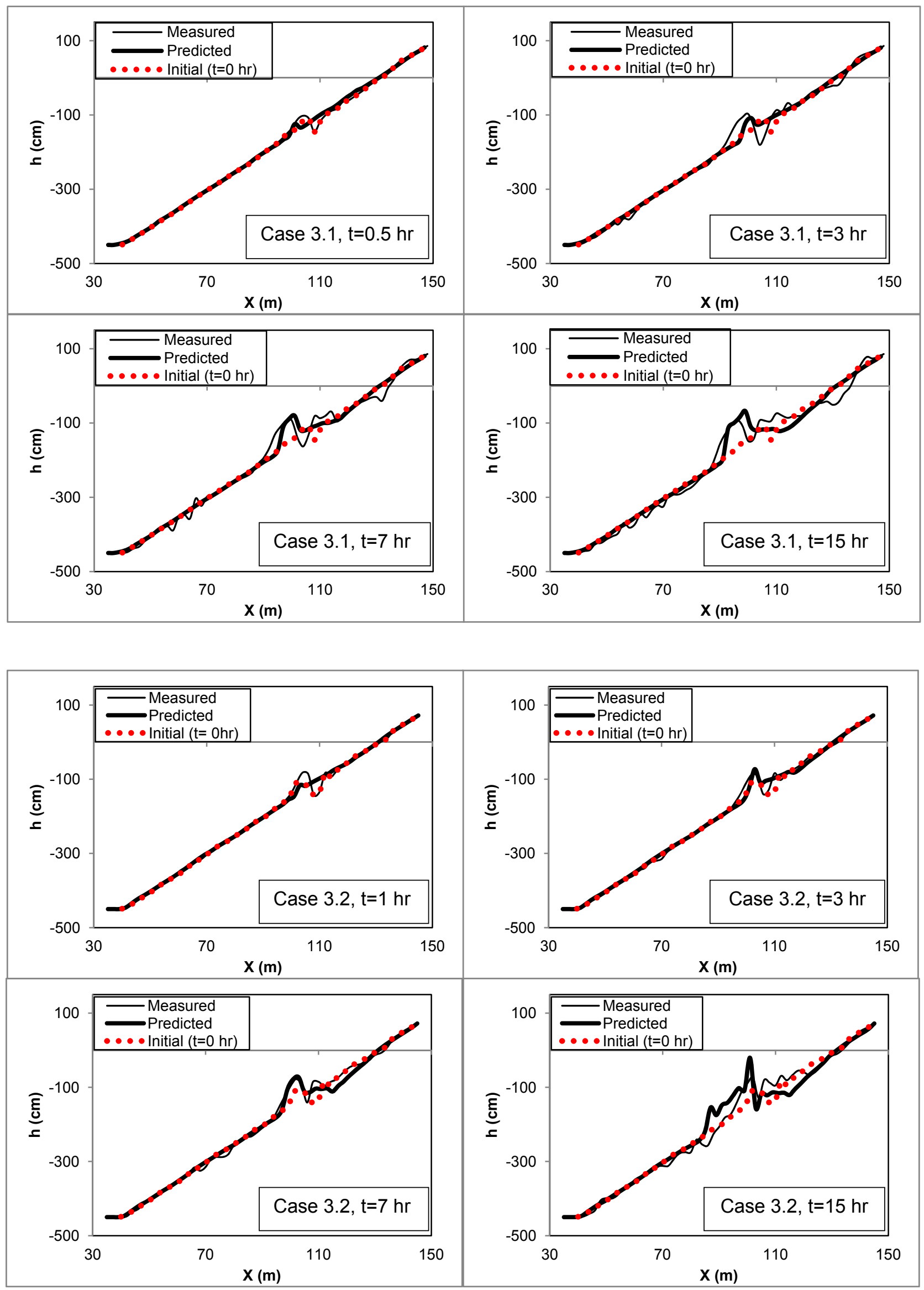

Fig. 15. Measured and computed beach profiles from Kajima et al. [1983], Case 3.1 \& 3.2. 

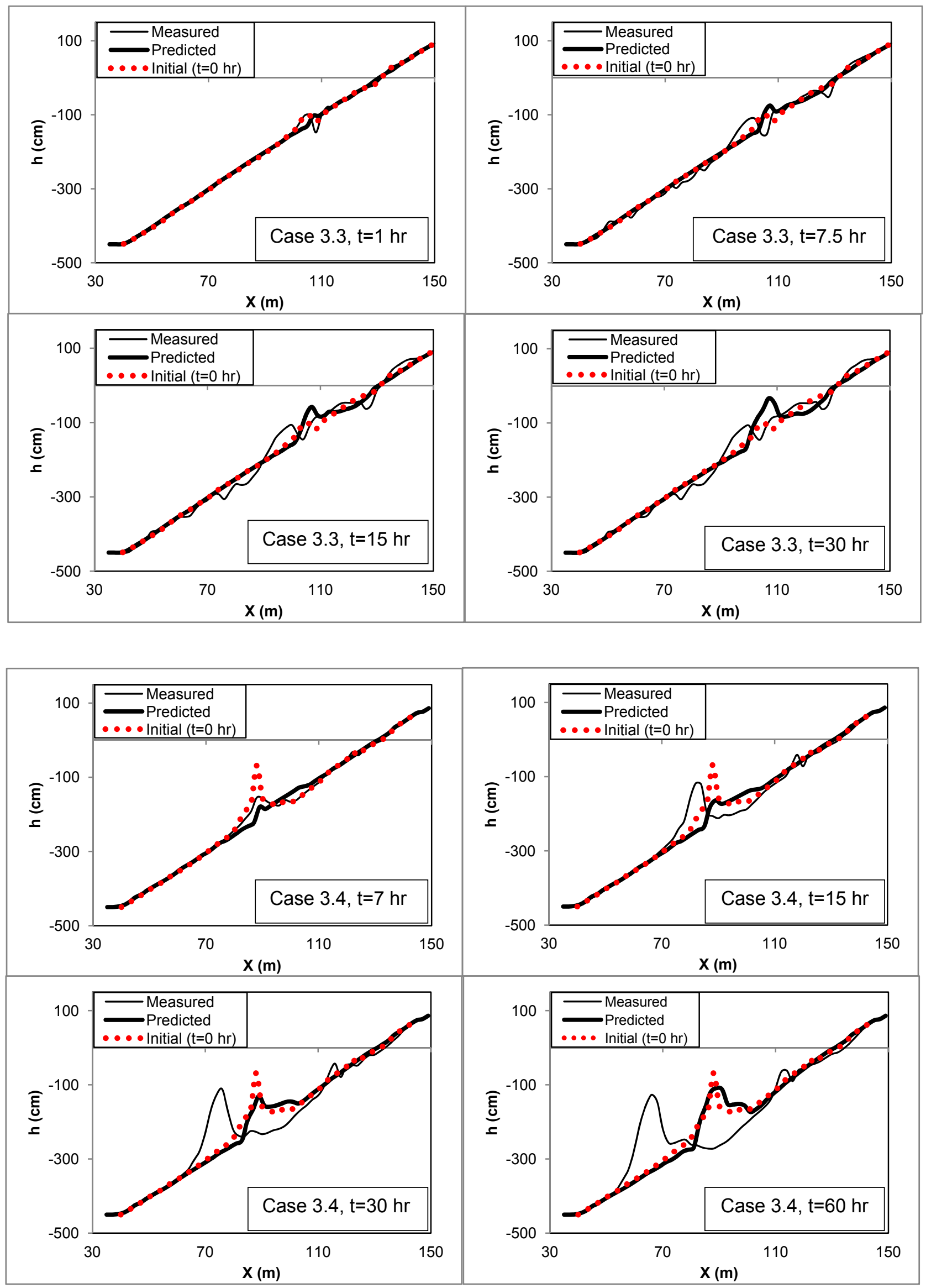

Fig. 16. Measured and computed beach profiles from Kajima et al. [1983], Case 3.3 \& 3.4. 

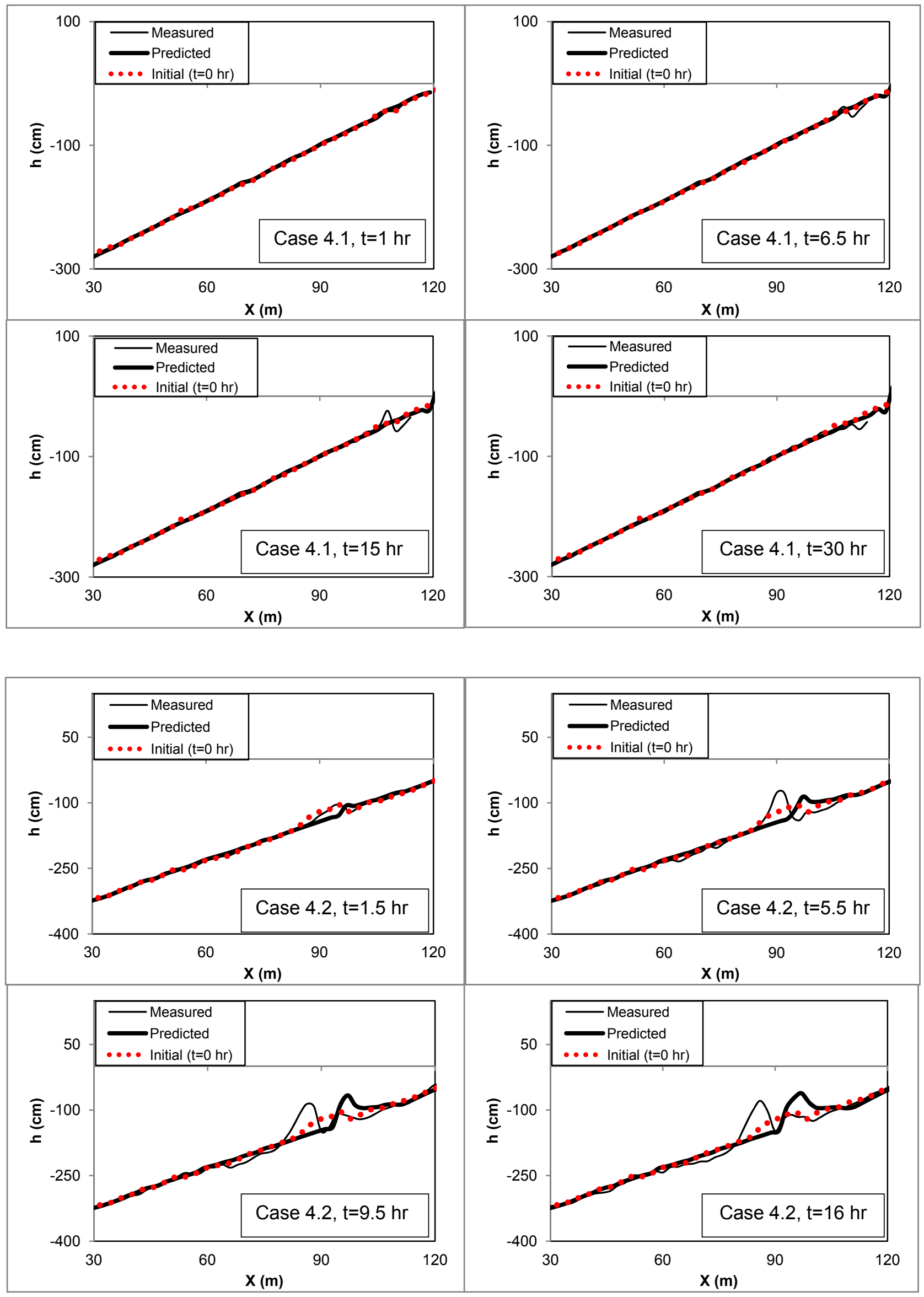

Fig. 17. Measured and computed beach profiles from Kajima et al. [1983], Case 4.1 \& 4.2. 

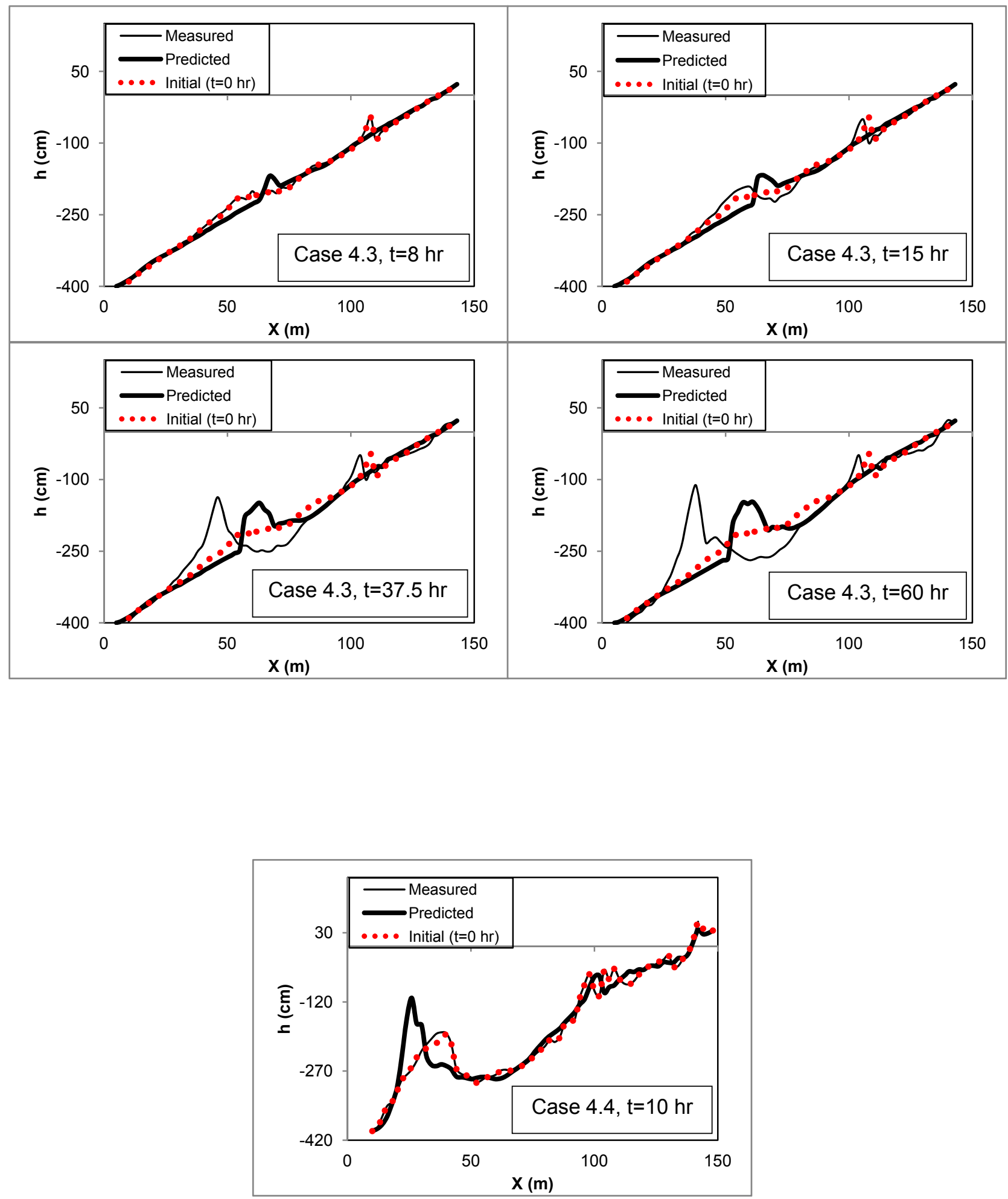

Fig. 18. Measured and computed beach profiles from Kajima et al. [1983], Case 4.3 \& 4.4. 

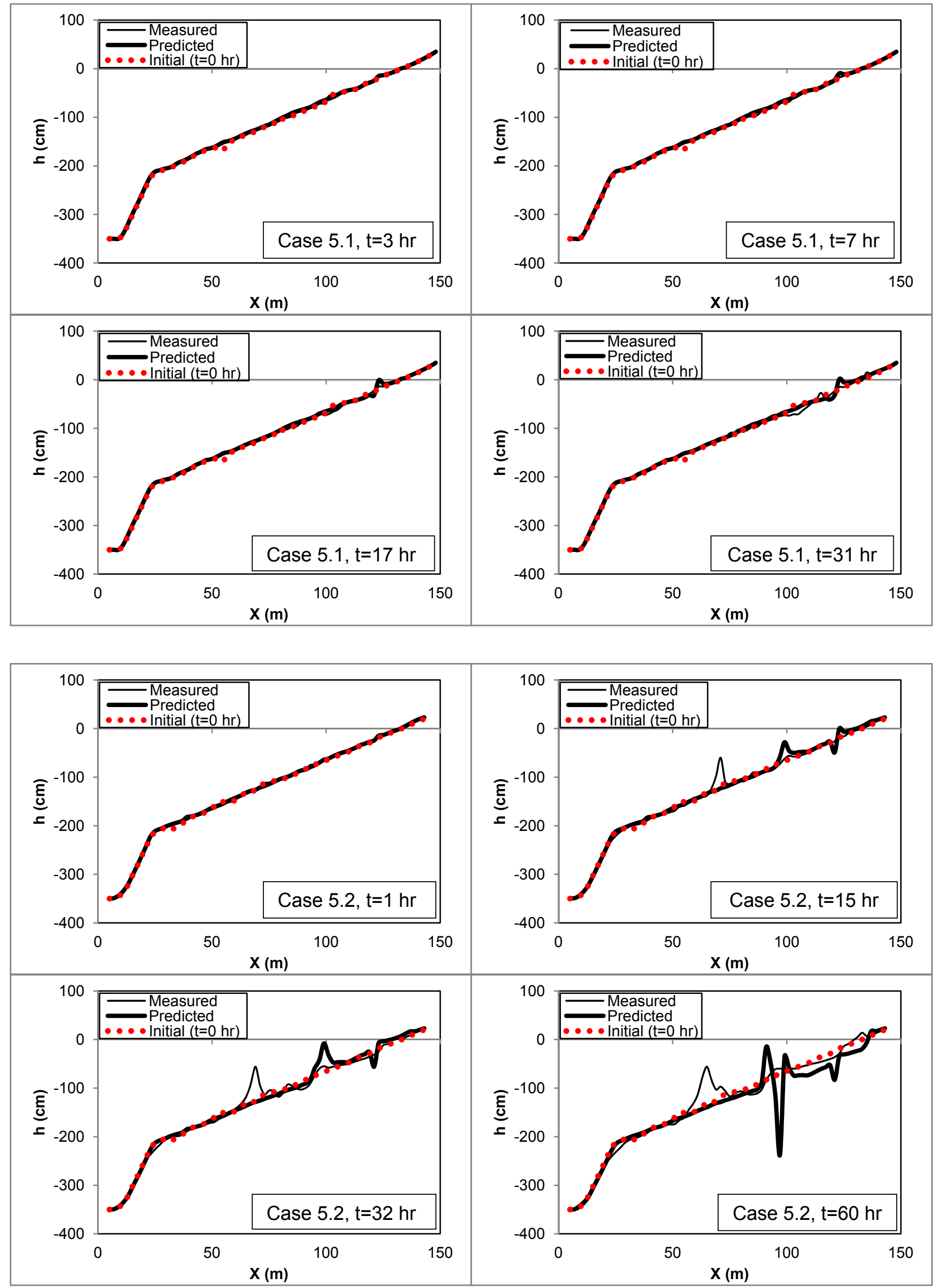

Fig. 19. Measured and computed beach profiles from Kajima et al. [1983], Case 5.1 \& 5.2. 


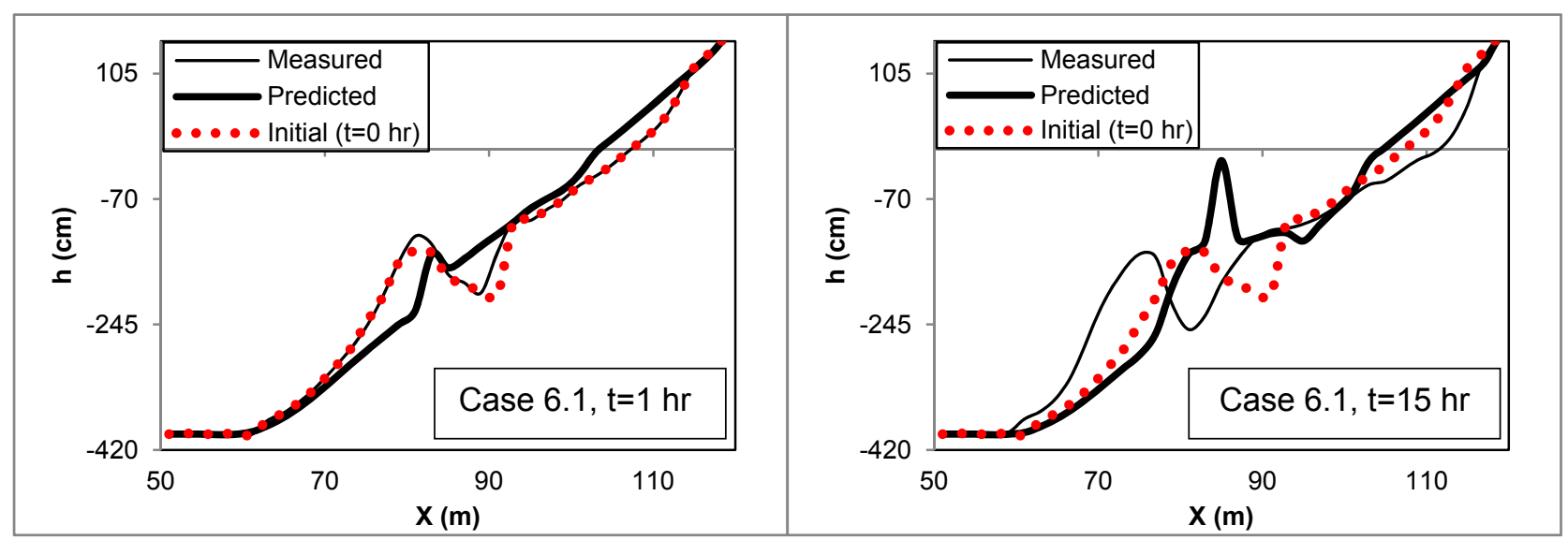

Fig. 20. Measured and computed beach profiles from Kajima et al. [1983], Case 6.1. 

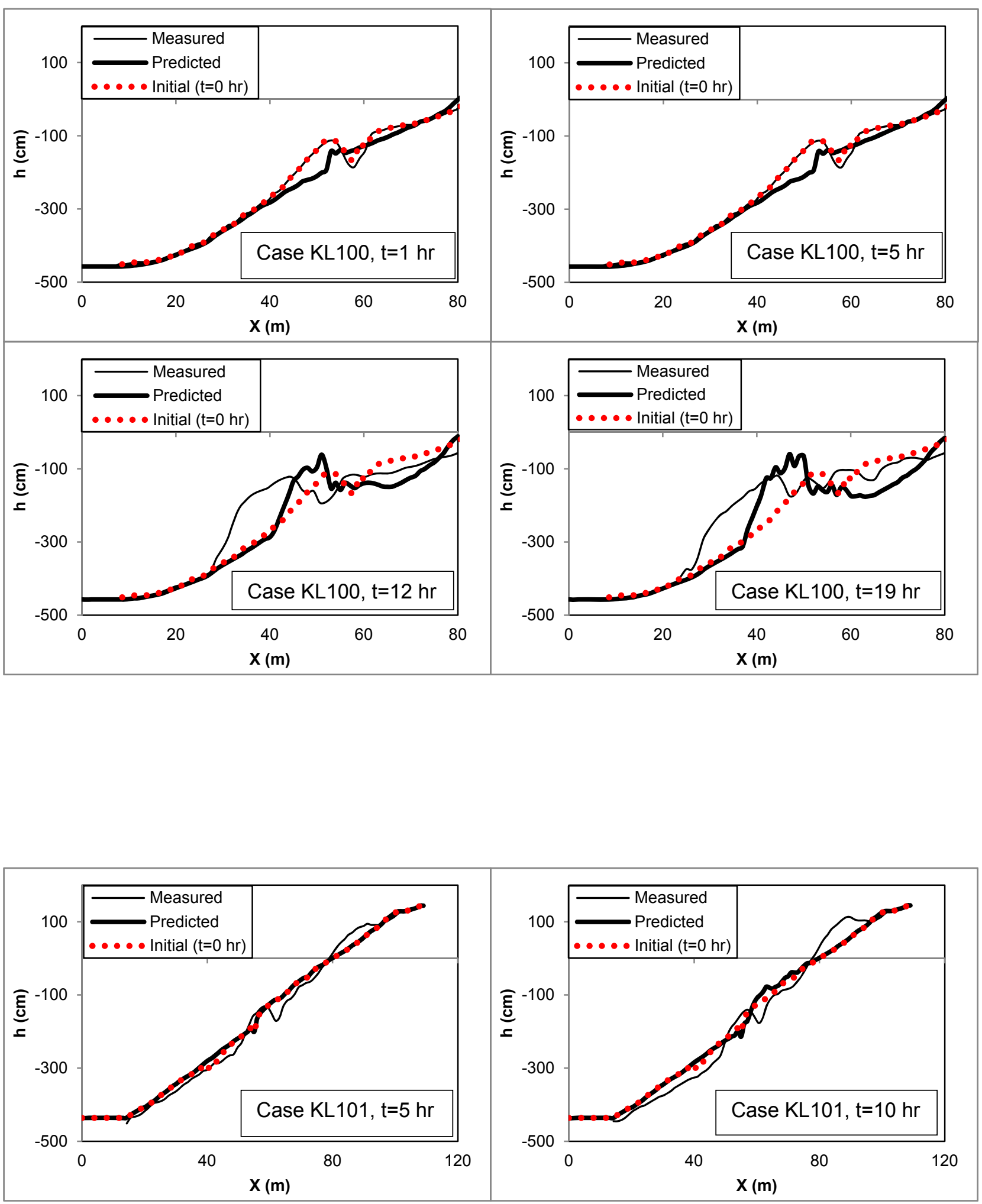

Fig. 21. Measured and computed beach profiles from Larson \& Kraus [1989], Case KL100 \& 101. 

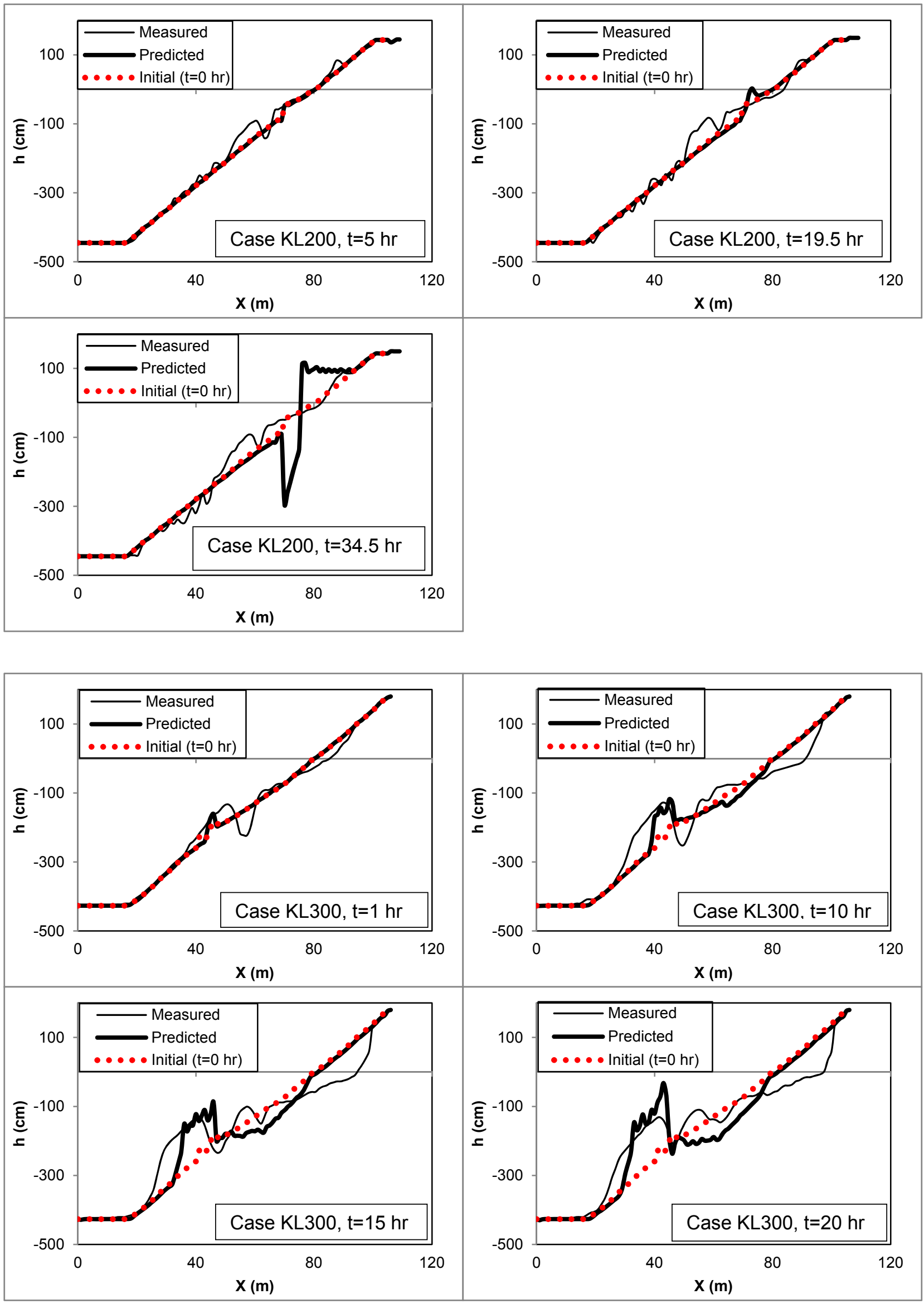

Fig. 22. Measured and computed beach profiles from Larson \& Kraus [1989], Case KL200 \& 300. 

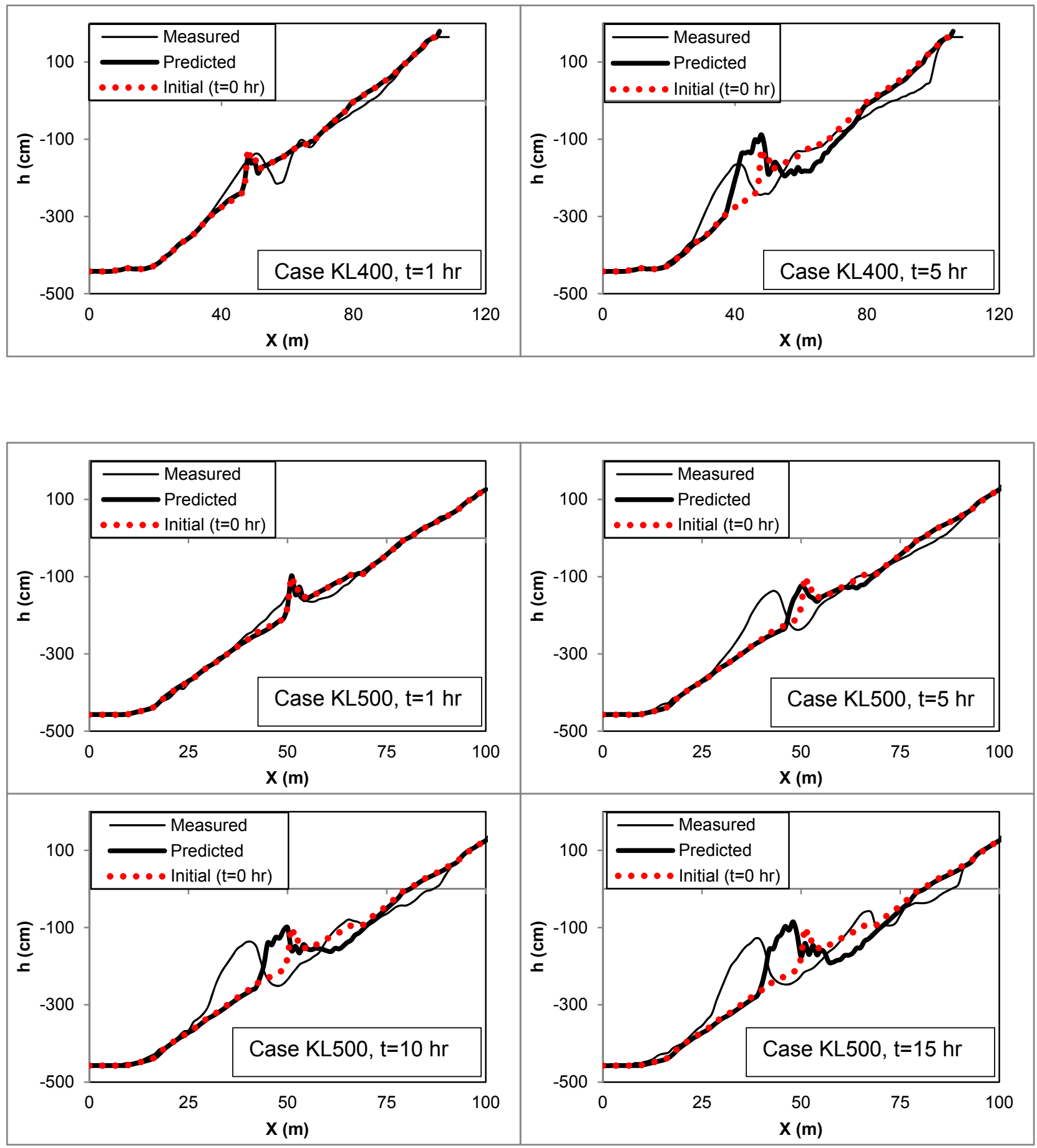

Fig. 23. Measured and computed beach profiles from Larson \& Kraus [1989], Case KL400 \& 500. 

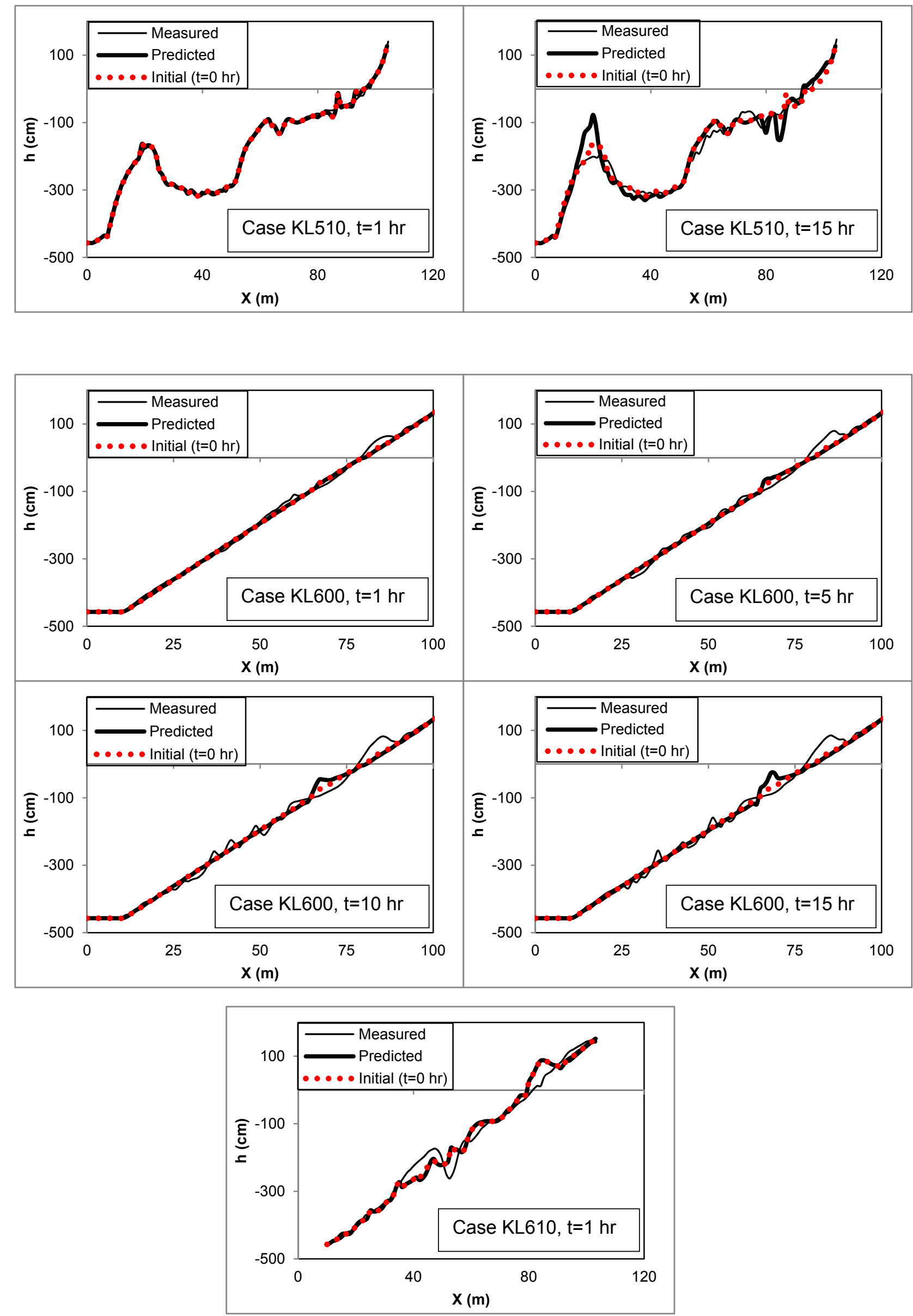

Fig. 24. Measured and computed beach profiles from Larson \& Kraus [1989], Case KL510, 600 \& 610. 

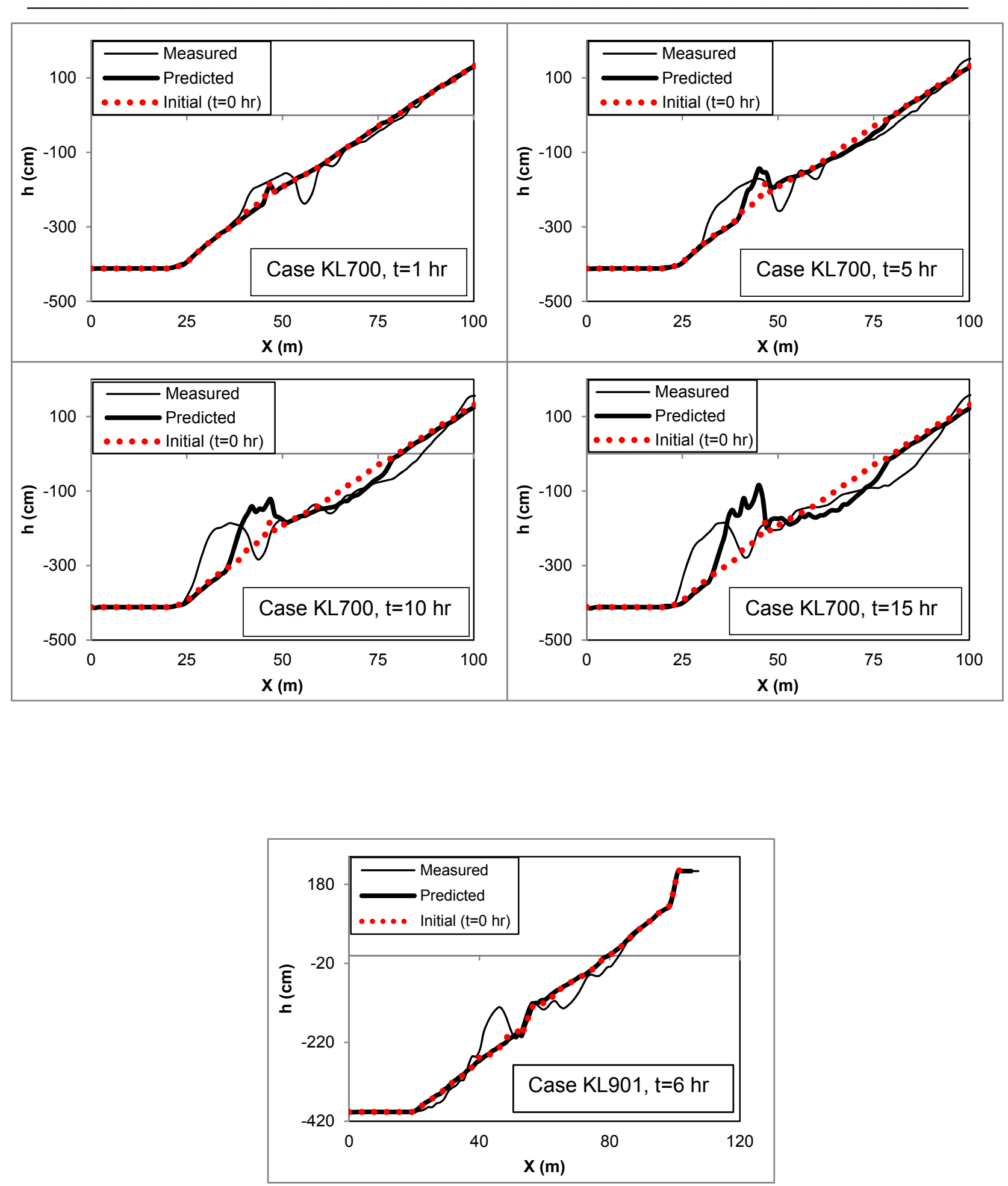

Fig. 25. Measured and computed beach profiles from Larson \& Kraus [1989], Case KL700 \& 901. 

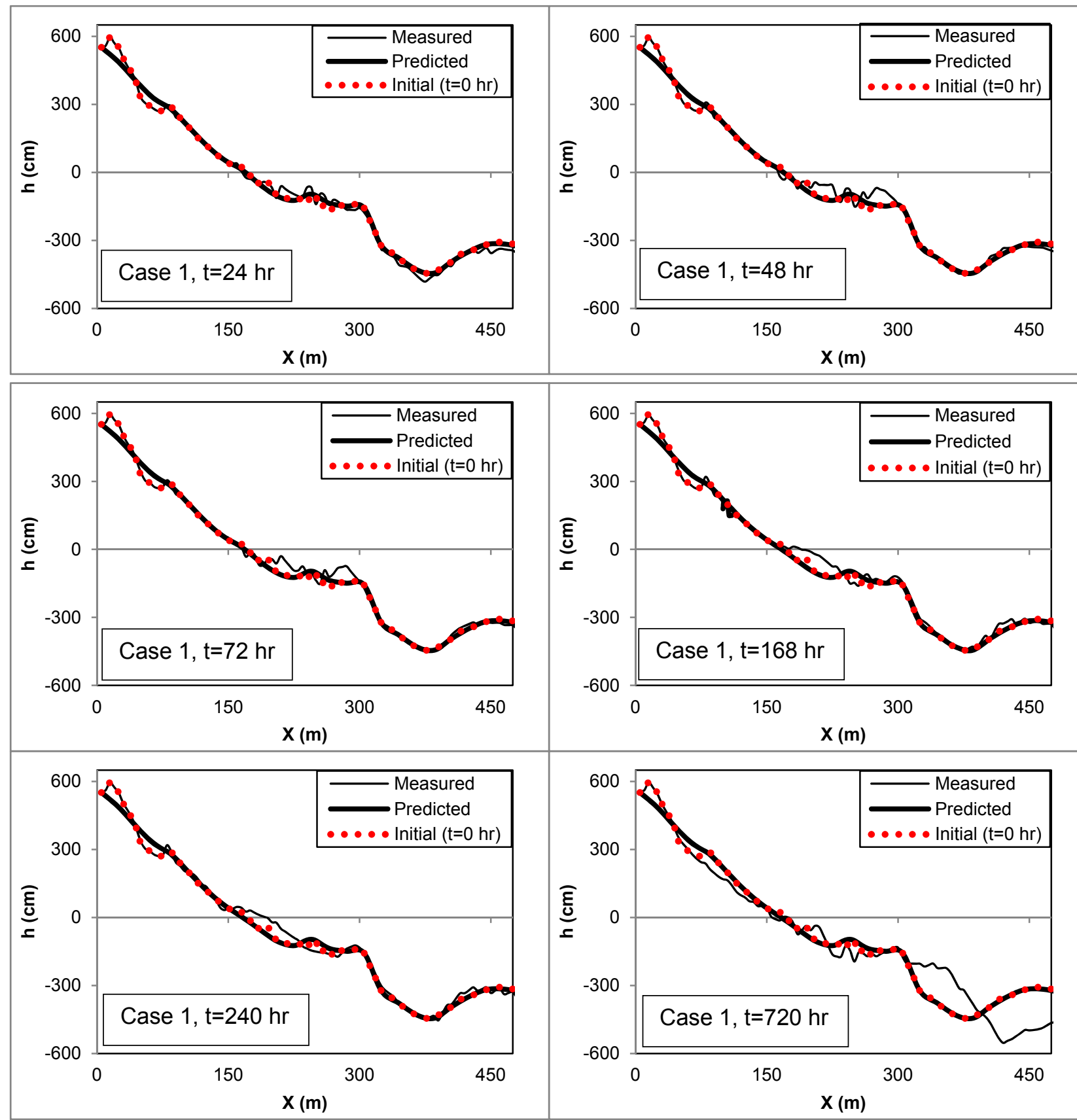

Fig. 26. Measured and computed beach profiles at Hazaki under non-storm conditions [PARI, 2005]. 


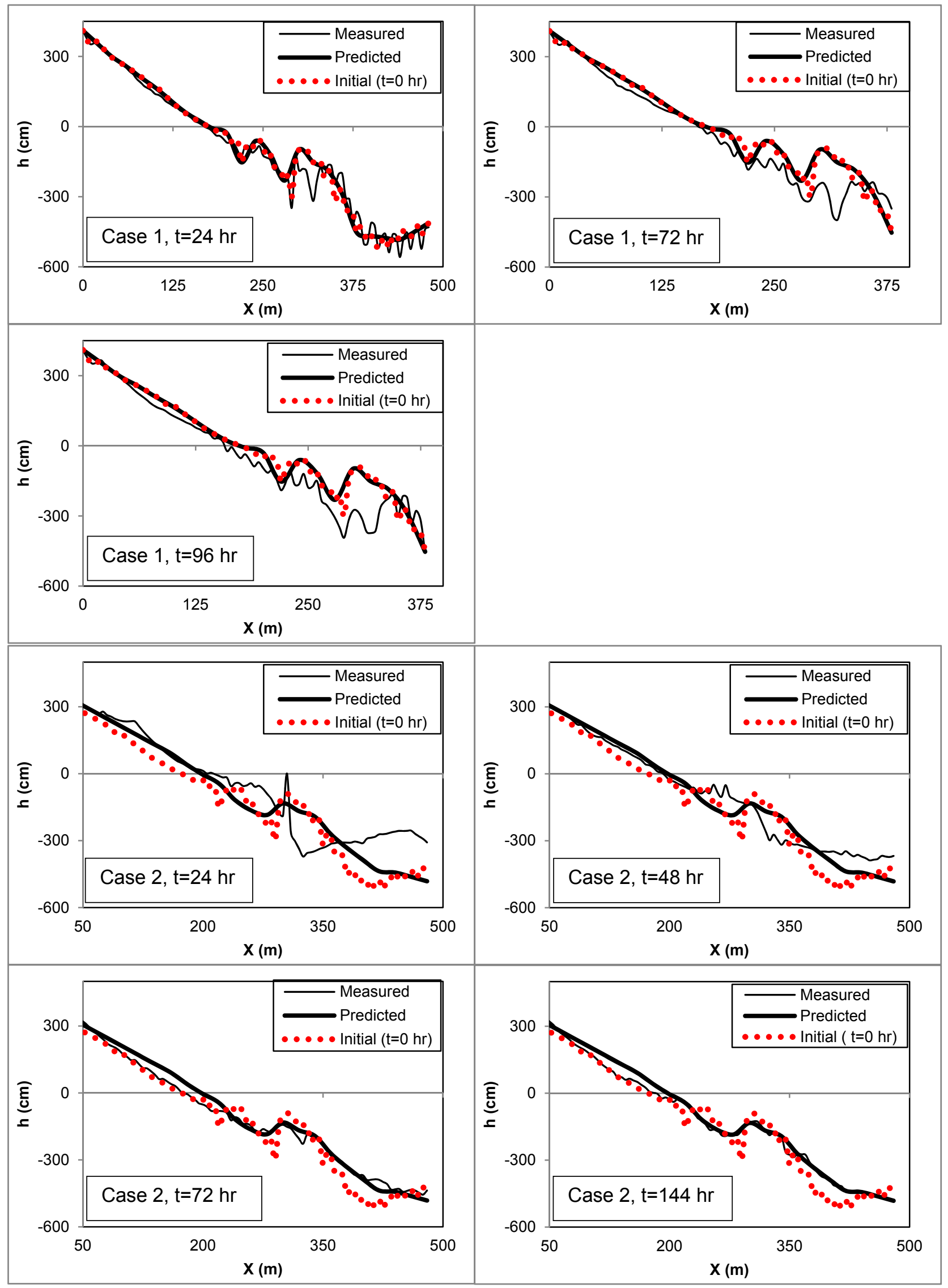

Fig. 27. Measured and computed beach profiles at Hazaki under storm conditions [PARI, 2009], Case $1 \& 2$. 

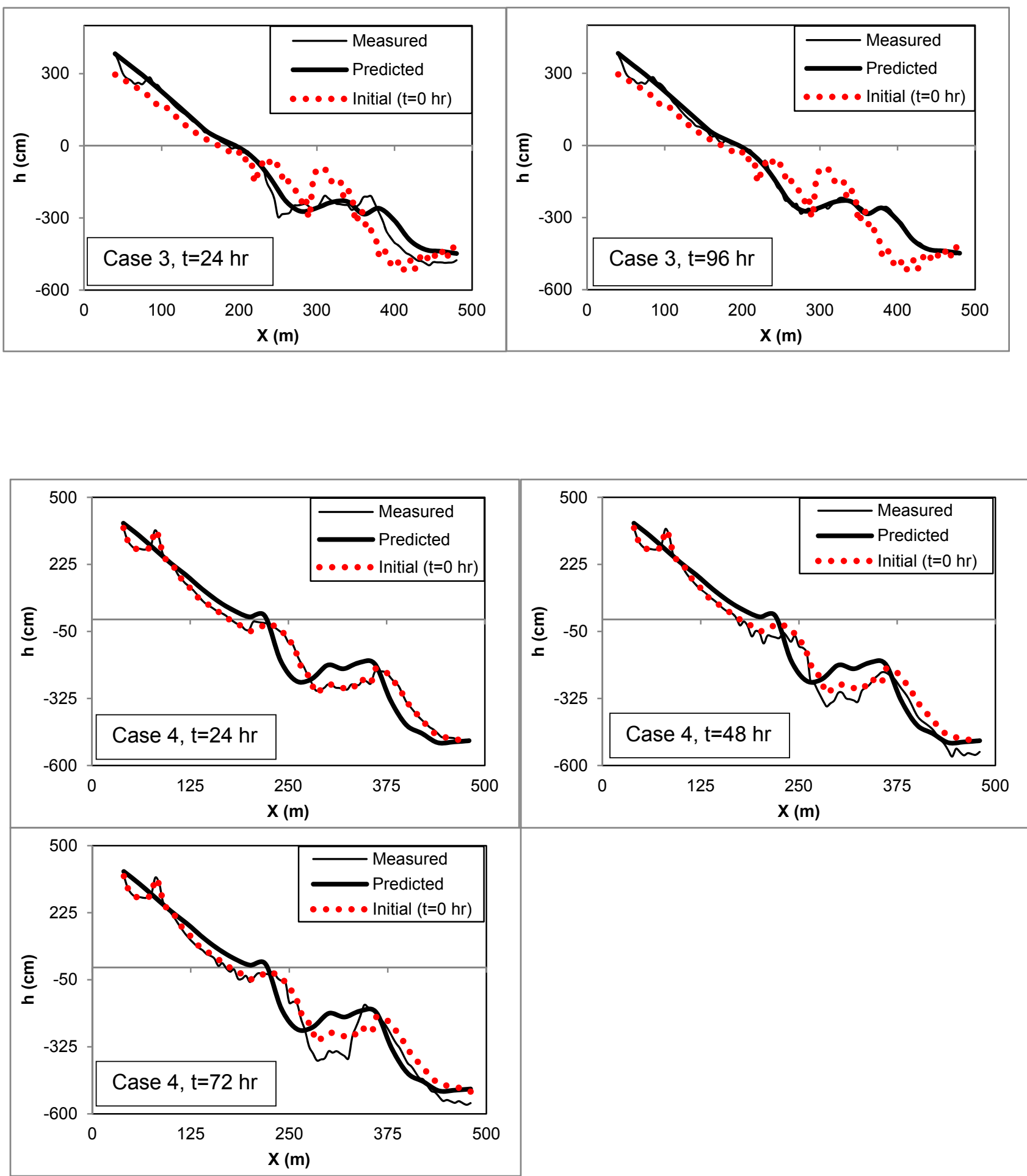

Fig. 28. Measured and computed beach profiles at Hazaki under storm conditions [PARI, 2009], Case $3 \& 4$. 

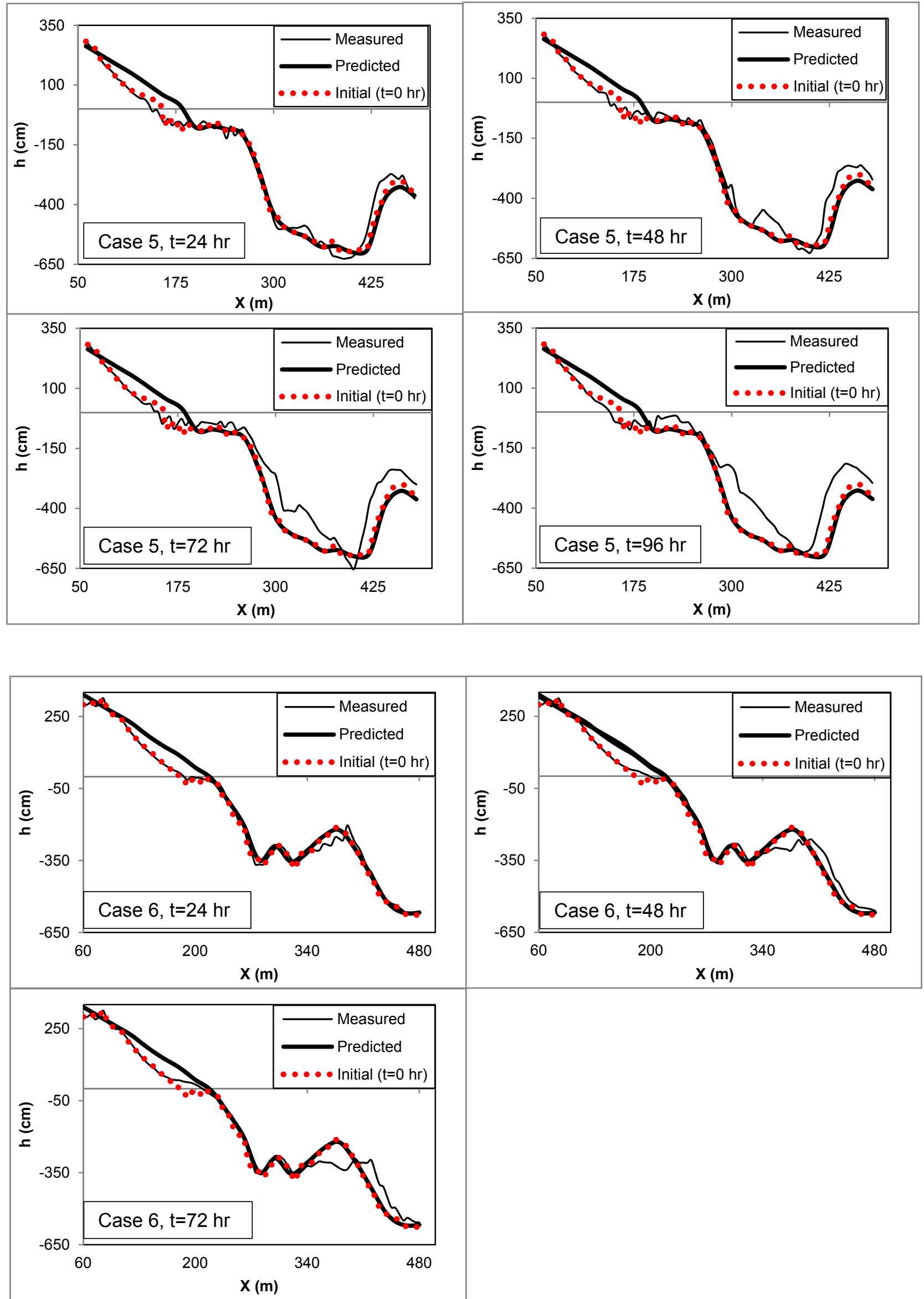

Fig. 29. Measured and computed beach profiles at Hazaki under storm conditions [PARI, 2009], Case $5 \& 6$. 


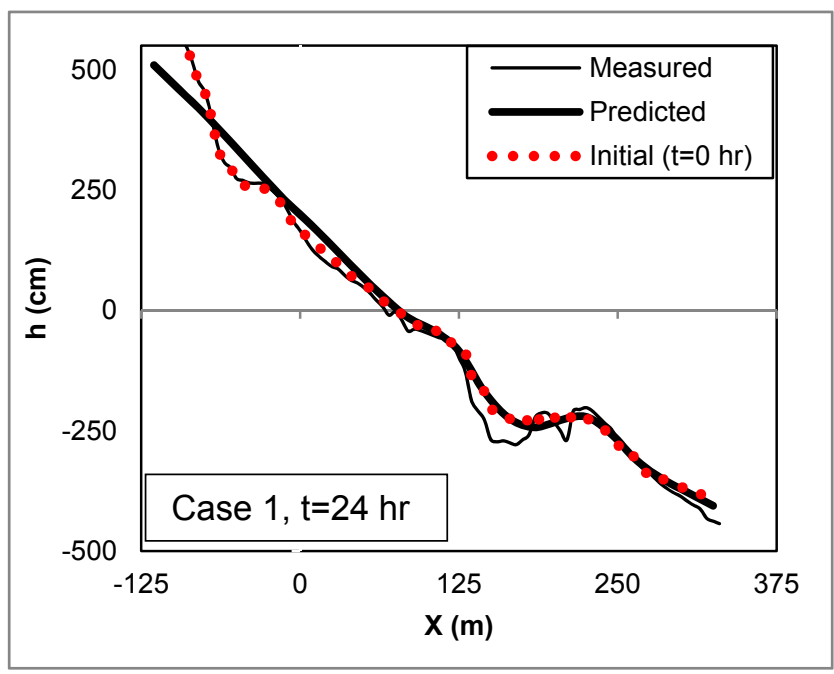

Fig. 30. Measured and computed beach profiles at Hazaki under storm conditions [Hasan \& Takewaka, $2007 \& 2009]$. 


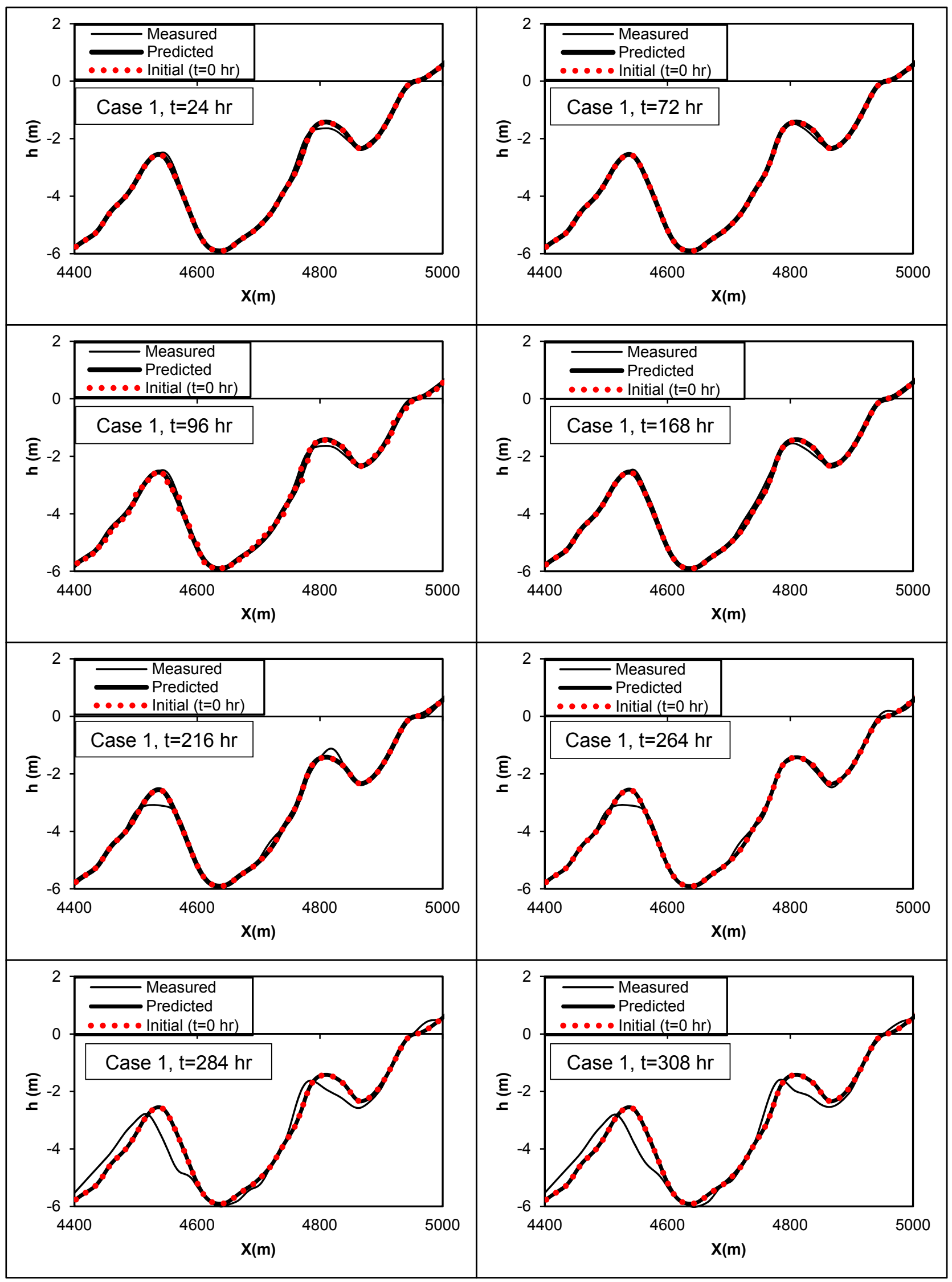

Fig. 31. Measured and computed beach profiles at Egmond beach, Netherlands [Ruessink et al., 2007]. 


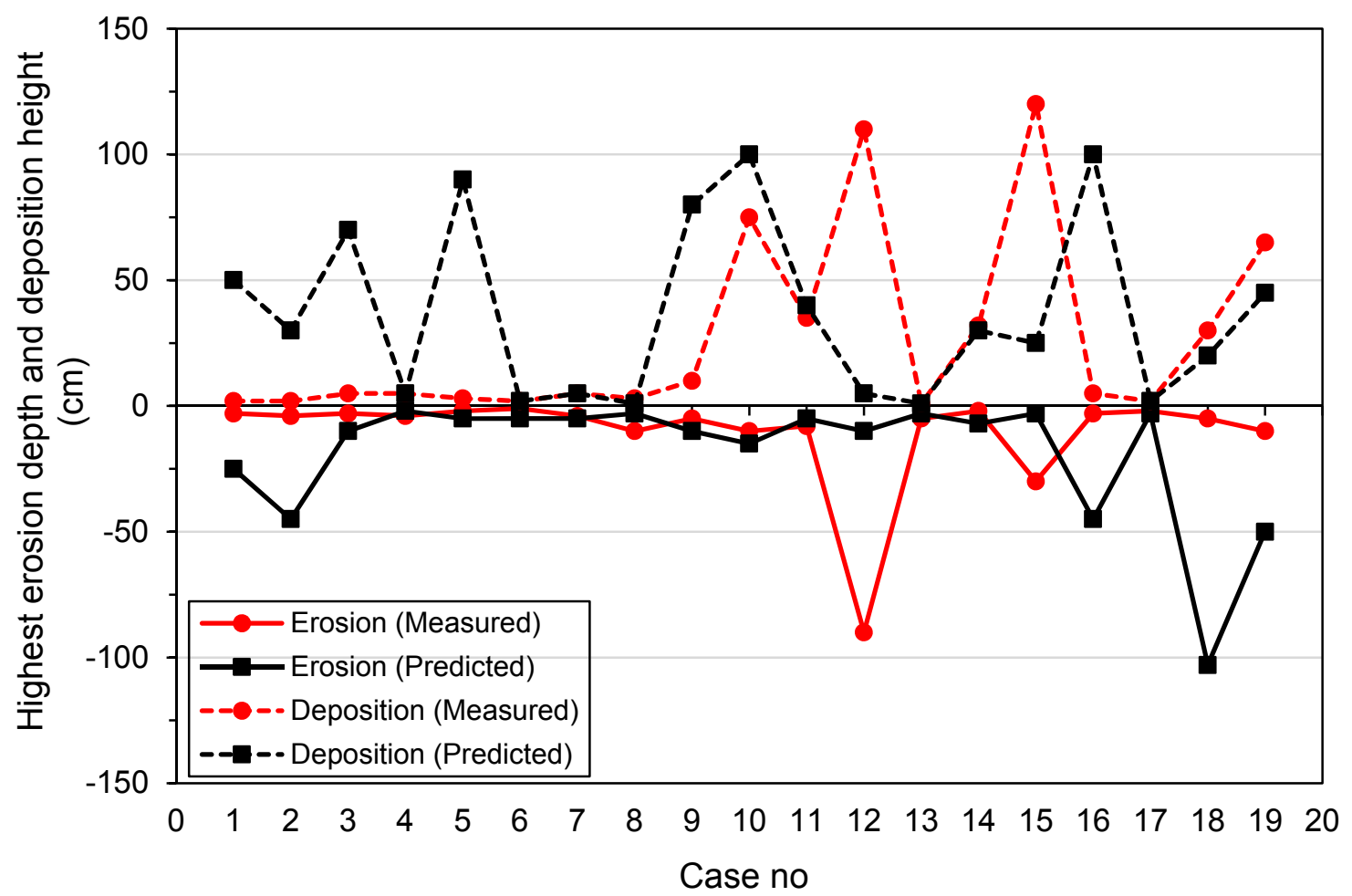

Fig. 32. Highest measured and predicted erosion depths and deposition heights for test cases of Kajima et al. [1983], (Case Nos 1-19 indicate Case 1.1, 1.2, 1.3, 1.4, 1.5, 1.6, 1.7, 2.2, 3.1, 3.2, $3.3,3.4,4.1,4.2,4.3,4.4,5.1,5.2 \& 5.3$ respectively).

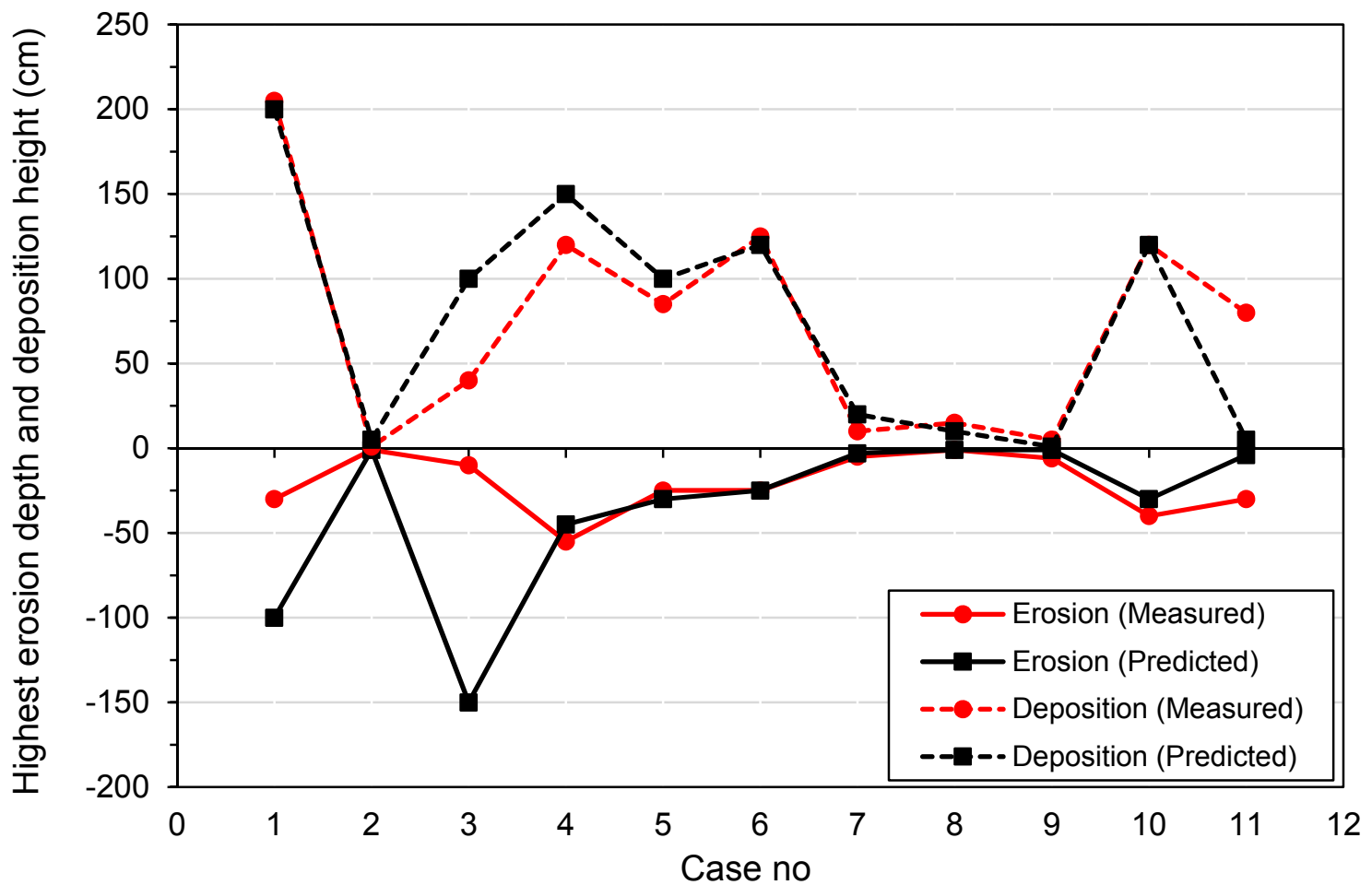

Fig. 33. Highest measured and predicted erosion depths and deposition heights for test cases of Kraus \& Larson [1988] (Case nos 1-11 indicate Case KL100, 101, 200, 300, 400, 500, 510, 600, $610,700 \& 901$ respectively). 


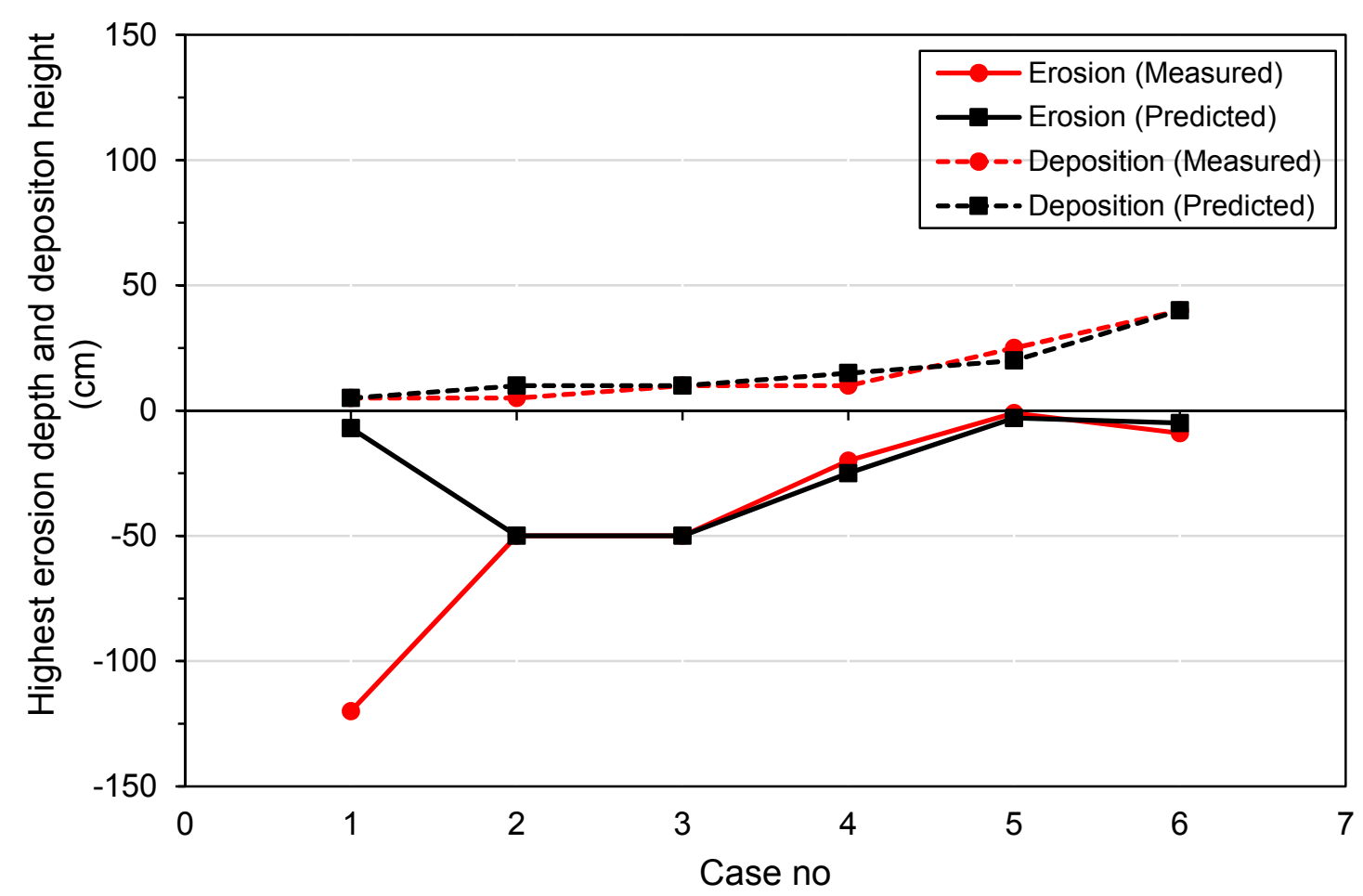

Fig. 34. Highest measured and predicted erosion depths and deposition heights for test cases of PARI [2009]. 
Table 1. Magnitudes of sediment flux at different levels across the water depth (Case 4.3, Kajima et al., 1983), Negative sign indicates flux towards the offshore direction.

\begin{tabular}{|c|c|c|c|}
\hline $\begin{array}{c}\text { Distance from } \\
\text { Offshore } \\
(m) \\
\end{array}$ & $\begin{array}{c}\text { Sediment Flux at } \\
\text { Wave Crest Level } \\
(\mathrm{g} / \mathrm{cm} . \mathrm{s})\end{array}$ & $\begin{array}{c}\text { Sediment Flux at } \\
\text { Wave Trough Level } \\
(\mathrm{g} / \mathrm{cm} . \mathrm{s})\end{array}$ & $\begin{array}{c}\text { Sediment Flux at } \\
\text { Boundary Layer Edge } \\
(\mathrm{g} / \mathrm{cm} . \mathrm{s})\end{array}$ \\
\hline 53.0 & -0.0021 & -0.6722 & -0.0556 \\
\hline 55.0 & -0.0023 & -0.6619 & -0.0183 \\
\hline 57.0 & -0.0021 & -0.6323 & 0.0019 \\
\hline 59.0 & -0.0018 & -0.6073 & 0.0123 \\
\hline 61.0 & -0.0013 & -0.5674 & 0.0174 \\
\hline 63.0 & -0.0009 & -0.5293 & 0.0193 \\
\hline 65.0 & -0.0005 & -0.4859 & 0.0194 \\
\hline 67.0 & -0.0001 & -0.4427 & 0.0184 \\
\hline 69.0 & 0.0002 & -0.4037 & 0.0168 \\
\hline 71.0 & 0.0004 & -0.3653 & 0.0149 \\
\hline 73.0 & 0.0006 & -0.3282 & 0.0129 \\
\hline 75.0 & 0.0005 & -0.2588 & 0.0115 \\
\hline 77.0 & 0.0004 & -0.1931 & 0.0103 \\
\hline 79.0 & 0.0003 & -0.1398 & 0.0093 \\
\hline 81.0 & 0.0002 & -0.1009 & 0.0084 \\
\hline 83.0 & 0.0002 & -0.0717 & 0.0076 \\
\hline 85.0 & 0.0001 & -0.0499 & 0.0070 \\
\hline 87.0 & 0.0001 & -0.0338 & 0.0064 \\
\hline 89.0 & 0.0001 & -0.0217 & 0.0060 \\
\hline 91.0 & 0.0000 & -0.0131 & 0.0058 \\
\hline 93.0 & 0.0000 & -0.0072 & 0.0058 \\
\hline 95.0 & 0.0000 & -0.0025 & 0.0061 \\
\hline 97.0 & 0.0007 & -0.5099 & 0.0177 \\
\hline 99.0 & 0.0014 & -0.4657 & 0.0127 \\
\hline 101.0 & 0.0011 & -0.3372 & 0.0118 \\
\hline 103.0 & 0.0007 & -0.2288 & 0.0115 \\
\hline 105.0 & 0.0005 & -0.1457 & 0.0114 \\
\hline 107.0 & 0.0003 & -0.0932 & 0.0110 \\
\hline 109.0 & 0.0002 & -0.0564 & 0.0108 \\
\hline 111.0 & 0.0001 & -0.0294 & 0.0111 \\
\hline 113.0 & 0.0001 & -0.0110 & 0.0123 \\
\hline
\end{tabular}


Table 2. Magnitudes of sediment flux at different levels across water depth (Case 500, Kraus and Larson, 1988), Negative sign indicates flux towards the offshore direction.

\begin{tabular}{|c|c|c|c|}
\hline $\begin{array}{l}\text { Distance from } \\
\text { Offshore } \\
(m)\end{array}$ & $\begin{array}{c}\text { Sediment Flux at } \\
\text { Wave Crest Level } \\
(\mathrm{g} / \mathrm{cm} . \mathrm{s})\end{array}$ & $\begin{array}{c}\text { Sediment Flux at } \\
\text { Wave Trough Level } \\
(\mathrm{g} / \mathrm{cm} . \mathrm{s})\end{array}$ & $\begin{array}{c}\text { Sediment Flux at } \\
\text { Boundary Layer Edge } \\
(\mathrm{g} / \mathrm{cm} . \mathrm{s})\end{array}$ \\
\hline 45.0 & -0.0073 & -1.9935 & -0.2105 \\
\hline 46.0 & -0.0089 & -2.1800 & -0.1463 \\
\hline 47.0 & -0.0100 & -2.3475 & -0.1007 \\
\hline 48.0 & -0.0105 & -2.4877 & -0.0669 \\
\hline 49.0 & -0.0102 & -2.5779 & -0.0400 \\
\hline 50.0 & -0.0096 & -2.6540 & -0.0208 \\
\hline 51.0 & -0.0086 & -2.7191 & -0.0078 \\
\hline 52.0 & -0.0071 & -2.7334 & 0.0028 \\
\hline 53.0 & -0.0055 & -2.7728 & 0.0076 \\
\hline 54.0 & -0.0037 & -2.7931 & 0.0097 \\
\hline 55.0 & -0.0017 & -2.7672 & 0.0112 \\
\hline 56.0 & 0.0003 & -2.7270 & 0.0111 \\
\hline 57.0 & 0.0024 & -2.6997 & 0.0081 \\
\hline 58.0 & 0.0046 & -2.6572 & 0.0041 \\
\hline 59.0 & 0.0068 & -2.6002 & -0.0006 \\
\hline 60.0 & 0.0089 & -2.5298 & -0.0059 \\
\hline 61.0 & 0.0081 & -2.2343 & -0.0056 \\
\hline 62.0 & 0.0074 & -1.9628 & -0.0054 \\
\hline 63.0 & 0.0067 & -1.7106 & -0.0049 \\
\hline 64.0 & 0.0056 & -1.4454 & -0.0017 \\
\hline 65.0 & 0.0050 & -1.2435 & -0.0014 \\
\hline 66.0 & 0.0045 & -1.0664 & -0.0016 \\
\hline 67.0 & 0.0038 & -0.8938 & -0.0010 \\
\hline 68.0 & 0.0032 & -0.7323 & 0.0001 \\
\hline 69.0 & 0.0028 & -0.6127 & -0.0006 \\
\hline 70.0 & 0.0022 & -0.4855 & 0.0005 \\
\hline 71.0 & 0.0019 & -0.3927 & 0.0002 \\
\hline 72.0 & 0.0016 & -0.3168 & -0.0005 \\
\hline 73.0 & 0.0014 & -0.2459 & -0.0005 \\
\hline 74.0 & 0.0010 & -0.1788 & 0.0006 \\
\hline 75.0 & 0.0008 & -0.1360 & 0.0002 \\
\hline 76.0 & 0.0007 & -0.0995 & 0.0000 \\
\hline 77.0 & 0.0005 & -0.0689 & 0.0001 \\
\hline 78.0 & 0.0003 & -0.0404 & 0.0017 \\
\hline 79.0 & 0.0002 & -0.0181 & 0.0048 \\
\hline 80.0 & 0.0001 & -0.0392 & 0.0076 \\
\hline 81.0 & 0.0001 & -0.0360 & 0.0067 \\
\hline 82.0 & 0.0001 & -0.0322 & 0.0060 \\
\hline 83.0 & 0.0001 & -0.0258 & 0.0056 \\
\hline 84.0 & 0.0001 & -0.0182 & 0.0056 \\
\hline 85.0 & 0.0001 & -0.0118 & 0.0058 \\
\hline
\end{tabular}


Table 3. Data sources used for formulation of suspended sediment concentration models (taken from Jayaratne \& Shibayama, 2007; Jayaratne et al., 2011).

\begin{tabular}{|c|c|c|c|c|c|c|c|}
\hline \multicolumn{8}{|c|}{ Full-Scale Rippled Bed (Laboratory Measurements) } \\
\hline No & Data Source & Cases & $\begin{array}{l}\text { Average } \\
\text { Grain Size } \\
(\mathrm{mm})\end{array}$ & $\begin{array}{l}\text { Velocity } \\
\text { Amplitude } \\
(\mathrm{m} / \mathrm{s})\end{array}$ & $\begin{array}{l}\text { Wave } \\
\text { Period } \\
\text { (s) }\end{array}$ & $\begin{array}{l}\text { Type of } \\
\text { Waves }\end{array}$ & $\begin{array}{l}\text { Experimental } \\
\text { Facility }\end{array}$ \\
\hline \multirow[t]{2}{*}{1} & Ribberink \& Al-Salem & $14(\mathrm{~A})$ & 0.21 & $0.3-1.5$ & $2.0-10.0$ & Regular & LOWT \\
\hline & [1994] & $6(\mathrm{~B})$ & 0.21 & $0.2-0.33$ & $5.0-9.1$ & Irregular & LOWT \\
\hline 2 & Clubb [2001] & 4 & 0.34 & $0.53-0.84$ & $5.0-10.0$ & Sine/Asym & AOFT \\
\hline \multirow[t]{2}{*}{3} & Thorne et al. [2002] & 10 & 0.33 & - & $4.0-6.0$ & Regular & Deltaflume \\
\hline & & 4 & 0.33 & - & $4.92-5.10$ & Irregular & Deltaflume \\
\hline 4 & Thorne et al. [2003] & 1 & 0.33 & - & 5.0 & $\begin{array}{l}\text { Regular } \\
\text { Asym }\end{array}$ & Deltaflume \\
\hline \multirow[t]{2}{*}{5} & Van der Werf et al. & 22 & 0.35 & $0.5-1.0$ & $5.0-10.0$ & Regular & LOWT \\
\hline & {$[2006]$} & & $0.22,0.44$ & - & $3.5-12.5$ & Irregular & LOWT \\
\hline \multirow[t]{2}{*}{6} & $\begin{array}{l}\text { Van der Werf et al. } \\
\text { [2007] }\end{array}$ & 14 & 0.44 & $0.22-0.47$ & $5.0-7.4$ & Regular & AOFT \\
\hline & Total Cases & 75 & & & & & \\
\hline \multicolumn{8}{|c|}{ Full-Scale Sheet Flow (Laboratory Measurements) } \\
\hline 1 & $\begin{array}{l}\text { Ribberink \& Al-Salem } \\
\text { [1994] }\end{array}$ & 2 & 0.21 & - & $6.5-9.1$ & Regular & LOWT \\
\hline 2 & Katopodi et al. [1994] & 4 & 0.21 & - & 7.2 & Regular & LOWT \\
\hline 3 & Hamm et al. [1998] & 3 & 0.20 & $6.76-8.52$ & $1.25-1.75$ & Regular & LOWT \\
\hline \multirow[t]{2}{*}{4} & Dohmen-Janssen [1999] & 3 & 0.41 & - & $3.0-3.6$ & Regular & LOWT \\
\hline & Total Cases & 12 & & & & & \\
\hline \multicolumn{8}{|c|}{ Full-Scale Breaking Agitation (Laboratory Measurements) } \\
\hline 1 & Kajima et al. [1983] & 137 & $0.27-0.47$ & $23.0-180.0$ & $3.0-12.0$ & Regular & $\begin{array}{l}\text { Large wave } \\
\text { flume }\end{array}$ \\
\hline 2 & $\begin{array}{l}\text { Dette and Uliczka } \\
\text { [1986] }\end{array}$ & 11 & 0.33 & 150.0 & 6.0 & $\begin{array}{l}\text { Regular/ } \\
\text { Irregular }\end{array}$ & $\begin{array}{l}\text { Large wave } \\
\text { flume }\end{array}$ \\
\hline & Total Cases & 148 & & & & & \\
\hline
\end{tabular}


Table 4. Complete data sources used for comparison of simulated beach profiles [1983-2009].

\begin{tabular}{|c|c|c|c|c|c|c|c|}
\hline \multicolumn{8}{|c|}{ Large-Scale Laboratory Studies } \\
\hline No & Data Source & Cases & $\begin{array}{c}\text { Average } \\
\text { Grain Size } \\
(\mathrm{mm})\end{array}$ & $\begin{array}{l}\text { Wave } \\
\text { Height } \\
(\mathrm{cm})\end{array}$ & $\begin{array}{l}\text { Wave } \\
\text { Period } \\
\text { (s) }\end{array}$ & $\begin{array}{l}\text { Initial Beach } \\
\text { Condition }\end{array}$ & $\begin{array}{c}\text { Experimental } \\
\text { Facility/ } \\
\text { Location }\end{array}$ \\
\hline 1 & Kajima et al. [1983] & 19 & $0.27-0.47$ & $23.0-166.0$ & $3.0-12.0$ & Uniform & $\begin{array}{c}\text { Wave } \\
\text { flume/CRIEPI }\end{array}$ \\
\hline 2 & Kraus \& Larson [1988] & 12 & $0.22-0.40$ & $55.0-168.0$ & $3.75-16.0$ & $\begin{array}{l}\text { Uniform, Non- } \\
\text { uniform }\end{array}$ & $\begin{array}{c}\text { Wave } \\
\text { flume/CERC }\end{array}$ \\
\hline & Total Cases & 31 & & & & & \\
\hline \multicolumn{8}{|c|}{ Field Measurements } \\
\hline \multirow[t]{3}{*}{3} & PARI, Japan & & & & & & \multirow{3}{*}{$\begin{array}{c}\text { HORS/Hazaki, } \\
\text { Japan }\end{array}$} \\
\hline & Non-storm condition [2005] & 1 & 0.18 & 165 & 11.8 & Uniform & \\
\hline & Storm condition [2009] & 6 & 0.18 & $56.0-220.0$ & $3.5-13.7$ & $\begin{array}{l}\text { Uniform, Non- } \\
\text { uniform }\end{array}$ & \\
\hline 4 & $\begin{array}{l}\text { Hasan \& Takewaka } \\
{[2007,2009]}\end{array}$ & 1 & 0.23 & 369.0 & 12.1 & Non-uniform & $\begin{array}{c}\text { HORS/Hazaki, } \\
\text { Japan }\end{array}$ \\
\hline \multirow[t]{2}{*}{5} & Ruessink et al. [2007] & 1 & 0.265 & 200.0 & 8.0 & Uniform & $\begin{array}{l}\text { Egmond/ } \\
\text { Netherlands }\end{array}$ \\
\hline & Total Cases & 9 & & & & & \\
\hline
\end{tabular}

Table 5. Test cases of Kajima et al. [1983] used for model comparison.

\begin{tabular}{ccccccc}
\hline Case No & $\begin{array}{c}\text { Average } \\
\text { Grain Size } \\
(\mathrm{mm})\end{array}$ & $\begin{array}{c}\text { Wave Height } \\
(\mathrm{cm})\end{array}$ & $\begin{array}{c}\text { Wave Period } \\
(\mathrm{s})\end{array}$ & $\begin{array}{c}\text { Initial Water } \\
\text { Depth } \\
(\mathrm{cm})\end{array}$ & $\begin{array}{c}\text { Bottom } \\
\text { Slope } \\
(-)\end{array}$ & $\begin{array}{c}\text { Initial Beach } \\
\text { Condition }\end{array}$ \\
\hline 1.1 & 0.47 & 44.0 & 6.0 & 450.0 & 0.05 & Uniform \\
1.2 & 0.47 & 92.0 & 6.0 & 450.0 & 0.05 & Uniform \\
1.3 & 0.47 & 105.0 & 9.0 & 450.0 & 0.05 & Uniform \\
1.4 & 0.47 & 53.0 & 3.0 & 450.0 & 0.05 & Uniform \\
1.5 & 0.47 & 23.0 & 4.5 & 450.0 & 0.05 & Uniform \\
1.6 & 0.47 & 51.0 & 6.0 & 450.0 & 0.05 & Uniform \\
1.7 & 0.47 & 30.0 & 4.5 & 450.0 & 0.05 & Uniform \\
2.2 & 0.47 & 86.0 & 9.0 & 350.0 & 0.03 & Uniform \\
3.1 & 0.27 & 107.0 & 9.1 & 450.0 & 0.05 & Uniform \\
3.2 & 0.27 & 105.0 & 6.0 & 450.0 & 0.05 & Uniform \\
3.3 & 0.27 & 81.0 & 12.0 & 450.0 & 0.05 & Uniform \\
3.4 & 0.27 & 154.0 & 3.1 & 450.0 & 0.05 & Uniform \\
4.1 & 0.27 & 31.0 & 3.5 & 350.0 & 0.03 & Uniform \\
4.2 & 0.27 & 97.0 & 4.5 & 400.0 & 0.03 & Uniform \\
4.3 & 0.27 & 151.0 & 3.1 & 400.0 & 0.03 & Uniform \\
4.4 & 0.27 & 100.0 & 9.0 & 400.0 & 0.03 & Uniform \\
5.1 & 0.27 & 29.0 & 5.8 & 350.0 & 0.02 & Uniform \\
5.2 & 0.27 & 74.0 & 3.1 & 350.0 & 0.02 & Uniform \\
6.1 & 0.27 & 166.0 & 5.0 & 400.0 & 0.10 & Uniform \\
\hline
\end{tabular}


Table 6. Test cases of Kraus and Larson [1988] used for model comparison.

\begin{tabular}{ccccccc}
\hline Case No & $\begin{array}{c}\text { Average } \\
\text { Grain Size } \\
(\mathrm{mm})\end{array}$ & $\begin{array}{c}\text { Wave Height } \\
(\mathrm{cm})\end{array}$ & $\begin{array}{c}\text { Wave Period } \\
(\mathrm{s})\end{array}$ & $\begin{array}{c}\text { Initial Water } \\
\text { Depth } \\
(\mathrm{cm})\end{array}$ & $\begin{array}{c}\text { Bottom } \\
\text { Slope } \\
(-)\end{array}$ & $\begin{array}{c}\text { Initial Beach } \\
\text { Condition }\end{array}$ \\
\hline 100 & 0.22 & 128.0 & 11.33 & 457.0 & 0.067 & Uniform \\
101 & 0.40 & 128.0 & 11.33 & 457.0 & 0.067 & Uniform \\
200 & 0.22 & 55.0 & 11.33 & 457.0 & 0.067 & Uniform \\
300 & 0.22 & 168.0 & 11.33 & 427.0 & 0.067 & Uniform \\
400 & 0.22 & 162.0 & 5.60 & 442.0 & 0.067 & Uniform \\
500 & 0.22 & 152.0 & 3.75 & 457.0 & 0.067 & Uniform \\
510 & 0.22 & 152.0 & 3.75 & 457.0 & 0.067 & Non-uniform \\
600 & 0.22 & 61.0 & 16.0 & 457.0 & 0.067 & Uniform \\
610 & 0.22 & 152.0 & 3.75 & 457.0 & 0.067 & Non-uniform \\
700 & 0.22 & 162.0 & 16.0 & 411.0 & 0.067 & Uniform \\
901 & 0.40 & 134.0 & 7.87 & 396.0 & 0.067 & Uniform \\
911 & 0.40 & 134.0 & 7.87 & 396.0 & 0.067 & Uniform \\
\hline
\end{tabular}

Table 7. Non-storm and storm test cases of PARI [2005, 2009] used for model comparison.

\begin{tabular}{ccccccc}
\hline Case No & $\begin{array}{c}\text { Average } \\
\text { Grain Size } \\
(\mathrm{mm})\end{array}$ & $\begin{array}{c}\text { Wave Height } \\
(\mathrm{cm})\end{array}$ & $\begin{array}{c}\text { Wave Period } \\
(\mathrm{s})\end{array}$ & $\begin{array}{c}\text { Initial Water } \\
\text { Depth } \\
(\mathrm{cm})\end{array}$ & $\begin{array}{c}\text { Bottom } \\
\text { Slope } \\
(-)\end{array}$ & $\begin{array}{c}\text { Initial Beach } \\
\text { Condition }\end{array}$ \\
\hline \multicolumn{7}{c}{} \\
\hline & 0.18 & 165 & \multicolumn{5}{c}{ Non-Storm Conditions [2005] } \\
\hline 1 & 0.18 & 210.8 & 400.0 & 0.025 & Uniform \\
\hline 2 & 0.18 & 129.0 & 4.50 & 500.0 & 0.018 & Uniform \\
3 & 0.18 & 90.0 & 3.75 & 500.0 & 0.018 & Uniform \\
4 & 0.18 & 220.0 & 3.65 & 500.0 & 0.018 & Non-uniform \\
5 & 0.18 & 56.0 & 13.0 & 500.0 & 0.018 & Uniform \\
6 & 0.18 & 85.0 & 13.7 & 500.0 & 0.018 & Non-uniform \\
\hline
\end{tabular}

Table 8. Test cases of Hasan \& Takewaka [2007, 2009] used for model comparison.

\begin{tabular}{ccccccc}
\hline Case No & $\begin{array}{c}\text { Average } \\
\text { Grain Size } \\
(\mathrm{mm})\end{array}$ & $\begin{array}{c}\text { Wave Height } \\
(\mathrm{cm})\end{array}$ & $\begin{array}{c}\text { Wave Period } \\
(\mathrm{s})\end{array}$ & $\begin{array}{c}\text { Initial Water } \\
\text { Depth } \\
(\mathrm{cm})\end{array}$ & $\begin{array}{c}\text { Bottom } \\
\text { Slope } \\
(-)\end{array}$ & $\begin{array}{c}\text { Initial Beach } \\
\text { Condition }\end{array}$ \\
\hline 1 & 0.23 & 369.0 & 12.1 & 2400.0 & 0.019 & Non-uniform \\
\hline
\end{tabular}


Table 9. Test cases of Ruessink et al. [2007] used for model comparison.

\begin{tabular}{ccccccc}
\hline Case No & $\begin{array}{c}\text { Average } \\
\text { Grain Size } \\
(\mathrm{mm})\end{array}$ & $\begin{array}{c}\text { Wave Height } \\
(\mathrm{cm})\end{array}$ & $\begin{array}{c}\text { Wave Period } \\
(\mathrm{s})\end{array}$ & $\begin{array}{c}\text { Initial Water } \\
\text { Depth } \\
(\mathrm{cm})\end{array}$ & $\begin{array}{c}\text { Bottom } \\
\text { Slope } \\
(-)\end{array}$ & $\begin{array}{c}\text { Initial Beach } \\
\text { Condition }\end{array}$ \\
\hline 1 & 0.265 & 200.0 & 8.0 & 470.0 & 0.02 & Uniform \\
\hline
\end{tabular}


Table 10. Difference between predictions \& measurements, and measurements \& initial bathymetry for test cases of Kajima et al. [1983] Part 1.

\begin{tabular}{|c|c|c|c|}
\hline Case No & $\begin{array}{c}\text { Duration } \\
\quad(\mathrm{hr})\end{array}$ & $\begin{array}{c}\text { Difference between } \\
\text { Predictions \& } \\
\text { Measurements } \\
(\mathrm{cm})\end{array}$ & $\begin{array}{c}\text { Difference between } \\
\text { Measurements \& } \\
\text { Initial Bathymetry } \\
(\mathrm{cm})\end{array}$ \\
\hline \multirow{3}{*}{1.1} & 6 & 11.23 & 6.92 \\
\hline & 10 & 6.32 & 5.12 \\
\hline & 20 & 12.33 & 11.98 \\
\hline \multirow{2}{*}{1.2} & 1 & 6.75 & 7.18 \\
\hline & 13 & 18.93 & 17.74 \\
\hline \multirow{4}{*}{1.4} & 2 & 4.84 & 3.92 \\
\hline & 3 & 4.65 & 0.69 \\
\hline & 5.5 & 9.11 & 5.27 \\
\hline & 7.5 & 11.54 & 6.01 \\
\hline \multirow{4}{*}{1.5} & 6 & 10.98 & 8.15 \\
\hline & 18 & 14.01 & 11.39 \\
\hline & 30 & 14.51 & 14.11 \\
\hline & 48 & 14.91 & 14.83 \\
\hline \multirow{4}{*}{1.6} & 0.5 & 4.14 & 1.44 \\
\hline & 3 & 8.64 & 6.40 \\
\hline & 6 & 10.67 & 10.48 \\
\hline & 12 & 9.06 & 13.85 \\
\hline \multirow{4}{*}{1.7} & 1 & 2.99 & 2.99 \\
\hline & 5 & 6.08 & 5.59 \\
\hline & 16 & 9.01 & 8.96 \\
\hline & 48 & 11.47 & 12.83 \\
\hline \multirow{4}{*}{3.1} & 0.5 & 10.16 & 3.45 \\
\hline & 3 & 17.07 & 18.33 \\
\hline & 7 & 18.37 & 21.94 \\
\hline & 15 & 22.31 & 25.73 \\
\hline \multirow{4}{*}{3.2} & 1 & 10.60 & 6.17 \\
\hline & 3 & 9.77 & 10.62 \\
\hline & 7 & 11.00 & 14.96 \\
\hline & 15 & 23.16 & 18.69 \\
\hline \multirow{4}{*}{3.3} & 1 & 10.64 & 3.98 \\
\hline & 7.5 & 18.50 & 15.58 \\
\hline & 15 & 21.98 & 19.21 \\
\hline & 30 & 25.34 & 19.26 \\
\hline \multirow{4}{*}{3.4} & 7 & 12.55 & 12.68 \\
\hline & 15 & 33.84 & 31.67 \\
\hline & 30 & 50.05 & 49.63 \\
\hline & 60 & 70.80 & 66.31 \\
\hline \multirow{4}{*}{4.1} & 1 & 1.503 & 1.32 \\
\hline & 6.5 & 3.24 & 2.98 \\
\hline & 15 & 5.54 & 4.92 \\
\hline & 30 & 4.78 & 5.42 \\
\hline
\end{tabular}


Table 11. Difference between predictions \& measurements and measurements \& initial bathymetry for test cases of Kajima et al. [1983] Part 2.

\begin{tabular}{cccc}
\hline Case No & $\begin{array}{c}\text { Duration } \\
(\mathrm{hr})\end{array}$ & $\begin{array}{c}\text { Difference between } \\
\text { Predictions \& } \\
\text { Measurements } \\
(\mathrm{cm})\end{array}$ & $\begin{array}{c}\text { Difference between } \\
\text { Measurements \& } \\
\text { Initial Bathymetry } \\
(\mathrm{cm})\end{array}$ \\
\hline \multirow{4}{*}{4.2} & 1.5 & 31.20 & 2.50 \\
& 5.5 & 14.83 & 9.94 \\
& 9.5 & 16.47 & 12.28 \\
4.3 & 16 & 19.01 & 13.62 \\
\hline 4.4 & 8 & 28.99 & 0.97 \\
& 15 & 19.91 & 11.51 \\
& 37.5 & 41.46 & 31.66 \\
5.1 & 60 & 54.33 & 44.50 \\
& 10 & 35.21 & 4.05 \\
\hline & 3 & 2.32 & 1.64 \\
& 7 & 2.41 & 2.78 \\
& 17 & 3.33 & 3.66 \\
& 31 & 5.18 & 5.81 \\
\hline & 1 & 2.308 & 1.44 \\
& 15 & 10.71 & 11.82 \\
& 32 & 14.41 & 15.59 \\
\hline \multirow{2}{*}{6.1} & 60 & 30.64 & 6.08 \\
& 1 & 31.87 & 49.75 \\
\hline
\end{tabular}


Table 12. Difference between predictions \& measurements and measurements \& initial bathymetry for test cases of Kraus and Larson [1988].

\begin{tabular}{|c|c|c|c|}
\hline Case No & $\begin{array}{l}\text { Duration } \\
\text { (hr) }\end{array}$ & $\begin{array}{c}\text { Difference between } \\
\text { Predictions \& } \\
\text { Measurements } \\
(\mathrm{cm})\end{array}$ & $\begin{array}{c}\text { Difference between } \\
\text { Measurements \& } \\
\text { Initial Bathymetry } \\
(\mathrm{cm})\end{array}$ \\
\hline \multirow{4}{*}{ KL100 } & 1 & 17.49 & 4.95 \\
\hline & 5 & 13.97 & 12.62 \\
\hline & 12 & 26.53 & 25.25 \\
\hline & 19 & 26.33 & 25.78 \\
\hline \multirow{2}{*}{ KL101 } & 5 & 22.52 & 21.84 \\
\hline & 10 & 27.20 & 24.04 \\
\hline \multirow{3}{*}{ KL200 } & 6 & 12.08 & 12.64 \\
\hline & 19.5 & 19.47 & 17.54 \\
\hline & 34.5 & 16.27 & 16.85 \\
\hline \multirow{4}{*}{ KL300 } & 1 & 19.52 & 19.10 \\
\hline & 5 & 26.32 & 30.42 \\
\hline & 10 & 32.38 & 30.57 \\
\hline & 15 & 34.92 & 31.58 \\
\hline \multirow{2}{*}{ KL400 } & 1 & 104.56 & 19.35 \\
\hline & 15 & 24.38 & 25.02 \\
\hline \multirow{4}{*}{ KL500 } & 1 & 12.56 & 1.47 \\
\hline & 5 & 28.48 & 25.24 \\
\hline & 10 & 34.44 & 22.88 \\
\hline & 15 & 85.32 & 20.14 \\
\hline \multirow{2}{*}{ KL510 } & 1 & 6.18 & 6.04 \\
\hline & 15 & 11.89 & 11.22 \\
\hline \multirow{4}{*}{ KL600 } & 1 & 8.93 & 8.48 \\
\hline & 5 & 11.92 & 10.42 \\
\hline & 10 & 16.14 & 13.17 \\
\hline & 15 & 17.62 & 13.13 \\
\hline KL610 & 1 & 14.12 & 13.90 \\
\hline \multirow{4}{*}{ KL700 } & 1 & 4.96 & 5.26 \\
\hline & 5 & 7.11 & 5.98 \\
\hline & 10 & 12.97 & 19.31 \\
\hline & 15 & 19.46 & 24.89 \\
\hline KL901 & 1 & 24.55 & 44.00 \\
\hline \multirow{4}{*}{ KL911 } & 6 & 26.52 & 24.83 \\
\hline & 15.5 & 46.04 & 31.79 \\
\hline & 31 & 51.73 & 33.12 \\
\hline & 40.5 & 59.81 & 37.27 \\
\hline
\end{tabular}


Table 13. Difference between predictions \& measurements and measurements \& initial bathymetry for non-storm test case of PARI [2005].

\begin{tabular}{cccc}
\hline Case No & $\begin{array}{c}\text { Duration } \\
(\mathrm{hr})\end{array}$ & $\begin{array}{c}\text { Difference between } \\
\text { Predictions \& } \\
\text { Measurements } \\
(\mathrm{cm})\end{array}$ & $\begin{array}{c}\text { Difference between } \\
\text { Measurements \& } \\
\text { Initial Bathymetry } \\
(\mathrm{cm})\end{array}$ \\
\hline & 24 & 11.24 & 8.20 \\
1 & 48 & 14.13 & 13.43 \\
& 72 & 13.15 & 10.45 \\
& 168 & 15.87 & 13.75 \\
& 240 & 16.21 & 13.63 \\
\hline
\end{tabular}

Table 14. Difference between predictions \& measurements and measurements \& initial bathymetry for storm test cases of PARI [2009].

\begin{tabular}{cccc}
\hline Case No & $\begin{array}{c}\text { Duration } \\
(\mathrm{hr})\end{array}$ & $\begin{array}{c}\text { Difference between } \\
\text { Predictions \& } \\
\text { Measurements } \\
(\mathrm{cm})\end{array}$ & $\begin{array}{c}\text { Difference between } \\
\text { Measurements \& } \\
\text { Initial Bathymetry } \\
(\mathrm{cm})\end{array}$ \\
\hline \multirow{2}{*}{1} & 24 & 25.94 & 26.00 \\
& 72 & 46.01 & 46.08 \\
& 96 & 42.68 & 42.75 \\
\hline \multirow{2}{*}{2} & 24 & 53.52 & 62.05 \\
& 48 & 36.17 & 42.72 \\
& 72 & 27.64 & 33.35 \\
& 144 & 25.75 & 32.97 \\
\hline \multirow{2}{*}{3} & 24 & 23.47 & 46.32 \\
& 96 & 16.15 & 46.28 \\
\hline & 24 & 37.20 & 2.32 \\
& 48 & 39.01 & 17.32 \\
\end{tabular}


Table 15. Difference between predictions \& measurements and measurements \& initial bathymetry for test case of Hasan and Takewaka [2007, 2009].

\begin{tabular}{cccc}
\hline Case No & $\begin{array}{c}\text { Duration } \\
(\mathrm{hr})\end{array}$ & $\begin{array}{c}\text { Difference between } \\
\text { Predictions \& } \\
\text { Measurements } \\
(\mathrm{cm})\end{array}$ & $\begin{array}{c}\text { Difference between } \\
\text { Measurements \& } \\
\text { Initial Bathymetry } \\
(\mathrm{cm})\end{array}$ \\
\hline 1 & 24 & 32.82 & 29.04 \\
\hline
\end{tabular}

Table 16. Difference between predictions \& measurements and measurements \& initial bathymetry for test case of Ruessink et al. [2007].

\begin{tabular}{cccc}
\hline Case No & $\begin{array}{c}\text { Duration } \\
(\mathrm{hr})\end{array}$ & $\begin{array}{c}\text { Difference between } \\
\text { Predictions \& } \\
\text { Measurements } \\
(\mathrm{cm})\end{array}$ & $\begin{array}{c}\text { Difference between } \\
\text { Measurements \& } \\
\text { Initial Bathymetry } \\
(\mathrm{cm})\end{array}$ \\
\hline 24 & 1.470 & 1.470 \\
& 72 & 0.495 & 0.496 \\
1 & 168 & 1.470 & 1.467 \\
& 216 & 1.536 & 1.537 \\
& 264 & 2.404 & 2.405 \\
& 284 & 6.351 & 2.351 \\
& 308 & 6.739 & 6.867 \\
\hline
\end{tabular}

